\title{
Simulations of preindustrial, present-day, and 2100 conditions in the NASA GISS composition and climate model G-PUCCINI
}

\author{
D. T. Shindell ${ }^{1,2}$, G. Faluvegi ${ }^{1,2}$, N. Unger ${ }^{1,2}$, E. Aguilar ${ }^{1,2}$, G. A. Schmidt ${ }^{1,2}$, D. M. Koch $^{1,3}$, S. E. Bauer ${ }^{1,2}$, and \\ R. L. Miller ${ }^{1,4}$ \\ ${ }^{1}$ NASA Goddard Institute for Space Studies, New York, NY, USA \\ ${ }^{2}$ Center for Climate Systems Research, Columbia University, NY, USA \\ ${ }^{3}$ Dept. of Geophysics, Yale University, New Haven, USA \\ ${ }^{4}$ Dept. of Applied Physics and Applied Math, Columbia University, NY, USA
}

Received: 3 February 2006 - Published in Atmos. Chem. Phys. Discuss.: 15 June 2006

Revised: 14 September 2006 - Accepted: 26 September 2006 - Published: 4 October 2006

\begin{abstract}
A model of atmospheric composition and climate has been developed at the NASA Goddard Institute for Space Studies (GISS) that includes composition seamlessly from the surface to the lower mesosphere. The model is able to capture many features of the observed magnitude, distribution, and seasonal cycle of trace species. The simulation is especially realistic in the troposphere. In the stratosphere, high latitude regions show substantial biases during period when transport governs the distribution as meridional mixing is too rapid in this model version. In other regions, including the extrapolar tropopause region that dominates radiative forcing (RF) by ozone, stratospheric gases are generally well-simulated. The model's stratosphere-troposphere exchange (STE) agrees well with values inferred from observations for both the global mean flux and the ratio of Northern $(\mathrm{NH})$ to Southern Hemisphere (SH) downward fluxes.

Simulations of preindustrial (PI) to present-day (PD) changes show tropospheric ozone burden increases of $11 \%$ while the stratospheric burden decreases by $18 \%$. The resulting tropopause $\mathrm{RF}$ values are $-0.06 \mathrm{~W} / \mathrm{m}^{2}$ from stratospheric ozone and $0.40 \mathrm{~W} / \mathrm{m}^{2}$ from tropospheric ozone. Global mean mass-weighted $\mathrm{OH}$ decreases by $16 \%$ from the PI to the PD. STE of ozone also decreased substantially during this time, by $14 \%$. Comparison of the PD with a simulation using 1979 pre-ozone hole conditions for the stratosphere shows a much larger downward flux of ozone into the troposphere in 1979, resulting in a substantially greater tropospheric ozone burden than that seen in the PD run. This implies that reduced STE due to stratospheric ozone depletion may have offset as much as $2 / 3$ of the tropospheric ozone burden increase from PI to PD. However, the model overestimates the downward flux of
\end{abstract}

Correspondence to: D. T. Shindell

(dshindell@giss.nasa.gov) ozone at high Southern latitudes, so this estimate is likely an upper limit.

In the future, the tropospheric ozone burden increases by $101 \%$ in 2100 for the A2 scenario including both emissions and climate changes. The primary reason is enhanced STE, which increases by $124 \%$ (168\% in the SH extratropics, and $114 \%$ in the $\mathrm{NH}$ extratropics). Climate plays a minimal role in the SH increases, but contributes $38 \%$ in the $\mathrm{NH}$. Chemistry and dry deposition both change so as to reduce tropospheric ozone, partially in compensation for the enhanced STE, but the increased ozone influx dominates the burden changes. The net RF due to projected ozone changes is $0.8 \mathrm{~W} / \mathrm{m}^{2}$ for $\mathrm{A} 2$. The influence of climate change alone is $-0.2 \mathrm{~W} / \mathrm{m}^{2}$, making it a substantial contributor to the net RF. The tropospheric oxidation capacity increases seven percent in the full A2 simulation, and $36 \%$ due to A2 climate change alone.

\section{Introduction}

There are many ways in which changes in atmospheric composition and climate are coupled. The interactions are especially pronounced in the case of chemically reactive gases and aerosols. For example, atmospheric humidity increases as climate warms, altering reactions involving water vapor and aqueous phase chemistry in general, which in turn affects the abundance of radiative active species such as ozone and sulfate. Additional couplings exist via climate-sensitive natural emissions, such as methane from wetlands and isoprene from forests, aerosol-chemistry-cloud interactions in a changing climate, and large-scale circulation shifts in response to climate change, such as stratosphere-troposphere

Published by Copernicus GmbH on behalf of the European Geosciences Union. 
exchange (STE). This paper presents the latest version of the NASA Goddard Institute for Space Studies (GISS) composition and climate model as part of our continuing efforts to more realistically simulate the range of physical interactions important to past, present and future climates.

The trace gas photochemistry has been expanded from the earlier troposphere-only scheme described in Shindell et al. $(2001,2003)$ to include gases and reactions important in the stratosphere. This builds upon previous modeling of tropospheric or stratospheric chemistry within GCMs (e.g. Austin et al., 2003; Stevenson et al., 2006) and initial work including both tropospheric and stratospheric chemistry (e.g. Dameris et al., 2005). At the same time, the sulfate aerosol and trace gas chemistry have been fully coupled (Bell et al., 2005) and interactions between chemistry and mineral dust have been added to the model. Climate-sensitive emissions have been included for methane from wetlands, $\mathrm{NO}_{\mathrm{x}}$ from lightning, dust from soils, and DMS from the ocean. Water isotopes and a passive linearly increasing tracer have been included, allowing better transport diagnostics. All components have been developed within the new GISS modelE climate model (Schmidt et al., 2006). Since the climate model developed under the modelE project has been named GISS model III, and the chemistry is also the third major version of its development following Shindell et al. (2001, 2003), it is appropriate to call this model the GISS composition and climate model III. We prefer, however, a more descriptive name: the GISS model for Physical Understanding of Composition-Climate INteractions and Impacts (GPUCCINI).

We present a detailed description of the model in Sect. 2, followed by an evaluation against available observations in Sect. 3. Section 4 presents the response to preindustrial and 2100 composition and climate changes as an initial application of this model. We conclude with a discussion of the model's successes and limitations with an eye towards determination of the suitability of the current model for various potential future studies.

\section{Model description}

\subsection{Trace gas and aerosol chemistry}

The trace gas photochemistry has been expanded from the tropospheric scheme developed previously (Shindell et al., 2001a, 2003) to include species and reactions important in the stratosphere. Table 1 lists the molecules included in the gas photochemistry. Table 2 presents the additional 78 new reactions incorporated within the chemistry scheme. Together with the reactions included previously, the photochemistry now includes 155 reactions. Rate coefficients are taken from the NASA JPL 2000 handbook (Sander et al., 2000). Photolysis rates are calculated using the Fast-J2 scheme (Bian and Prather, 2002), except for the photolysis of water and nitric oxide (NO) in the Schumann-Runge bands, which are parameterized according to Nicolet (1984) and Nicolet and Cieslik (1980). The chemical solver is a hybrid of equilibrium calculations for the shortest-lived radicals, an interative calculation for a few species with intermediate lifetimes, and an explicit calculation for longer-lived species. Transported species are advected using second-order moments (Prather, 1986), which is able to maintain large gradients and in essence provides information at a substantially higher $(\sim 4 \times)$ resolution than the GCM grid.

Heterogeneous chemistry in the stratosphere follows the reactions listed in Table 2. Aerosol surface areas are set to match those used in the GCM's calculation of radiative transfer based upon an updated version of the volcanic plus background aerosol timeseries of Sato et al. (1993). Surface areas for polar stratospheric clouds (PSCs) are set using simple temperature thresholds for type I and II particles, 195 and $188 \mathrm{~K}$, respectively, with a parameterization of sedimentation also included. A more sophisticated model based on Hanson and Mauersberger (1988) is being incorporated into the chemistry code, but is not yet functional. Thus the simulations do not include all potential pathways for interactions between polar ozone chemistry and climate or emissions changes as PSC formation is not sensitive to water or nitric acid abundance variations. Given that the model's transport biases limit the realism of its polar ozone simulations in any case, it was deemed a better use of resources to address this in future higher resolution runs than to repeat these simulations with a more advanced PSC scheme.

Chemistry can be included in the full model domain, or it can be restricted to levels below the meteorological tropopause. In the latter case, climatological ozone is used in the stratosphere and $\mathrm{NO}_{\mathrm{x}}$ is prescribed as a fixed fraction of the ozone abundance as in our previous models. While we focus on the full chemistry model, both configurations are evaluated here so that future studies can select the most appropriate version.

To better understand the model's simulation of stratospheric transport, we have incorporated a passive, linearly increasing tracer as a standard feature along with the chemical tracers. This tracer is initialized in the lowest model layer with a value that increases by one unit each year, with a linear interpolation used to set monthly values. The difference between the tracer value at a given point and the surface level value then gives the mean time in years since the air left the surface. By comparing values throughout the stratosphere with those at the tropical tropopause, we can evaluate the age of air in the stratosphere and compare with observations of $\mathrm{CO}_{2}$ and $\mathrm{SF}_{6}$.

The updated modelE version of the sulfate and sea salt model is described and evaluated by Koch et al. (2006), though in those simulations the aerosols were not coupled with chemistry. It includes prognostic simulations of DMS (dimethyl sulfide), MSA (methane sulfonic acid), $\mathrm{SO}_{2}$ and sulfate mass distributions. The influence of interactive 
Table 1. Gases included in the model.

\begin{tabular}{|c|c|c|c|}
\hline \multicolumn{2}{|c|}{ Transported } & \multicolumn{2}{|c|}{ Not Transported } \\
\hline (1) & $\mathrm{O}_{\mathrm{x}}$ & (28) & NO \\
\hline (2) & $\mathrm{NO}_{\mathrm{x}}$ & (29) & $\mathrm{NO}_{2}$ \\
\hline (3) & $\mathrm{HNO}_{3}$ & (30) & $\mathrm{NO}_{3}$ \\
\hline (4) & $\mathrm{N}_{2} \mathrm{O}_{5}$ & (31) & HONO \\
\hline (5) & $\mathrm{HO}_{2} \mathrm{NO}_{2}$ & (32) & $\mathrm{OH}$ \\
\hline (6) & $\mathrm{H}_{2} \mathrm{O}_{2}$ & (33) & $\mathrm{HO}_{2}$ \\
\hline (7) & $\mathrm{CO}$ & (34) & $\mathrm{O}$ \\
\hline (8) & $\mathrm{HCHO}$ & (35) & $\mathrm{O}\left({ }^{1} \mathrm{D}\right)$ \\
\hline (9) & $\mathrm{CH}_{3} \mathrm{OOH}$ & (36) & $\mathrm{O}_{3}$ \\
\hline (10) & $\mathrm{H}_{2} \mathrm{O}$ & (37) & $\mathrm{CH}_{3} \mathrm{O}_{2}$ \\
\hline (11) & $\mathrm{CH}_{4}$ & (38) & $\mathrm{C}_{2} \mathrm{O}_{3}$ \\
\hline (12) & PANs & (39) & Aldehydes $\mathrm{a}$ \\
\hline (13) & Isoprene & (40) & $\mathrm{XO}_{2}^{\mathrm{d}}$ \\
\hline (14) & Alkyl Nitrates ${ }^{\mathrm{a}}$ & (41) & $\mathrm{XO}_{2} \mathrm{~N}^{\mathrm{e}}$ \\
\hline (15) & Alkenes ${ }^{\mathrm{a}}$ & (42) & RXPAR $^{f}$ \\
\hline (16) & Paraffins ${ }^{\mathrm{a}}$ & (43) & $\mathrm{ROR}^{\mathrm{g}}$ \\
\hline (17) & $\mathrm{ClO}_{\mathrm{x}}$ & (44) & $\mathrm{Cl}$ \\
\hline (18) & $\mathrm{BrO}_{\mathrm{x}}$ & (45) & $\mathrm{ClO}$ \\
\hline (19) & $\mathrm{HCl}$ & (46) & $\mathrm{OClO}$ \\
\hline (20) & $\mathrm{HOCl}$ & (47) & $\mathrm{Cl}_{2} \mathrm{O}_{2}$ \\
\hline (21) & $\mathrm{ClONO}_{2}$ & (48) & $\mathrm{Cl}_{2}$ \\
\hline (22) & $\mathrm{HBr}$ & (49) & $\mathrm{ClNO}_{2}$ \\
\hline (23) & $\mathrm{HOBr}$ & (50) & $\mathrm{Br}$ \\
\hline (24) & $\mathrm{BrONO}_{2}$ & (51) & $\mathrm{BrO}$ \\
\hline (25) & $\mathrm{N}_{2} \mathrm{O}$ & (52) & $\mathrm{BrCl}$ \\
\hline (26) & $\mathrm{CFCs}^{\mathrm{b}}$ & (53) & $\mathrm{N}$ \\
\hline (27) & Linearly increasing tracer ${ }^{\mathrm{c}}$ & (54) & $\mathrm{H}$ \\
\hline
\end{tabular}

a Alkyl nitrates, alkenes, paraffins, and aldehydes are lumped families. Alkenes include propene, $>\mathrm{C} 3$ alkenes, and $>\mathrm{C} 2$ alkynes, paraffins include ethane, propane, butane, pentane, >C5 alkanes and ketones, while aldehydes include acetaldehyde and higher aldehydes (not formaldehyde).

${ }^{\mathrm{b}}$ CFCs are defined here as the sum of all CFCs, using the characteristics of CFC-11.

${ }^{\mathrm{c}}$ Linear tracer is a tracer with a linearly increasing surface abundance that can be scaled to $\mathrm{SF}_{6}$ or $\mathrm{CO}_{2}$ to evaluate the models age of air against observations.

${ }^{d} \mathrm{XO}_{2}$ is a surrogate species to represent primarily hydrocarbon oxidation byproducts that subsequently convert $\mathrm{NO}$ to $\mathrm{NO}_{2}$, and also leads to a small amount of organic peroxide formation.

${ }^{\mathrm{e}} \mathrm{XO}_{2} \mathrm{~N}$ is a surrogate species to represent hydrocarbon oxidation byproducts that subsequently convert NO to alkyl nitrates, and also leads to a small amount of organic peroxide formation.

${ }^{\mathrm{f}}$ RXPAR is a paraffin budget corrector to correct a bias in the oxidation of alkenes related to an overly short chain length for the lumped alkenes.

$\mathrm{g}$ ROR are radical byproducts of paraffin oxidation.

chemistry and aerosols in this model has been investigated extensively (Bell et al., 2005). The mineral dust aerosol model transports four different sizes classes of dust particles with radii between $0.1-1,1-2,2-4$, and $4-8$ microns. Particle sources are identified using the topographic prescription of (Ginoux, 2001). Direct dust emission increases with the third power of the wind speed above a threshold that increases with soil moisture. Emission is calculated by integrating over a probability distribution of surface wind speed that depends upon the speed explicitly calculated by the GCM at each grid box, along with the magnitude of fluctua- tions resulting from subgrid circulations created by boundary layer turbulence, and dry and moist convection. Dust particles are removed from the atmosphere by a combination of gravitational settling, turbulent mixing, and wet scavenging. Dust also affects the radiation field, and thus influences photolysis rates. A more detailed description of the dust model, along with a comparison to regional observations, is given by Miller et al. (2006) and Cakmur et al. (2006).

The model includes heterogeneous chemistry for the uptake of nitric acid on mineral dust aerosol surfaces. This is described by a pseudo first-order rate coefficient which gives 
Table 2. Additional reactions included in the model.

\begin{tabular}{|c|c|}
\hline \multicolumn{2}{|r|}{ Bimolecular Reactions } \\
\hline (1) & $\mathrm{Cl}+\mathrm{O}_{3} \rightarrow \mathrm{ClO}+\mathrm{O}_{2}$ \\
\hline (2) & $\mathrm{ClO}+\mathrm{O} \rightarrow \mathrm{Cl}+\mathrm{O}_{2}$ \\
\hline (3) & $\mathrm{Cl}+\mathrm{OClO} \rightarrow \mathrm{ClO}+\mathrm{ClO}$ \\
\hline (4) & $\mathrm{ClO}+\mathrm{O}_{3} \rightarrow \mathrm{ClOO}+\mathrm{O}_{2}$ \\
\hline (5) & $\mathrm{ClO}+\mathrm{O}_{3} \rightarrow \mathrm{OClO}+\mathrm{O}_{2}$ \\
\hline (6) & $\mathrm{O}+\mathrm{OClO} \rightarrow \mathrm{ClO}+\mathrm{O}_{2}$ \\
\hline (7) & $\mathrm{OH}+\mathrm{Cl}_{2} \rightarrow \mathrm{HOCl}+\mathrm{Cl}$ \\
\hline (8) & $\mathrm{OH}+\mathrm{HCl} \rightarrow \mathrm{H}_{2} \mathrm{O}+\mathrm{Cl}$ \\
\hline (9) & $\mathrm{OH}+\mathrm{HOCl} \rightarrow \mathrm{H}_{2} \mathrm{O}+\mathrm{ClO}$ \\
\hline (10) & $\mathrm{O}+\mathrm{HCl} \rightarrow \mathrm{OH}+\mathrm{Cl}$ \\
\hline (11) & $\mathrm{O}+\mathrm{HOCl} \rightarrow \mathrm{OH}+\mathrm{ClO}$ \\
\hline (12) & $\mathrm{OClO}+\mathrm{OH} \rightarrow \mathrm{HOCl}+\mathrm{O}_{2}$ \\
\hline (13) & $\mathrm{Cl}+\mathrm{HOCl} \rightarrow \mathrm{Cl}_{2}+\mathrm{OH}$ \\
\hline (14) & $\mathrm{Cl}+\mathrm{H}_{2} \mathrm{O}_{2} \rightarrow \mathrm{HCl}+\mathrm{HO}_{2}$ \\
\hline (15) & $\mathrm{Cl}+\mathrm{HO}_{2} \rightarrow \mathrm{HCl}+\mathrm{O}_{2}$ \\
\hline (16) & $\mathrm{Cl}+\mathrm{HO}_{2} \rightarrow \mathrm{OH}+\mathrm{ClO}$ \\
\hline (17) & $\mathrm{ClO}+\mathrm{OH} \rightarrow \mathrm{HO}_{2}+\mathrm{Cl}$ \\
\hline (18) & $\mathrm{ClO}+\mathrm{OH} \rightarrow \mathrm{HCl}+\mathrm{O}_{2}$ \\
\hline (19) & $\mathrm{ClO}+\mathrm{HO}_{2} \rightarrow \mathrm{HOCl}+\mathrm{O}_{2}$ \\
\hline (20) & $\mathrm{ClO}+\mathrm{NO} \rightarrow \mathrm{NO}_{2}+\mathrm{Cl}$ \\
\hline (21) & $\mathrm{ClONO}_{2}+\mathrm{O} \rightarrow \mathrm{ClO}+\mathrm{NO}_{3}$ \\
\hline$(22)$ & $\mathrm{HCl}+\mathrm{O}\left({ }^{1} \mathrm{D}\right) \rightarrow \mathrm{Cl}+\mathrm{OH}$ \\
\hline (23) & $\mathrm{NO}+\mathrm{OClO} \rightarrow \mathrm{NO}_{2}+\mathrm{ClO}$ \\
\hline (24) & $\mathrm{HBr}+\mathrm{OH} \rightarrow \mathrm{H}_{2} \mathrm{O}+\mathrm{Br}$ \\
\hline$(25)$ & $\mathrm{BrO}+\mathrm{O} \rightarrow \mathrm{Br}+\mathrm{O}_{2}$ \\
\hline (26) & $\mathrm{Br}+\mathrm{O}_{3} \rightarrow \mathrm{BrO}+\mathrm{O}_{2}$ \\
\hline (27) & $\mathrm{BrO}+\mathrm{NO} \rightarrow \mathrm{Br}+\mathrm{NO}_{2}$ \\
\hline (28) & $\mathrm{Br}+\mathrm{HO}_{2} \rightarrow \mathrm{HBr}+\mathrm{O}_{2}$ \\
\hline (29) & $\mathrm{BrO}+\mathrm{HO}_{2} \rightarrow \mathrm{HOBr}+\mathrm{O}_{2}$ \\
\hline (30) & $\mathrm{Br}+\mathrm{OClO} \rightarrow \mathrm{BrO}+\mathrm{ClO}$ \\
\hline (31) & $\mathrm{BrO}+\mathrm{ClO} \rightarrow \mathrm{OClO}+\mathrm{Br}$ \\
\hline$(32)$ & $\mathrm{BrO}+\mathrm{ClO} \rightarrow \mathrm{Br}+\mathrm{ClOO}$ \\
\hline (33) & $\mathrm{BrO}+\mathrm{ClO} \rightarrow \mathrm{BrCl}+\mathrm{O}_{2}$ \\
\hline (34) & $\mathrm{BrO}+\mathrm{BrO} \rightarrow \mathrm{Br}+\mathrm{Br}$ \\
\hline$(35)$ & $\mathrm{Br}+\mathrm{H}_{2} \mathrm{O}_{2} \rightarrow \mathrm{HBr}+\mathrm{HO}_{2}$ \\
\hline$(36)$ & $\mathrm{BrO}+\mathrm{OH} \rightarrow \mathrm{Br}+\mathrm{HO}_{2}$ \\
\hline (37) & $\mathrm{BrO}+\mathrm{OH} \rightarrow \mathrm{HBr}+\mathrm{O}_{2}$ \\
\hline$(38)$ & $\mathrm{Cl}+\mathrm{CH}_{4} \rightarrow \mathrm{HCl}+\mathrm{CH}_{3} \mathrm{O}_{2}$ \\
\hline (39) & $\mathrm{Cl}+\mathrm{H}_{2} \rightarrow \mathrm{HCl}+\mathrm{H}$ \\
\hline (40) & $\mathrm{O}+\mathrm{HBr} \rightarrow \mathrm{OH}+\mathrm{Br}$ \\
\hline (41) & $\mathrm{ClO}+\mathrm{CH}_{3} \mathrm{O}_{2} \rightarrow \mathrm{ClOO}+\mathrm{HCHO}+\mathrm{HO}_{2}$ \\
\hline$(42)$ & $\mathrm{N}_{2} \mathrm{O}+\mathrm{O}\left({ }^{1} \mathrm{D}\right) \rightarrow \mathrm{N}_{2}+\mathrm{O}_{2}$ \\
\hline
\end{tabular}

$\begin{array}{ll}\text { (43) } & \mathrm{N}_{2} \mathrm{O}+\mathrm{O}\left({ }^{1} \mathrm{D}\right) \rightarrow \mathrm{NO}+\mathrm{NO} \\ (44) & \mathrm{O}+\mathrm{O}_{3} \rightarrow \mathrm{O}_{2}+\mathrm{O}_{2} \\ (45) & \mathrm{O}+\mathrm{OH} \rightarrow \mathrm{O}_{2}+\mathrm{H} \\ (46) & \mathrm{O}+\mathrm{HO}_{2} \rightarrow \mathrm{OH}+\mathrm{O}_{2} \\ (47) & \mathrm{N}+\mathrm{O}_{2} \rightarrow \mathrm{NO}+\mathrm{O} \\ (48) & \mathrm{N}+\mathrm{NO}_{2} \rightarrow \mathrm{N}_{2} \mathrm{O}+\mathrm{O} \\ (49) & \mathrm{N}+\mathrm{NO} \rightarrow \mathrm{N}_{2}+\mathrm{O} \\ (50) & \mathrm{H}+\mathrm{O}_{3} \rightarrow \mathrm{OH}+\mathrm{O}_{2} \\ (51) & \mathrm{H}+\mathrm{O}_{2}+\mathrm{M} \rightarrow \mathrm{HO}_{2}+\mathrm{M} \\ (52) & \mathrm{ClO}+\mathrm{ClO} \rightarrow \mathrm{Cl}_{2}+\mathrm{O}_{2} \\ (53) & \mathrm{ClO}+\mathrm{ClO} \rightarrow \mathrm{ClOO}^{\mathrm{Cl}} \\ (54) & \mathrm{ClO}+\mathrm{ClO} \rightarrow \mathrm{OClO}+\mathrm{Cl} \\ (55) & \mathrm{O}+\mathrm{H}_{2} \mathrm{O}_{2} \rightarrow\end{array}$

\begin{tabular}{|c|c|}
\hline \multicolumn{2}{|r|}{ Monomolecular reactions } \\
\hline$(56)$ & $\mathrm{Cl}_{2} \mathrm{O}_{2}+\mathrm{M} \rightarrow \mathrm{ClO}+\mathrm{ClO}+\mathrm{M}$ \\
\hline \multicolumn{2}{|r|}{ Termolecular reactions } \\
\hline (57) & $\mathrm{ClO}+\mathrm{ClO}+\mathrm{M} \rightarrow \mathrm{Cl}_{2} \mathrm{O}_{2}+\mathrm{M}$ \\
\hline$(58)$ & $\mathrm{ClO}+\mathrm{NO}_{2}+\mathrm{M} \rightarrow \mathrm{ClONO}_{2}+\mathrm{M}$ \\
\hline (59) & $\mathrm{BrO}+\mathrm{NO}_{2}+\mathrm{M} \rightarrow \mathrm{BrONO}_{2}+\mathrm{M}$ \\
\hline \multicolumn{2}{|r|}{ Heterogeneous reactions } \\
\hline$(60)$ & $\mathrm{N}_{2} \mathrm{O}_{5}+\mathrm{H}_{2} \mathrm{O} \rightarrow \mathrm{HNO}_{3}+\mathrm{HNO}_{3}$ \\
\hline$(61)$ & $\mathrm{ClONO}_{2}+\mathrm{H}_{2} \mathrm{O} \rightarrow \mathrm{HOCl}+\mathrm{HNO}_{3}$ \\
\hline$(62)$ & $\mathrm{ClONO}_{2}+\mathrm{HCl} \rightarrow \mathrm{Cl}_{2}+\mathrm{HNO}_{3}$ \\
\hline$(63)$ & $\mathrm{HOCl}+\mathrm{HCl} \rightarrow \mathrm{Cl}_{2}+\mathrm{H}_{2} \mathrm{O}$ \\
\hline (64) & $\mathrm{N}_{2} \mathrm{O}_{5}+\mathrm{HCl} \rightarrow \mathrm{ClNO}_{2}+\mathrm{HNO}_{3}$ \\
\hline \multicolumn{2}{|r|}{ Photolysis Reactions } \\
\hline$(65)$ & $\mathrm{ClO}+\mathrm{h} v \rightarrow \mathrm{Cl}+\mathrm{O}$ \\
\hline (66) & $\mathrm{Cl}_{2}+\mathrm{h} v \rightarrow \mathrm{Cl}+\mathrm{Cl}$ \\
\hline (67) & $\mathrm{OClO}+\mathrm{h} v \rightarrow \mathrm{O}+\mathrm{ClO}$ \\
\hline (68) & $\mathrm{Cl}_{2} \mathrm{O}_{2}+\mathrm{h} v \rightarrow \mathrm{Cl}+\mathrm{Cl}+\mathrm{O}_{2}$ \\
\hline (69) & $\mathrm{HOCl}+\mathrm{h} v \rightarrow \mathrm{OH}+\mathrm{Cl}$ \\
\hline (70) & $\mathrm{ClONO}_{2}+\mathrm{h} v \rightarrow \mathrm{Cl}+\mathrm{NO}_{3}$ \\
\hline (71) & $\mathrm{BrONO}_{2}+\mathrm{h} v \rightarrow \mathrm{BrO}+\mathrm{NO}_{2}$ \\
\hline (72) & $\mathrm{HOBr}+\mathrm{h} v \rightarrow \mathrm{Br}+\mathrm{OH}$ \\
\hline (73) & $\mathrm{BrO}+\mathrm{h} v \rightarrow \mathrm{Br}+\mathrm{O}$ \\
\hline (74) & $\mathrm{CFC}+\mathrm{h} v \rightarrow \mathrm{Cl}$ \\
\hline (75) & $\mathrm{O}_{2}+\mathrm{h} v \rightarrow \mathrm{O}+\mathrm{O}$ \\
\hline (76) & $\mathrm{N}_{2} \mathrm{O}+\mathrm{h} v \rightarrow \mathrm{N}_{2}+\mathrm{O}\left({ }^{1} \mathrm{D}\right)$ \\
\hline (77) & $\mathrm{NO}+\mathrm{h} v \rightarrow \mathrm{N}+\mathrm{O}$ \\
\hline (78) & $\mathrm{H}_{2} \mathrm{O}+\mathrm{h} v \rightarrow \mathrm{OH}+\mathrm{H}$ \\
\hline
\end{tabular}

$\mathrm{M}$ is any body that can serve to carry away excess energy. $\mathrm{ClOO}$ is assumed to decay immediately to $\mathrm{Cl}+\mathrm{O}_{2}$.

the net irreversible removal rate of gas-phase species to an aerosol surface. We use the uptake coefficient of 0.1 recommended from laboratory measurements (Hanisch and Crowley, 2001), though this value is fairly uncertain. The effects of mineral dust on sulfate have been described elsewhere (Bauer and Koch, 2005). The model includes simulations of carbonaceous, sea-salt and nitrate aerosols as well, though these do not directly influence the simulations of other trace species in the model and are described in detail elsewhere (Koch and Hansen, 2005; Koch et al., 2006).

The model also includes the stable water isotopes HDO and $\mathrm{H}_{2}^{18} \mathrm{O}$, which are fully coupled to the GCM's hydrologic cycle. Comparison between the modeled and observed values of these isotopes, and especially of their vertical 
Table 3. Simulations with the full chemistry model.

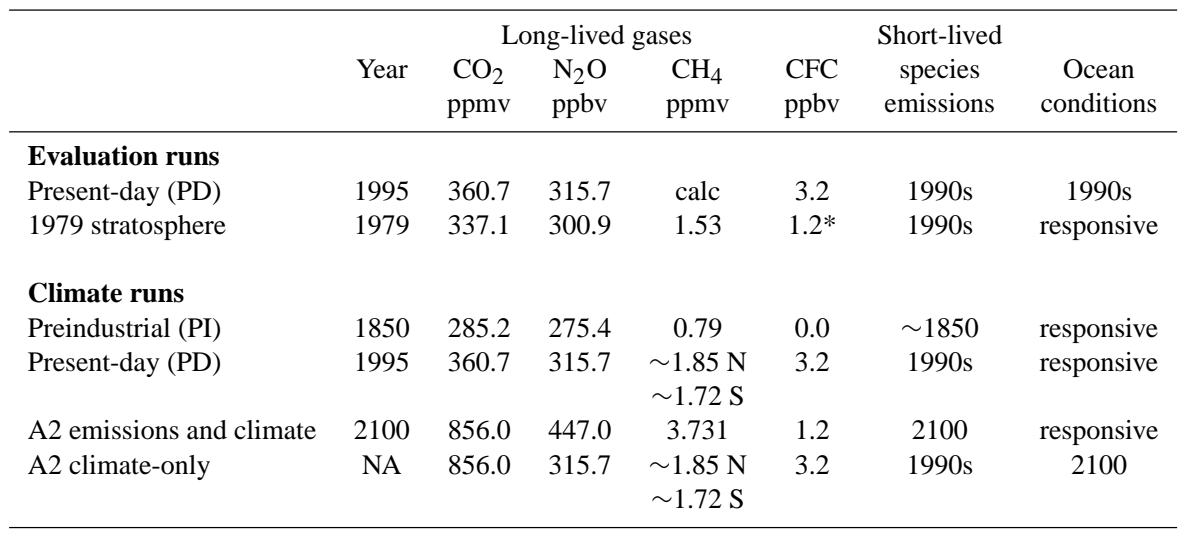

* This value represents approximately the CFC loading that had reached the stratosphere in 1979. Calc=calculated.

profiles, can be a useful way to evaluate (and improve) the stratosphere-troposphere exchange in the model and the parameterization of cloud physics (Schmidt et al., 2005).

An important new feature of modelE for the trace gas and aerosol species is a carefully constructed cloud tracer budget. Most chemical and aerosol models (including all GISS models other than modelE) do not save dissolved species in a cloud budget but instead return the dissolved (unscavenged) species to the model grid box at the end of each model timestep. In our model, we have created a cloud liquid budget and this has important implications for tracer distributions. Inclusion of the cloud tracer budget decreases sulfate production in the clouds (since most of the sulfate is ultimately rained out instead of released back to the grid box) (Koch et al., 2006) and reduces the abundance of soluble $\mathrm{O}_{3}$ precursors, such as nitric acid $\left(\mathrm{HNO}_{3}\right)$, which were systematically overestimated in previous models. We have also developed a new dry deposition module within modelE that is physically consistent with the other surface fluxes (e.g. water, heat) in the planetary boundary layer scheme of the GCM, which was not the case in earlier models (or indeed in most chemistryclimate models).

\subsection{Sources and sinks}

Emissions of trace gases and aerosols are largely the same as those used in previous versions (Shindell et al., 2003). They include the standard suite of emissions from fossil fuel and biomass burning, soils, industry, livestock, forests, wetlands, etc. These are based largely on GEIA inventories (Benkovitz et al., 1996). Sulfur emissions are from the EDGAR inventory as described in Bell et al. (2005). For the new long-lived species included here, $\mathrm{N}_{2} \mathrm{O}$ and CFCs (and $\mathrm{CO}_{2}$ ), we prescribe values at observed amounts (Table 3 ) in the lowest model layer. This technique is also available for methane, though in the present-day simulations described here we use the full set of methane emissions. CFCs are modeled using the characteristics of CFC-11 but with a magnitude designed to capture the total chlorine source from all CFC species (i.e. each $\mathrm{CFC}$ yields one chlorine atom when broken down, so the amount of CFCs is set to match total anthropogenic chlorine). We also assume there is a background chlorine value of $0.5 \mathrm{ppbv}$ from natural sources throughout the stratosphere. Total bromine is normalized to prescribed loading (World Meteorological Organization, 2003) throughout the stratosphere.

\subsection{Climate model}

During the past several years, primary GISS modeling efforts have been directed into an entirely rewritten and upgraded climate model under the modelE project (Schmidt et al., 2006). This resulting GISS model, called either modelE or model III, incorporates previously developed physical processes within a single standardized structure quite different from the older model. This structure is much more complicated to create, but makes the interaction between GISS model components easier and more physically realistic. The standardization across components has also allowed many improvements to be included relatively easily.

ModelE also includes several advances compared to previous versions, including more realistic physics and improved convection and boundary layer schemes. The horizontal resolution can be easily altered, unlike previous versions. Standard diagnostics include statistical comparisons with satellite data products such as ISCCP cloud cover, cloud height, and radiation products, MSU temperatures, TRMM precipitation, and ERBE radiation products. Over a full suite of evaluation comparisons, including the satellite data and standard reference climatologies for parameters such as circulation, precipitation, snow cover, and water vapor, modelE now substantially outperforms all other GISS model versions (of course not on every individual quantity), producing rms errors approximately $11 \%$ less than those for Model II'. 

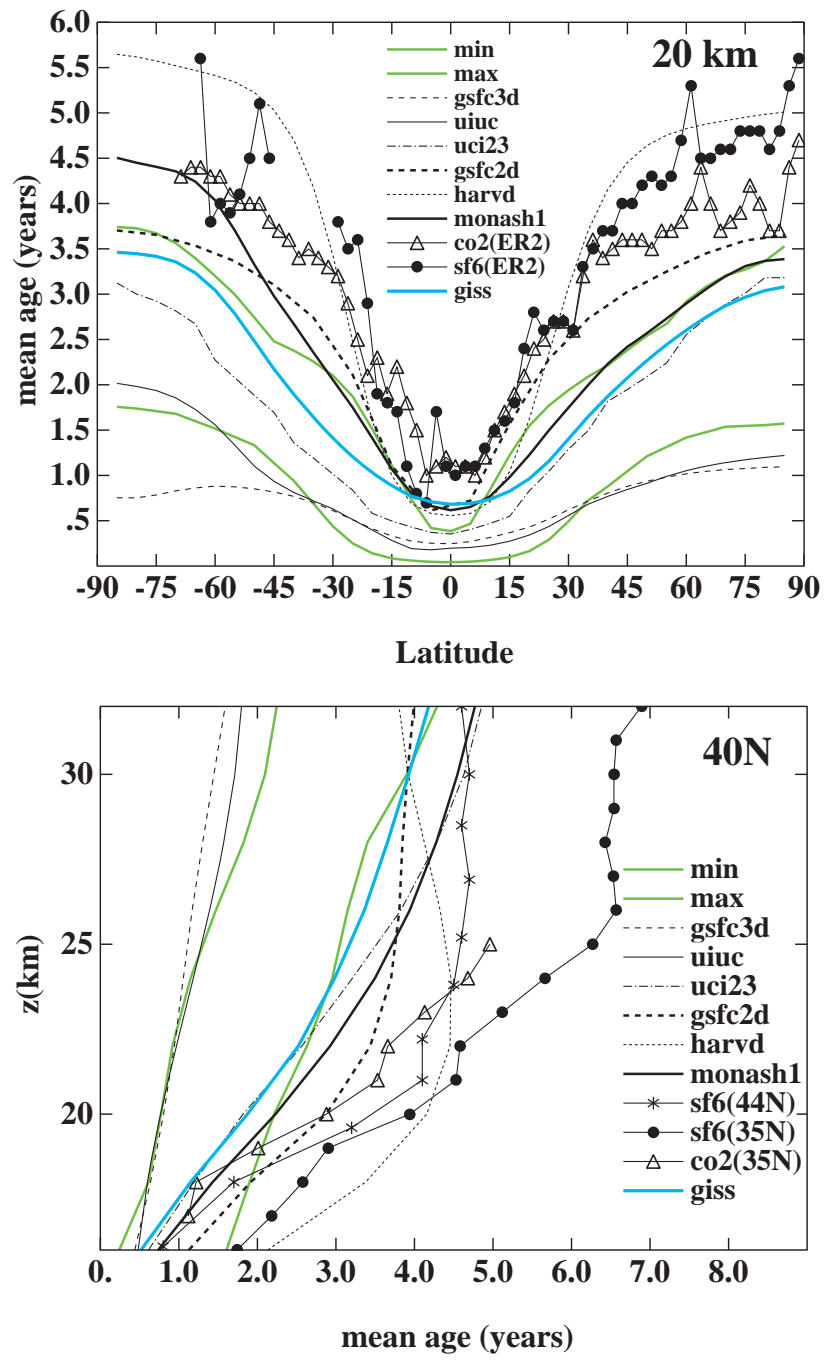

Fig. 1. Comparison of the modeled age of air with other models and data from Hall et al. (1999). The data (symbols) are based on $\mathrm{CO}_{2}$ and $\mathrm{SF}_{6}$ observations as per the references in the text. The "min" and "max" lines show the range of mean ages of models other than those explicitly plotted here. The current model is in blue.

The new modelE GCM was used for the GISS simulations performed for the forthcoming Intergovernmental Panel on Climate Change (IPCC) Fourth Assessment Report (AR4). Hence this model has been scrutinized in great detail, so that the behavior of physical processes have been compared with a wide range of observations and the model's response to a large number of forcings has been well-characterized.

Yet another important feature of modelE is the capability to run the GCM with linear relaxation, or "nudging", to reanalysis data for winds. This allows the model's meteorology to be forced to match fairly closely that which existed during particular times, making for a much cleaner comparison with observational datasets.
GISS model development has benefited particularly from the close interaction of the composition modelers with the basic climate model developers at all stages, which has enabled development of many consistent physical linkages such as the surface fluxes and liquid tracer budgets.

\subsection{Experimental setup for model evaluation}

We use a model version with 23 vertical layers (model top in the mesosphere at $0.01 \mathrm{hPa}$ ) and $4 \times 5$ degree horizontal resolution. Present-day simulations use seasonally varying climatological sea surface temperatures and sea ice coverage representative of the 1990s, and were run with constant boundary conditions (an equilibrium simulation) for 20 years following an 18 year spinup (Table 3). All of the simulations described here use the GCM's internally generated meteorological fields (i.e. none have been relaxed towards reanalysis fields).

For all the simulations described here, we use the stratospheric aerosol distribution for 1984, a mid-range year in terms of volcanic loading. For the tropospheric chemistryonly version, the stratospheric ozone climatology is set to 1990s levels. Additionally, the tropospheric chemistry-only simulations were run including interactive aerosols, which are coupled to the chemistry (Bell et al., 2005). Heterogeneous chemistry on dust was included in a separate sensitivity study to isolate its influence. Aerosol indirect effects were not included in these runs. In the full chemistry simulations, we revert to using offline prescribed aerosol fields for computational efficiency as the chemistry-aerosol coupling has a substantial effect on the aerosol simulation, but only a minor effect on the trace gases, which are our primary concern here (Unger et al., 2006).

The model has the capability to have changes in composition affect radiative transfer for radiatively active species including ozone, methane, water, aerosols and dust (but not $\mathrm{NO}_{2}$ ). The full chemistry simulations were performed including such interactions. However, since the simulations we report on here for model evaluation used prescribed presentday sea surface temperatures (SSTs) and sea ice conditions, changes in the radiatively active gases could not affect climate substantially, though they could influence atmospheric temperatures. In the climate simulations described in Sect. 4, however, this interaction becomes important.

\section{Evaluation of present-day simulation}

\subsection{Long-lived gases in the stratosphere}

Several long-lived species have been included as transported gases. These include nitrous oxide $\left(\mathrm{N}_{2} \mathrm{O}\right)$, a source of $\mathrm{NO}_{\mathrm{x}}$ radicals in the stratosphere, methane $\left(\mathrm{CH}_{4}\right)$ and water vapor $\left(\mathrm{H}_{2} \mathrm{O}\right)$, sources of stratospheric $\mathrm{HO}_{\mathrm{x}}$, and chlorofluorocarbons (CFCs), a source of halogens. A linearly increasing 

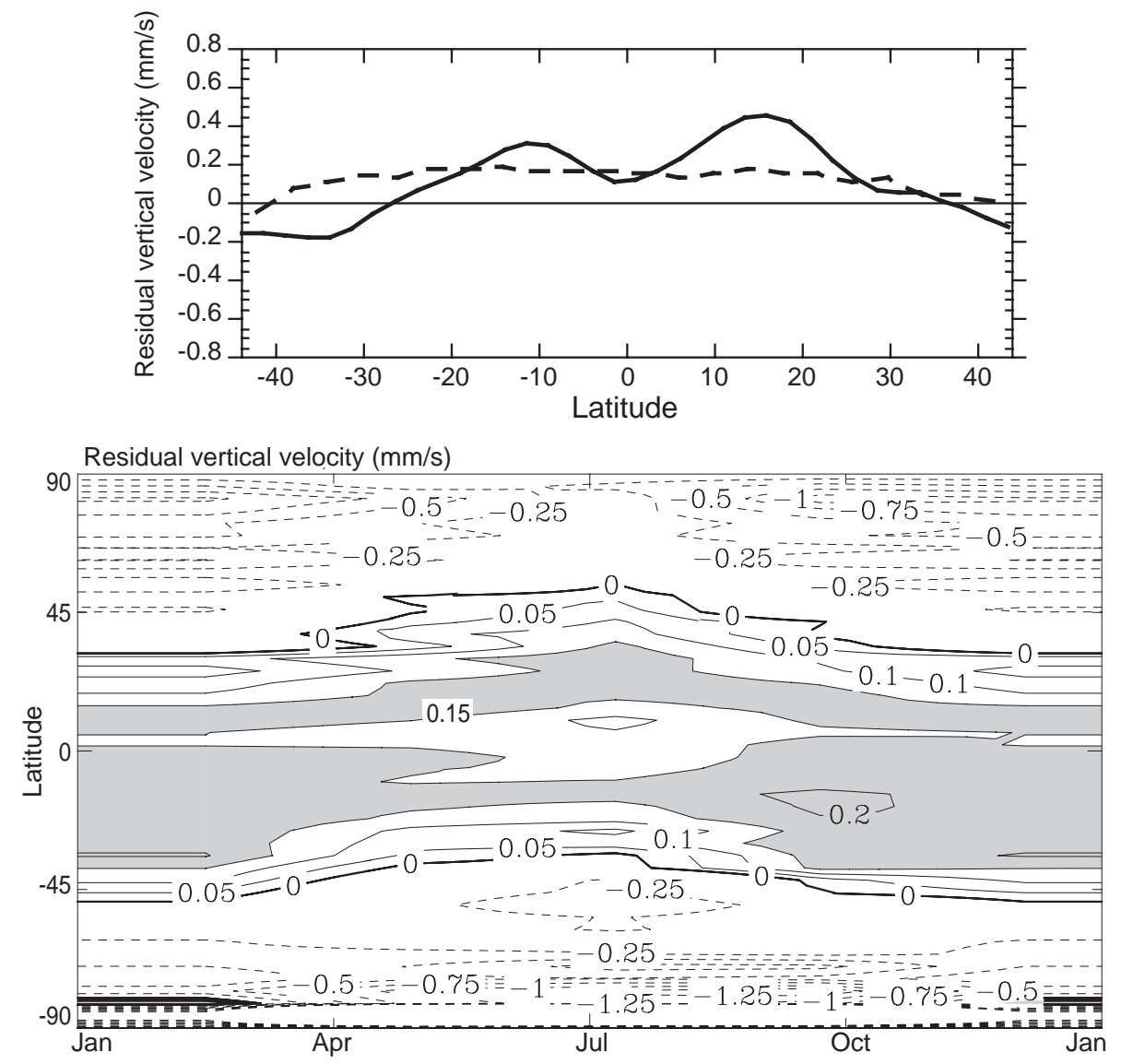

Fig. 2. Annual mean (top) and seasonal cycle (bottom) of residual vertical velocity at $68 \mathrm{hPa}$. For the annual mean, the solid line is from UKMO analyses averaged over 1992-2001, while the dashed line is from the GCM present-day control run. Contours are .05 mm/s for positive values, $.25 \mathrm{~mm} / \mathrm{s}$ for negative. Areas with upwelling velocity $>0.15 \mathrm{~mm} / \mathrm{s}$ are shaded.

tracer to diagnose transport was also included. This is presented in Fig. 1, which shows the age of air in the stratosphere calculated using the linearly increasing tracer in comparison with values derived from $\mathrm{SF}_{6}$ and $\mathrm{CO}_{2}$ observations (Andrews et al., 1999; Boering et al., 1996; Elkins et al., 1996; Harnisch et al., 1996) and values from other models (Hall et al., 1999). Clearly the model's air in the high latitude lower stratosphere is too young, a feature seen in most GCMs and even in CTMs driven by assimilated meteorological data (Scheele et al., 2005; Schoeberl et al., 2003).

The annual mean residual vertical velocity in the model underestimates the maximum values seen in the UKMO analyses (Swinbank and O'Neill, 1994), and the region of upwelling extends too far poleward in the $\mathrm{SH}$, and to a much lesser extent in the NH (Fig. 2). The model's mean upwelling velocity is $35 \%$ slower than in the observations. However, the seasonal cycle shows the maximum upwelling occurring in the summer subtropics in both hemispheres, in accord with Rosenlof (1995) and Plumb and Eluszkiewicz (1999). This simulation of the seasonality of tropical upwelling is a marked improvement over that seen in the older
GISS model II, which failed to reproduce the austral summer maximum entirely (Butchart et al., 2006). The model also simulates a local minimum in upwelling near the equator, a feature seen in most GCMs but not in previous GISS models (Butchart et al., 2006). The underestimate of upwelling velocities indicates that air reaches the high latitude lower stratosphere too easily via meridional transport across the semi-permeable barriers in the stratosphere rather than via a Brewer-Dobson circulation that is too rapid.

Consistent with these circulation biases, the model's zonal mean $\mathrm{N}_{2} \mathrm{O}$ and $\mathrm{CH}_{4}$ distributions are too broad compared with satellite climatologies from the Halogen Occultation Experiment (HALOE) and the Cryogenic Limb Array Etalon Spectrometer (CLAES) (Randel et al., 1998) (Fig. 3). Also, the high mixing ratio values entering the stratosphere in the tropics do not penetrate to high enough altitudes before being chemically transformed. The distribution of CFCs in the model exhibits a similar shape. The weak meridional gradients in the distributions of these long-lived gases implies that transport across the subtropical and polar barriers is too rapid. Additionally, there may not be enough downward 

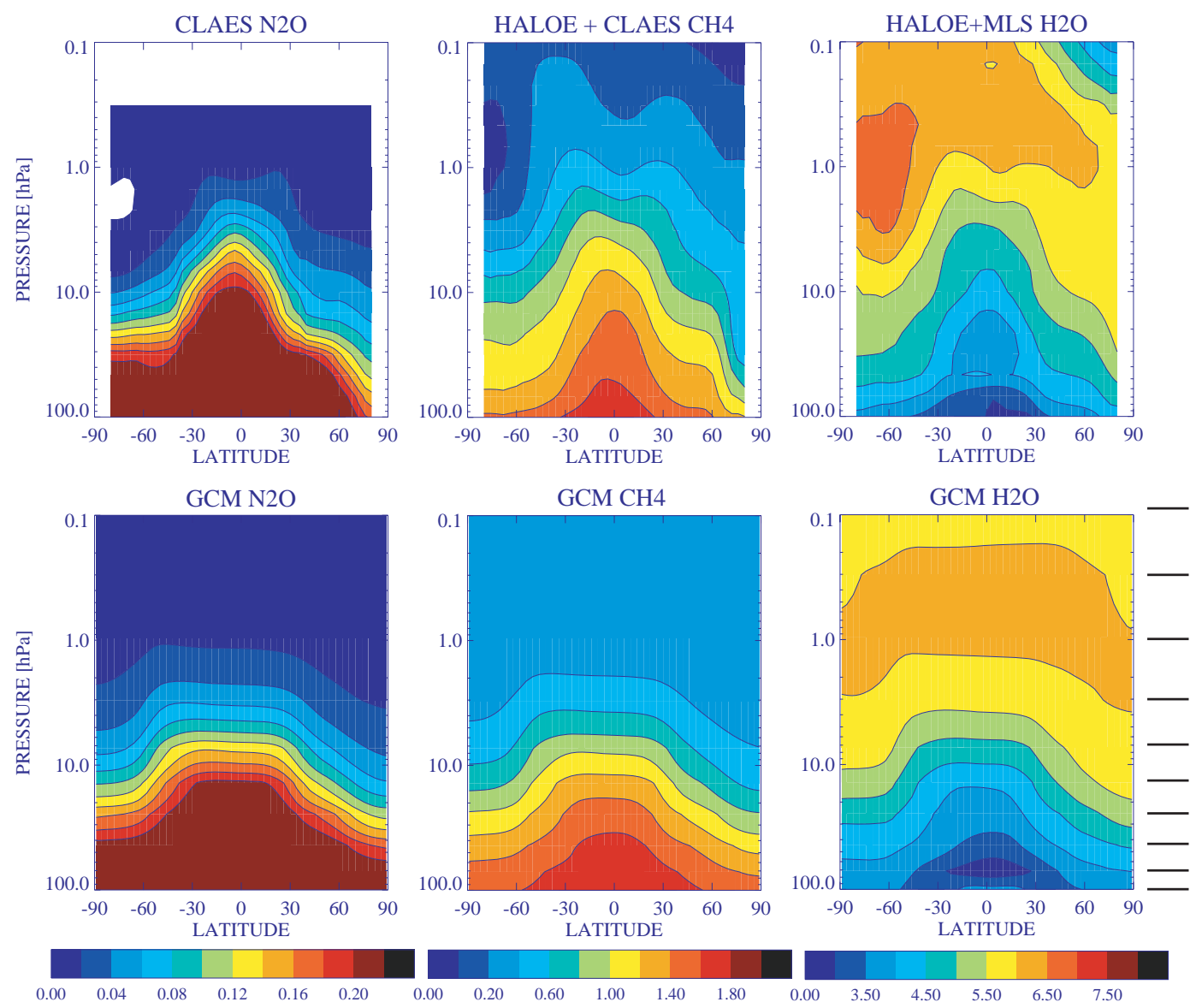

Fig. 3. Zonal mean April $\mathrm{N}_{2} \mathrm{O}, \mathrm{CH}_{4}$ and $\mathrm{H}_{2} \mathrm{O}$ from satellite observations and in the model. All values are in ppmv. $\mathrm{N}_{2} \mathrm{O}$ data is from the CLAES instrument, methane data from HALOE+CLAES, and water data from HALOE+MLS instruments. Tick marks along the right of the modeled water vapor distribution (lower right) show the model's vertical layering. Modeled water values have been offset by 0.7 ppmv to remove a negative bias in water entering the stratosphere and allow for easier comparison with the observed distribution within the stratosphere.

transport within the polar vortex, as seen near the North Pole in Fig. 3. This appears to result from the underestimate of polar isolation which keeps the polar region from cooling as much as it should, rather than biases in the overturning circulation given that the age of air is too short in the polar regions. In the interest of space, we concentrate on results for April, a month showing a "typical" ozone distribution neither too close to the solstices nor drastically affected by polar heterogeneous chemistry. The distributions are similarly too broad in other months.

The model's water vapor distribution in the stratosphere closely resembles the opposite of the methane distribution up through $\sim 1 \mathrm{hPa}$. However, the water vapor near the tropical tropopause entry point is too low, leading to a negative bias throughout the stratosphere. Given the extremely high sensitivity of water vapor to temperature and convective mixing in this region, the bias in water reflects only a small underestimate of modeled temperature or overestimate of modeled convective drying. As in observations, values increase by roughly $3 \mathrm{ppmv}$ from the tropical tropopause to the upper stratosphere at $2 \mathrm{hPa}$. However, the model's meridional gradients in stratospheric water are again too weak and the stratopause region water values are too low, both features being consistent with the circulation-induced biases in the methane distribution. Water vapor mixing ratios decrease below $5.5 \mathrm{ppmv}$ at about $0.2-0.3 \mathrm{hPa}$, as in observations, however this mesospheric loss takes place at all latitudes in the model but only near the springtime pole in observations. This may indicate that chemistry above the model top influences those layers, or that the current parameterization of mesospheric photolysis needs to be improved. Future work will explore this region further (and add Lyman-alpha photolysis). The seasonality of water vapor's entry into the stratosphere is simulated reasonably well, with a clear "tropical tape recorder" signal seen in the water vapor distribution (Schmidt et al., 2005). 


\subsection{Ozone}

The model's annual cycle of column ozone and the difference with respect to observations is shown in Fig. 4. The simulated distribution shows a broad minimum and little seasonality in the tropics, with greater ozone values and a larger seasonal cycle at high latitudes, in agreement with observations. However, the model underestimates the magnitude of the seasonal cycle at high northern latitudes, with too little ozone during the winter and too much ozone during the summer, and has a general positive bias over the Antarctic. The model's column ozone is within $10 \%$ of the observed value throughout the tropics and subtropics and over most midlatitude areas. High latitude differences are larger, in excess of $20 \%$ in some locations during some seasons.

There are two primary reasons for the high latitude biases apparent in Fig. 4. During the summer, high latitude temperatures in the modelE GCM without chemistry exhibit a cold bias of $\sim 10^{\circ} \mathrm{C}$ in the lowermost stratosphere (Schmidt et al., 2006). By slowing down the rates of ozone destroying reactions, this contributes to an increasing positive ozone biases during summer and fall seen in both hemispheres. The second reason is that the model's transport of gases into high latitudes is in general too rapid in the lower and middle stratosphere, with the subtropical and polar barriers being too permeable, as discussed in Sect. 3.1. This transport bias contributes to the underaccumulation of ozone in the Arctic during winter, and to the failure of the model to simulate lower ozone values over the Antarctic than at $\mathrm{SH}$ mid-latitudes during fall and winter, in both cases as air is not confined closely enough within the polar region. The model produces an Antarctic ozone hole whose timing is consistent with observations, as is the depletion relative to the wintertime values, though the minimum values are too large as those winter starting values are too large (as discussed previously).

Figure 5 presents the April zonal mean ozone distribution in the model and from the Microwave Limb Sounder (MLS) and HALOE instruments. Clearly the Arctic distribution is too closely centered around $10 \mathrm{hPa}$, similar to middle latitudes, consistent with an underestimate of downward transport within the polar vortex and too much mixing across the vortex boundary. The $\mathrm{SH}$ polar vortex similarly shows too much ozone from about $10-5 \mathrm{hPa}$ and contours of large ozone mixing ratios that extend too far poleward from the mid-latitude maximum. Ozone in the tropics is well-simulated, though the maximum ozone mixing ratio in the model is slightly less than in observations. In fact, the simulation is generally of high quality in regions where ozone's photochemical lifetime is short, suggesting that the model's chemistry scheme works well and that biases are indeed largely related to transport.

In addition to examining the present-day stratospheric ozone climatology, sufficient data exists to allow evaluation of the sensitivity of stratospheric ozone to perturbations. Observations from the Stratospheric Aerosol and Gas Experi-

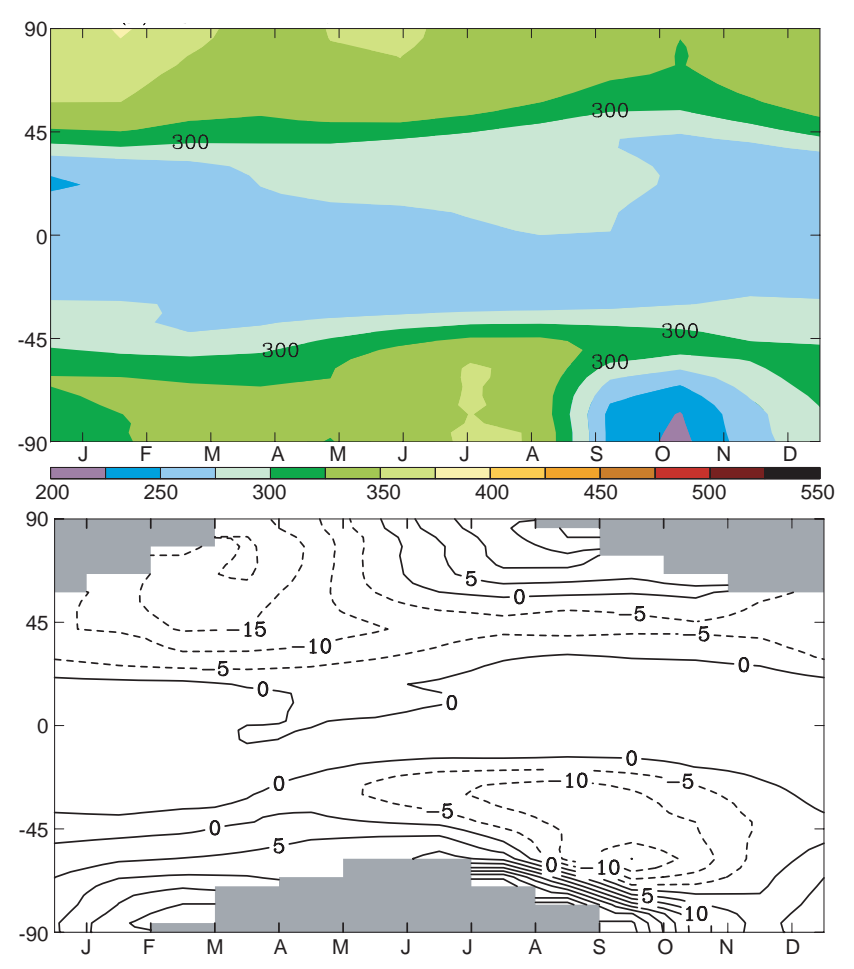

Fig. 4. Total ozone column (DU) in the model shown as latitude versus month (top) and percentage difference between modeled total column ozone and observations from the Earth Probe TOMS instrument averaged over 1996-2003 (bottom). Grey areas indicate no observations. Annual average global mean total ozone column is $287 \mathrm{DU}$, while the annual average global mean anomaly with respect to observations is $-1.6 \mathrm{DU}$.

ment (SAGE) series of satellites and high-latitude ozonesondes have been used to calculate ozone trends over the period 1979 to 2004 (updated from Randel and Wu, 1999). We have performed a simulation using 1979 climate and longlived trace gas conditions (Table 3), and can then compare the modeled change from 1979 to the present with these observations, as shown in Fig. 6. Note that our simulation did not include changes in emissions of short-lived tropospheric ozone precursors, as it was designed to isolate the impact of stratospheric ozone changes on the atmosphere.

Qualitatively, the model captures the pattern of local maxima in ozone loss in both polar regions in the lowermost stratosphere and in the upper stratosphere and also simulates the local minimum in the tropical stratosphere around 25-30 km altitude. Quantitatively, the model's ozone trends are typically a few percent larger than those seen in the satellite record. This is especially true in the Arctic lower stratosphere, though the uncertainty in the observed trends is very large as variability is high in this region. In the Antarctic lower stratosphere, the model's trend is in fairly good agreement with the magnitude calculated from observations, though the largest depletion extends over a larger area, 

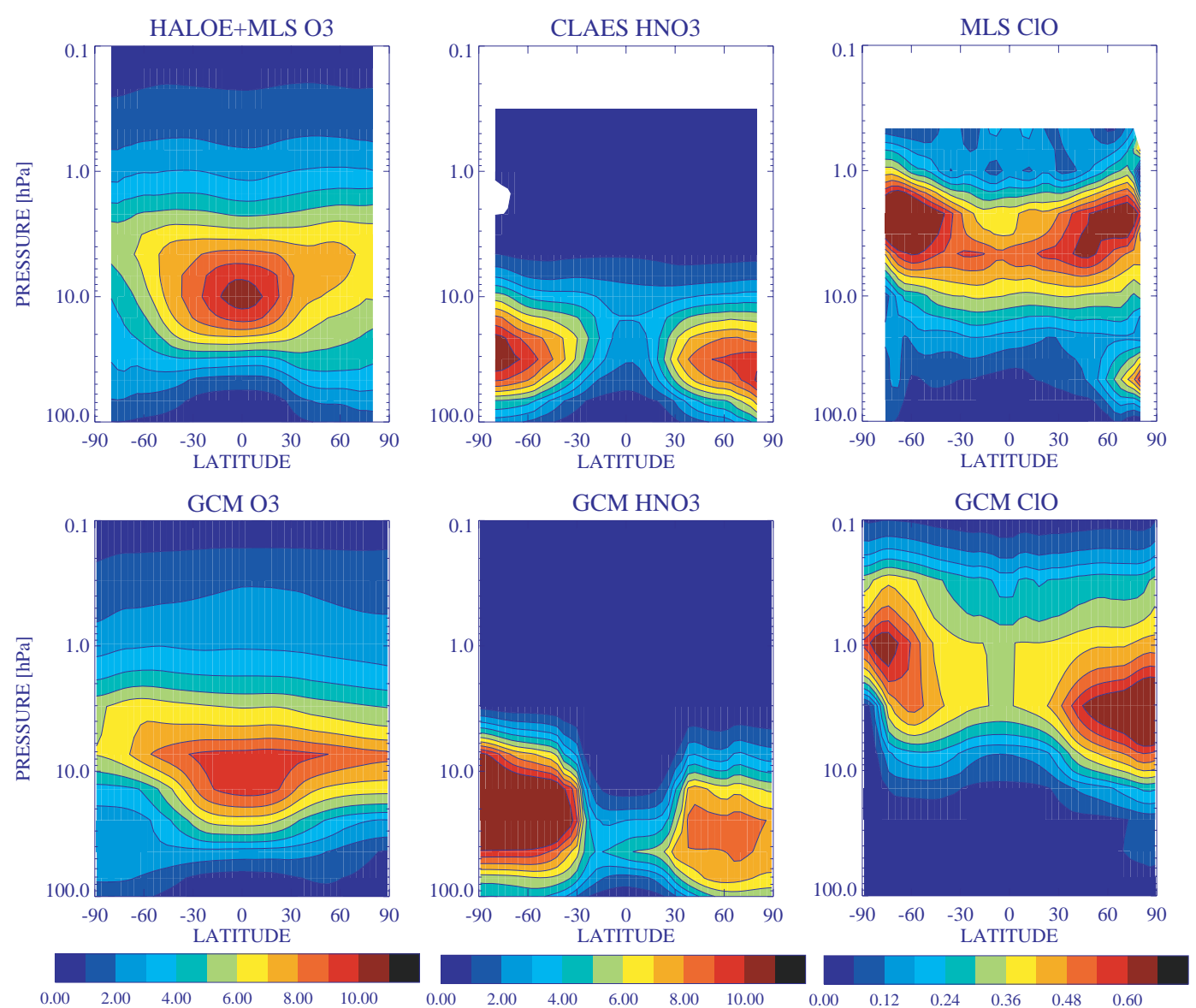

Fig. 5. Zonal mean April $\mathrm{O}_{3}$ (ppmv), $\mathrm{HNO}_{3}$ (ppbv) and $\mathrm{ClO}$ (ppbv) from satellite observations and in the model. Ozone observations are from the HALOE and MLS instruments, $\mathrm{HNO}_{3}$ data is from the CLAES instrument, and ClO measurements are from the MLS instrument.
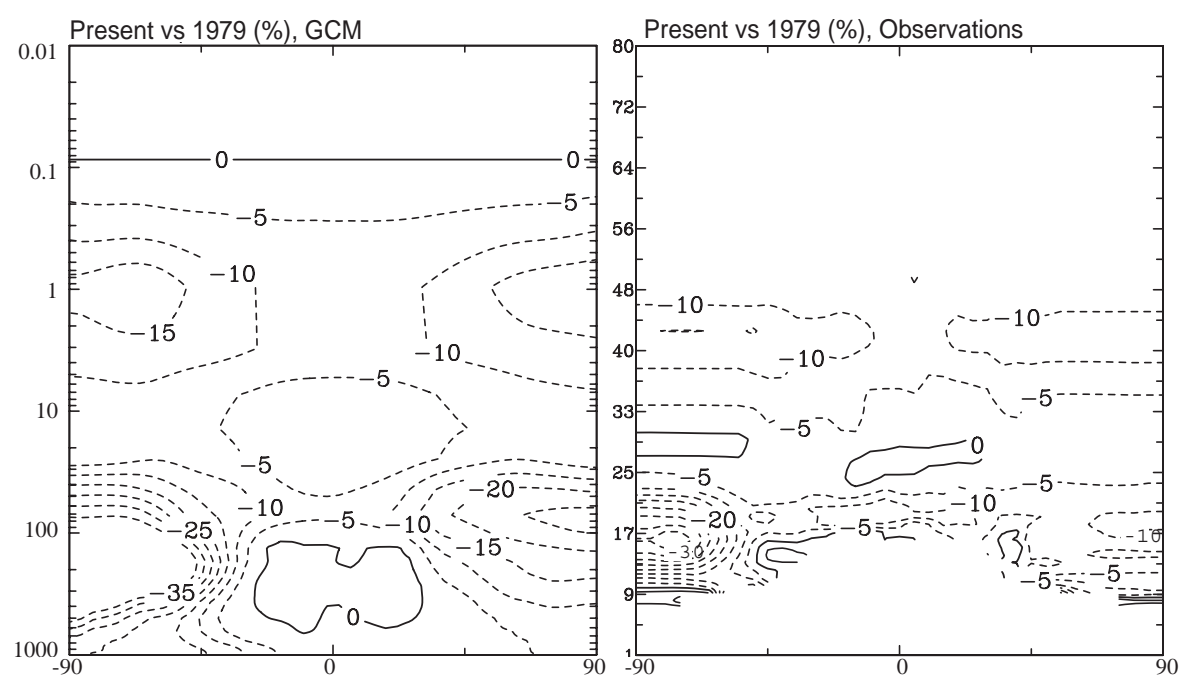

Fig. 6. Ozone changes with time (percent relative to 1979). Model PD (2000)-1979 (left), 1979-2004 observations from SAGE complimented with ozonesondes at high latitudes (right) (updated from Randel and Wu, 1999). 
Table 4. Ozone differences and biases (ppbv) between models and sondes.

\begin{tabular}{lccccccc}
\hline $\begin{array}{l}\text { Pressure } \\
\text { level } \\
\text { (hPa) }\end{array}$ & $\begin{array}{c}\text { Avg. difference, } \\
\text { model II }\end{array}$ & $\begin{array}{c}\text { Avg. difference, } \\
\text { modelE, } \\
\text { tropospheric } \\
\text { chemistry }\end{array}$ & $\begin{array}{c}\text { Avg. difference, } \\
\text { modelE, } \\
\text { full } \\
\text { chemistry }\end{array}$ & $\begin{array}{c}\text { Avg. bias, } \\
\text { modelE, } \\
\text { tropospheric } \\
\text { chemistry }\end{array}$ & $\begin{array}{c}\text { Avg. bias, } \\
\text { modelE, } \\
\text { full } \\
\text { chemistry }\end{array}$ & $\begin{array}{c}\text { Avg. bias, } \\
\text { modelE, } \\
\text { full chemistry, } \\
\text { w/o Syowa }\end{array}$ & $\begin{array}{c}\text { Standard } \\
\text { deviation } \\
\text { of obser- } \\
\text { vations }\end{array}$ \\
\hline 125 & $83.7(22 \%)$ & $50.2(13 \%)$ & $88.9(23 \%)$ & $3.5(1 \%)$ & $-16.1(4 \%)$ & $-33.9(9 \%)$ & 137 \\
200 & $44.9(22 \%)$ & $34.3(17 \%)$ & $47.2(23 \%)$ & $-23.8(12 \%)$ & $0.2(0 \%)$ & $-12.8(6 \%)$ & 74.2 \\
300 & $28.9(39 \%)$ & $17.9(24 \%)$ & $34.8(46 \%)$ & $5.9(8 \%)$ & $22.8(30 \%)$ & $16.1(21 \%)$ & 32.2 \\
500 & $10.6(23 \%)$ & $6.4(14 \%)$ & $10.3(22 \%)$ & $1.5(3 \%)$ & $-0.3(1 \%)$ & $-1.9(4 \%)$ & 11.4 \\
900 & $6.6(22 \%)$ & $5.7(19 \%)$ & $8.3(28 \%)$ & $-2.6(9 \%)$ & $-1.7(6 \%)$ & $-2.6(9 \%)$ & 9.9 \\
\hline
\end{tabular}

Comparisons are between the models and the 16 recommended sites of Logan (1999), having excluded the two sites with four months or less data. Average differences are a simple average of the month-by-month absolute value differences between the model and the sondes. Average biases are averages of the model-sonde differences without first taking the absolute value. Numbers in parentheses are percent difference with respect to observed values at these levels. The sites are: Resolute, Edmonton, Hohenpeissenberg, Sapporo, Boulder, Wallops Island, Tateno, Kagoshima, Naha, Hilo, Natal, Samoa, Pretoria, Aspendale, Lauder, and Syowa. All models are 23 layer versions.

especially down into the troposphere. However, the values in the troposphere and near the tropopause in general are all more negative in the model since these simulations did not include increases in tropospheric ozone precursors. As seen in runs that did include such increases, the troposphere became more and more polluted during the twentieth century, which would account for the positive trends seen in the lowermost portion of the SAGE data at mid-latitudes and in the tropics and also the smaller negative values seen at high latitudes.

To evaluate the lowermost stratosphere and troposphere, where satellite climatologies do not yet exist, we have extensively compared modeled annual cycles of ozone with a longterm balloon sonde climatology from remote sites (Logan, 1999). Annual cycles at several pressure levels are shown for selected sites in Fig. 7, while statistical comparisons with all sites are presented in Table 4. Results are included for simulations incorporating chemistry throughout the model domain and for simulations with tropospheric chemistry only. Values from the previous model II' version are also shown in the table for comparison.

The ozone values and annual cycles over a wide range of latitudes are reasonably well simulated (Fig. 7). The high latitude biases evident in the previous analysis of the total column are immediately apparent at the uppermost sonde levels, however. The full chemistry version underpredicts wintertime ozone at $125 \mathrm{hPa}$ at both Resolute and Hohenpeissenberg, and overpredicts at Lauder and especially at Syowa. The biases have only a minor effect on lower altitudes at most locations, with the exception of Syowa where they persist clearly through at least $500 \mathrm{hPa}$. The shape of the seasonal cycle is generally well reproduced in the model, with maximum and minimum values typically falling at the correct time of year. There is clearly an underestimate of ozone in the tropical upper troposphere at Natal, but this is not the case at other locations.
A broader comparison of all 16 ozonesonde sites, as shown in Table 4, demonstrates that the new composition and climate model gives a substantially improved simulation in comparison with the older model $\mathrm{II}^{\prime}$ tropospheric chemistry model. Running the new model in tropospheric chemistryonly mode leads to a better match with observations at all levels, though especially those away from the surface. Using the full chemistry calculation, inherently a more difficult endeavor compared with prescribing stratospheric ozone to exactly match observations, coincidentally leads to differences with respect to observations that are quite similar to those seen in the tropospheric chemistry-only model $\mathrm{II}^{\prime}$. However, this implies that at a level such as $125 \mathrm{hPa}$, in the stratosphere for many of the sites, the full chemistry model does a much better job for the low latitude sites for which this level is in the troposphere (consistent with the modelE tropospheric chemistry-only performance).

Transport from the stratosphere to the troposphere is substantially improved in the new modelE, as evidenced by the improvement in the tropospheric chemistry modelE versus $\mathrm{II}^{\prime}$. Thus the large positive bias in the full chemistry model at $300 \mathrm{hPa}$ does not result solely from excessive downward transport, a major problem in previous GISS GCMs. It is at least partially attributable to the overestimate of high latitude lower stratospheric ozone, especially in the SH. A similar statistical comparison of the full chemistry run with sonde data leaving out the two high latitude sites Resolute and Syowa shows average differences in ppbv reduced from 34.7 to 23.7 at $300 \mathrm{hPa}$, from 45.7 to 37.0 at $200 \mathrm{hPa}$, and from 83.2 to $75.8 \mathrm{ppbv}$ at $125 \mathrm{hPa}$, while at lower levels, there is little effect. This demonstrates that, as expected, a fair amount of the discrepancy with observations arises from the model's high latitude biases. However, some excessive downward transport may still be occurring, which is partially masked in the tropospheric chemistry-only run by the negative bias at $200 \mathrm{hPa}$. The large $300 \mathrm{hPa}$ positive bias is 

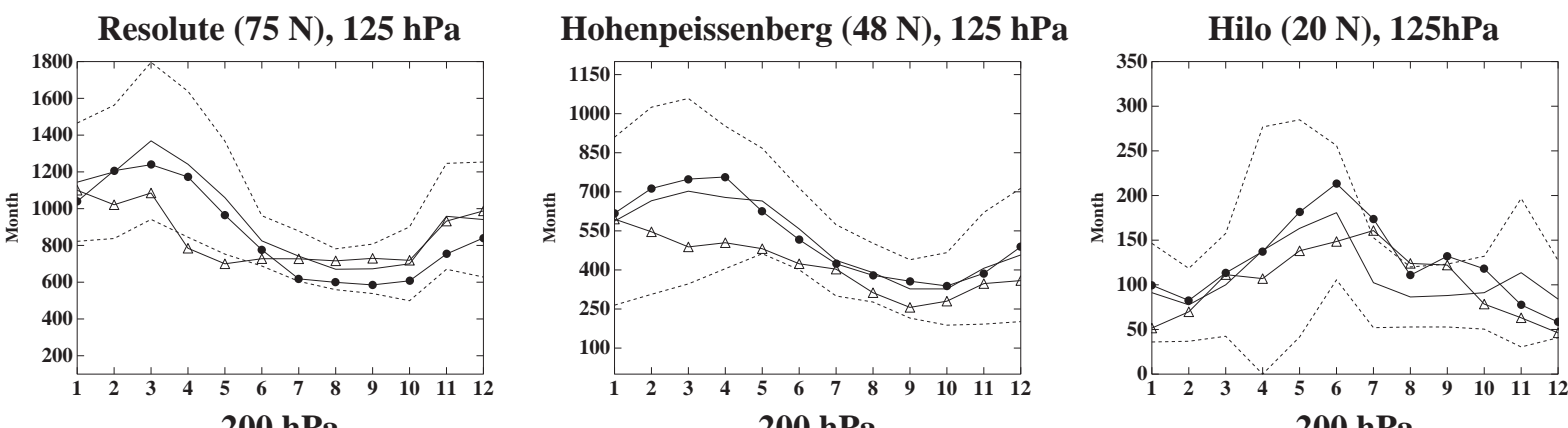

$200 \mathrm{hPa}$
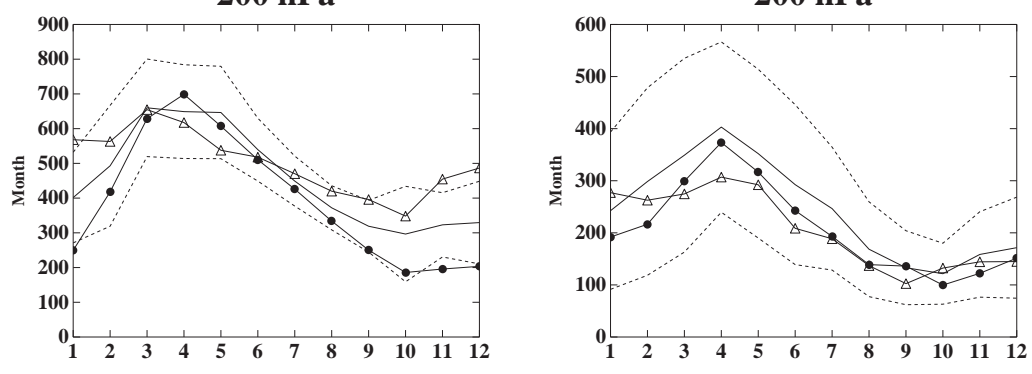

$200 \mathrm{hPa}$

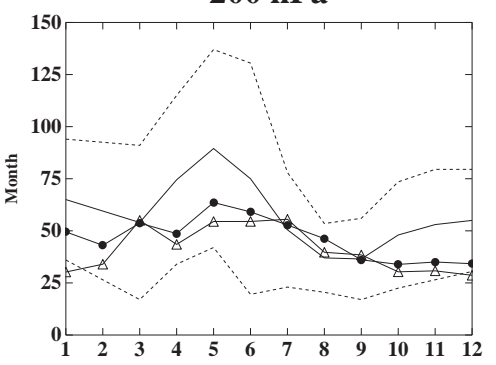

$300 \mathrm{hPa}$

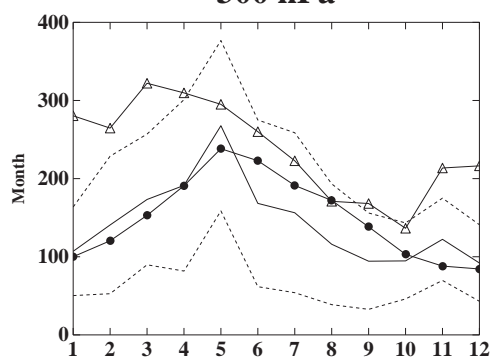

$300 \mathrm{hPa}$

$500 \mathrm{hPa}$
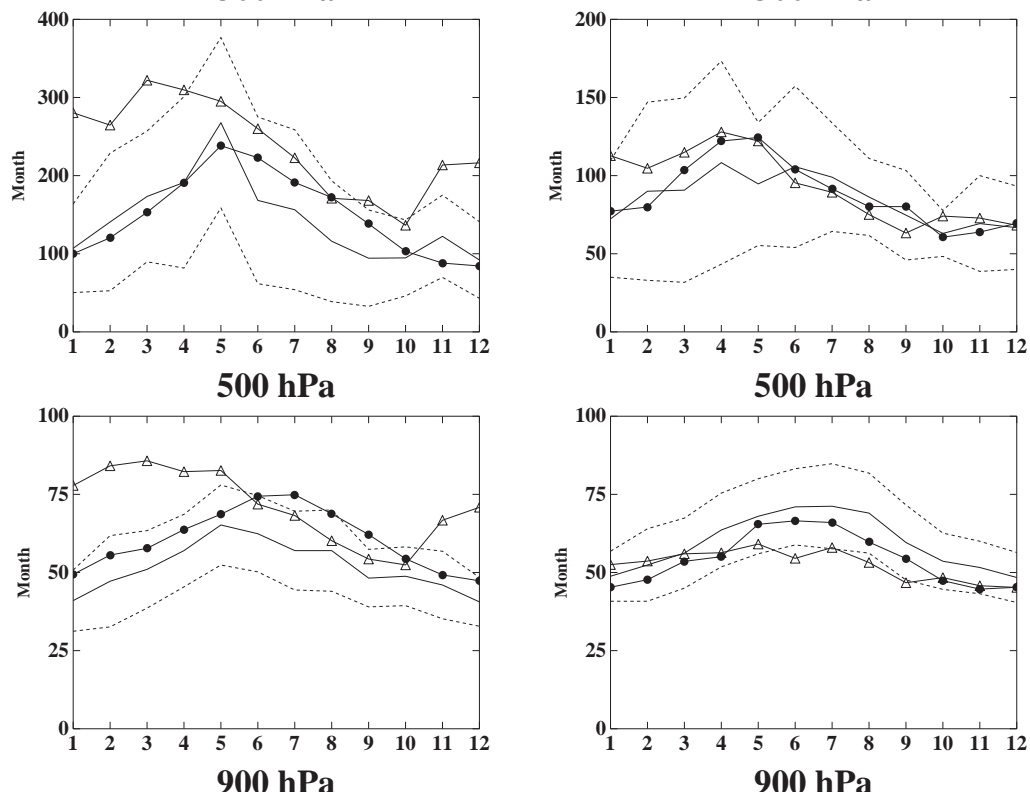

$300 \mathrm{hPa}$

$500 \mathrm{hPa}$
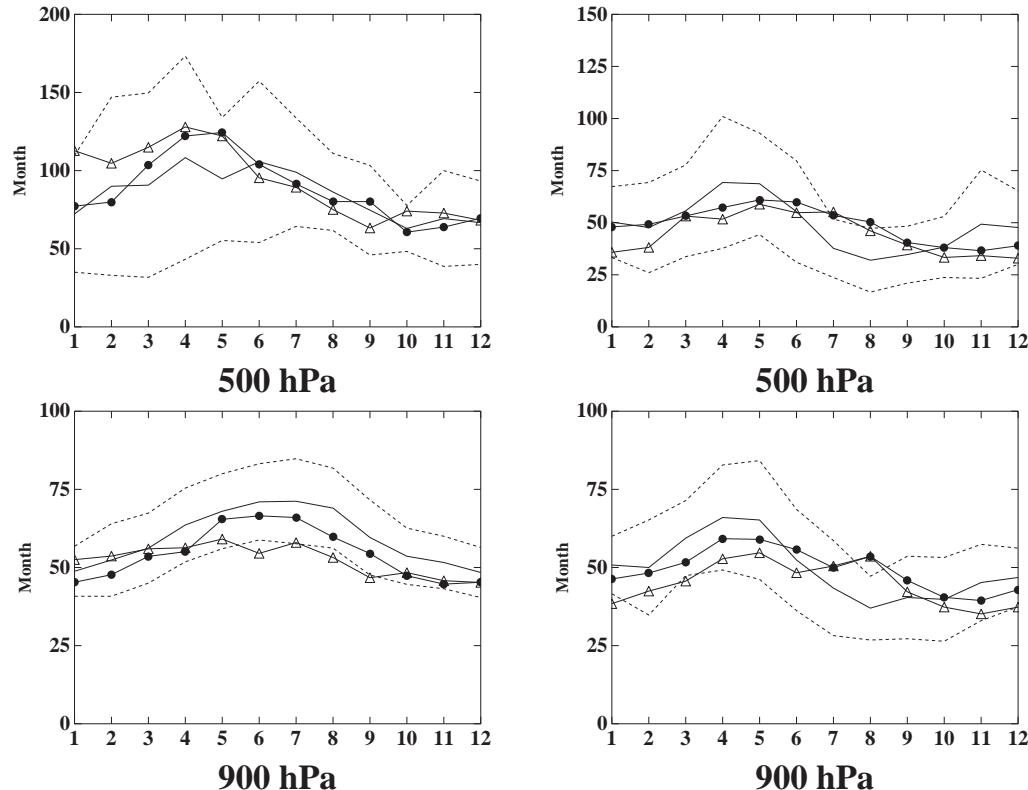

$500 \mathrm{hPa}$

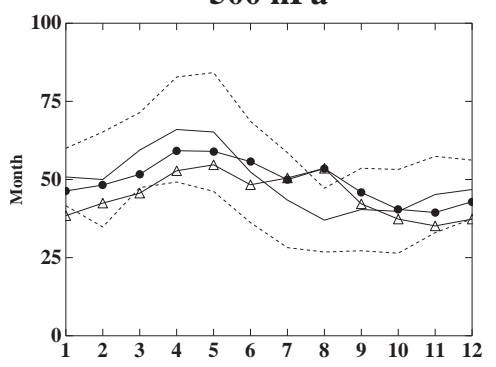

$900 \mathrm{hPa}$
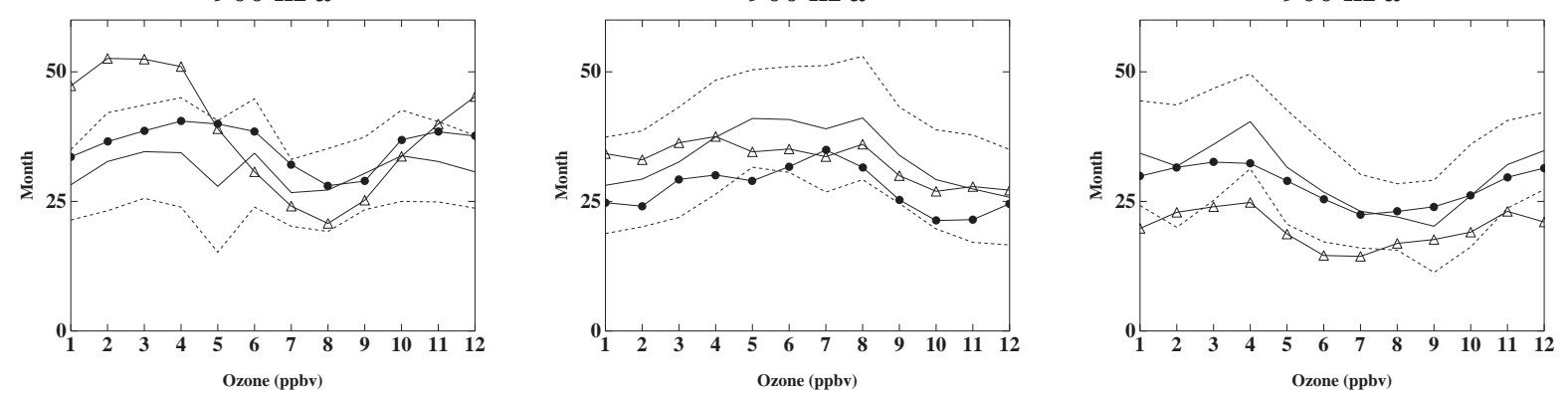

Fig. 7. Comparison of ozone's annual cycle in the model with an ozonesonde climatology (Logan, 1999) at the given locations and pressure levels. Solid lines give observed mean values, while filled circles and open triangles show results from the tropospheric chemistry-only and full chemistry simulations, respectively. Model values have been interpolated onto the given pressure levels. 


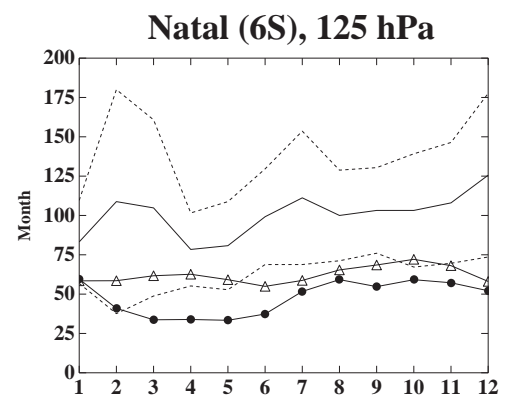

$200 \mathrm{hPa}$

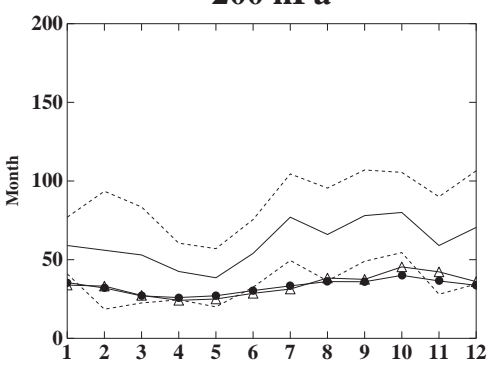

$300 \mathrm{hPa}$

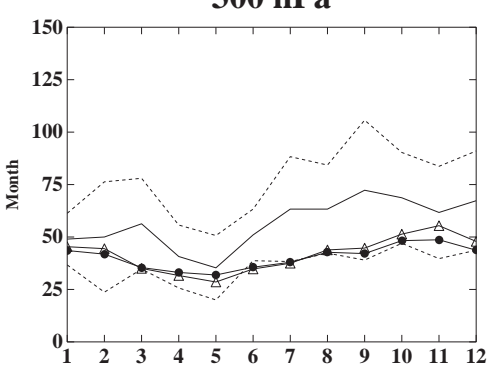

$500 \mathrm{hPa}$

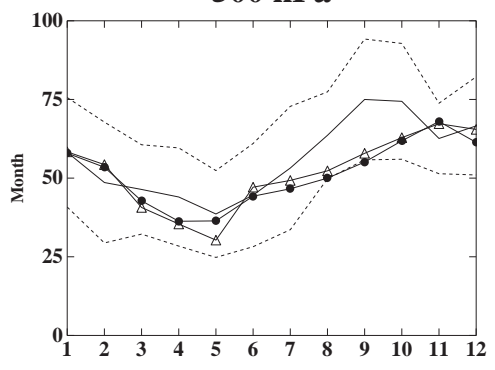

$900 \mathrm{hPa}$

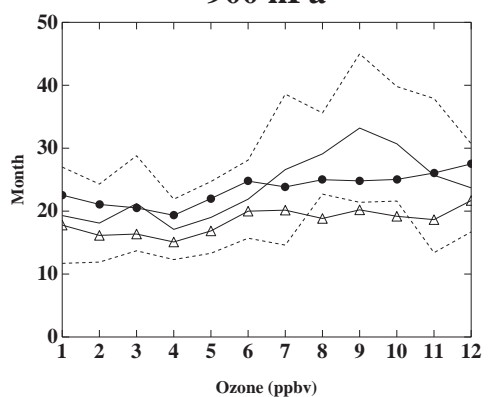

Fig. 7. Continued.

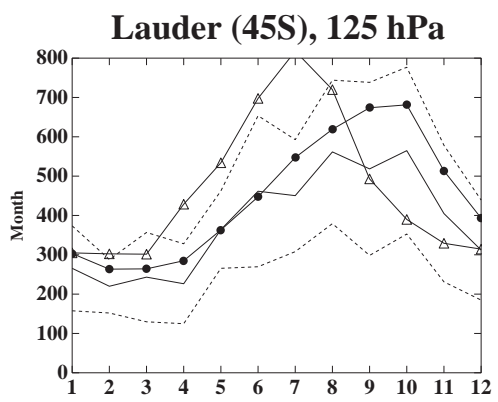

$200 \mathrm{hPa}$

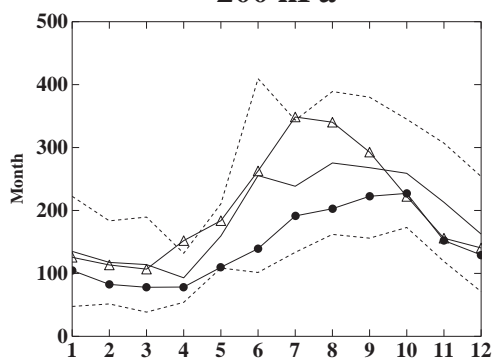

$300 \mathrm{hPa}$

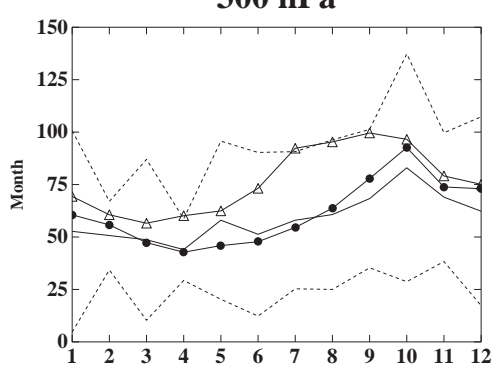

$500 \mathrm{hPa}$

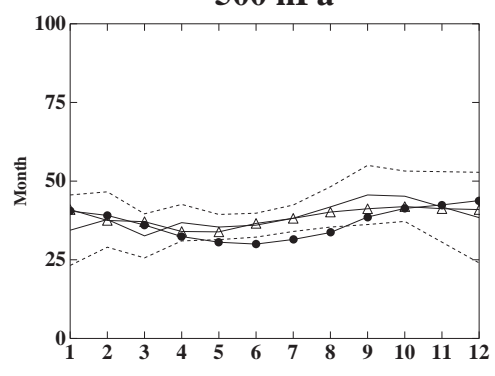

$900 \mathrm{hPa}$

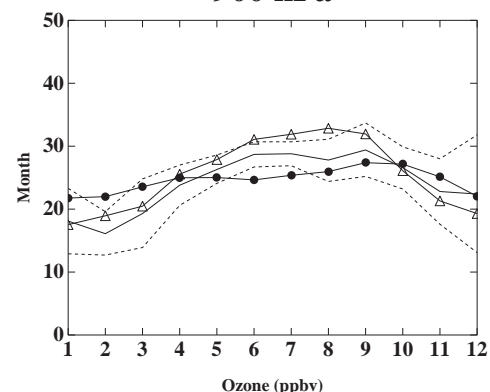

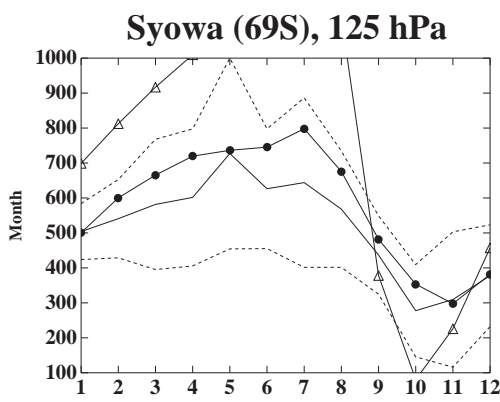

$200 \mathrm{hPa}$

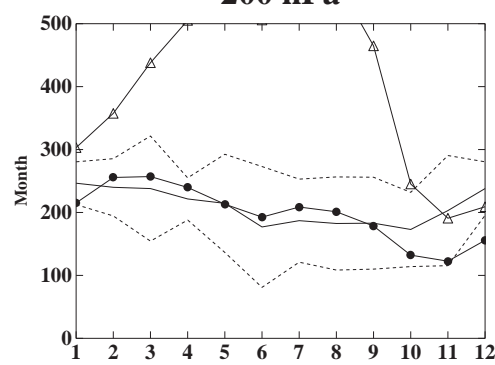

$300 \mathrm{hPa}$

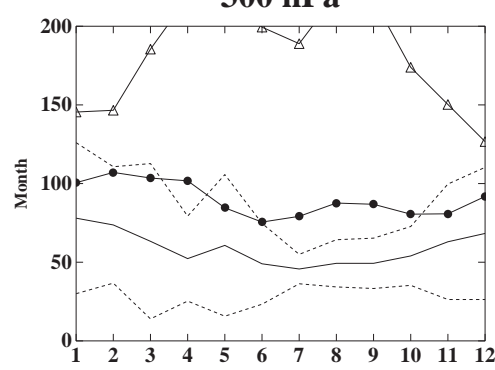

$500 \mathrm{hPa}$

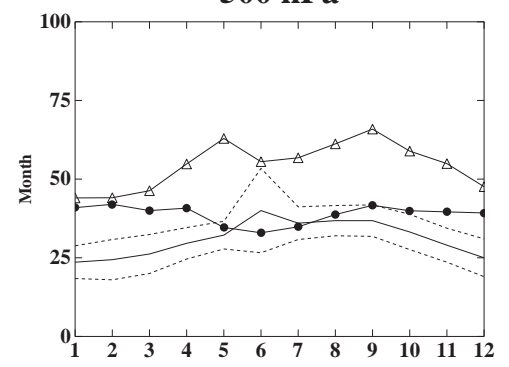

$900 \mathrm{hPa}$

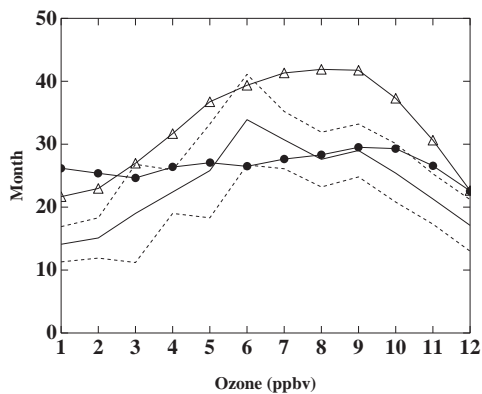



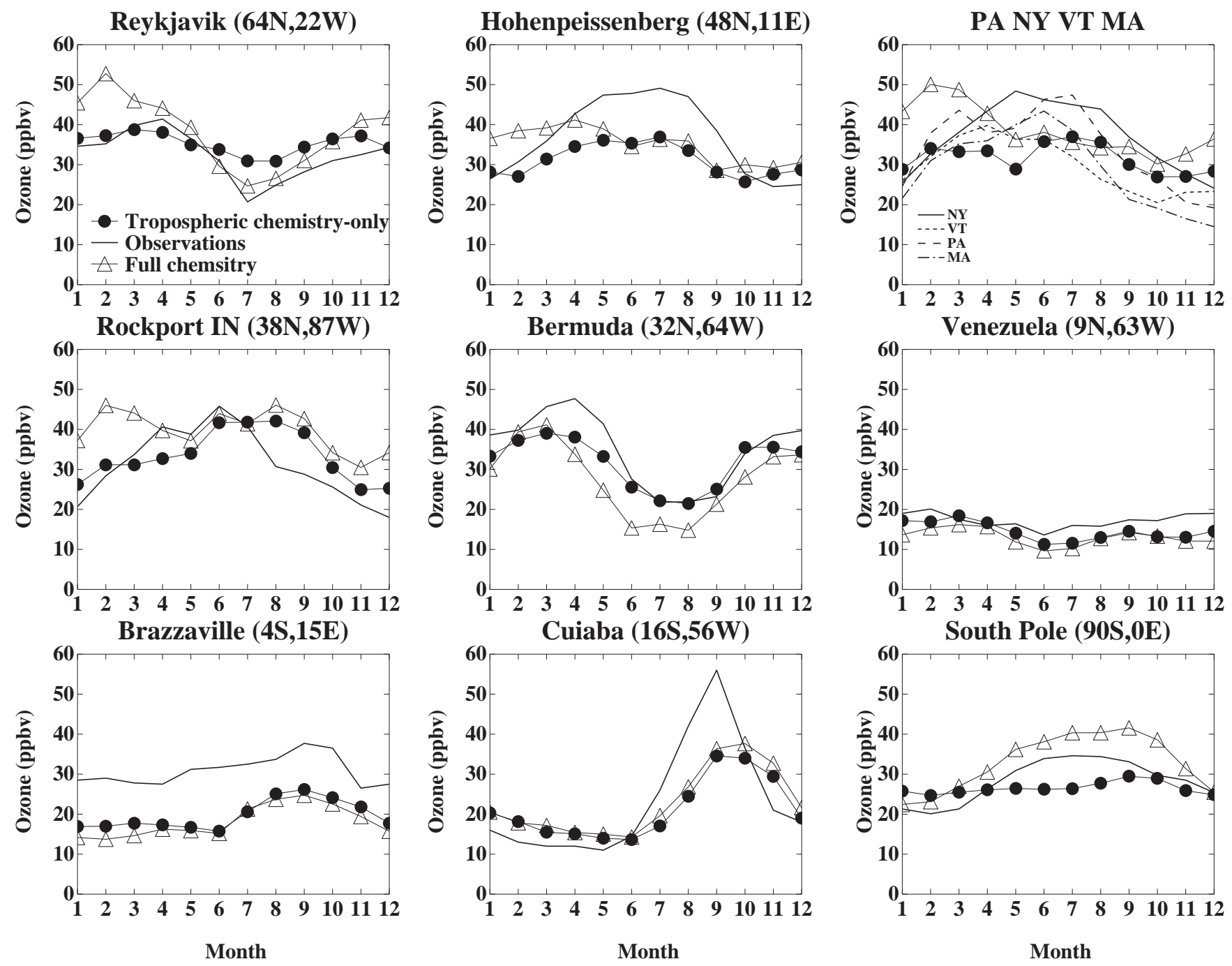

Fig. 8. Annual cycles of surface ozone in the model and in observations. Solid lines give observed mean values, while filled circles and open triangles show results from the tropospheric chemistry-only and full chemistry simulations, respectively. Note that observations at Brazzaville and Venezuela are averages of daily maximum values, so represent an upper bound.

thus not present in the modelE tropospheric chemistry-only run. Aside from this large positive bias (31\%), biases at other levels are generally quite small, with values of $12 \%$ or less (and often $3 \%$ or less) at all other levels for both the full chemistry and tropospheric chemistry-only simulations. The GISS tropospheric-only chemistry modelE participated in the ACCENT/IPCC AR4 assessment of chemistry models, which included an evaluation of present-day simulations against this same ozonesonde climatology. In comparison with the other models, the GISS model performed quite well, with a root-mean-square (rms) error value of $6.3 \mathrm{ppbv}$ compared with a range of rms error values of 4.6 to $17.8 \mathrm{ppbv}$ (Stevenson et al., 2006).

An additional simulation identical to the tropospheric chemistry-only run except including heterogeneous reactions on dust surfaces was also performed. The same statisti- cal comparison of ozone fields with sonde data for that run shows reductions in the mean ozone concentration at those sites of $1.3 \%$ at $300 \mathrm{hPa}$, of $9.8 \%$ at $500 \mathrm{hPa}$, and of $1.0 \%$ at $950 \mathrm{hPa}$. Changes are $0.5 \%$ or less at 125 and $200 \mathrm{hPa}$. The reduction occurs primarily via removal of nitric acid on dust surfaces (see Sect. 3.3), which reduces the reactive nitrogen available for ozone production. The overall effect on ozone is mixed, with minor improvements in the model-data comparison at some levels and minor reductions in quality at others.

The effect of the model's liquid tracer budget has also been assessed. The inclusion of liquid tracers leads to an overall reduction in ozone due to enhanced removal of soluble species such as $\mathrm{HNO}_{3}$ (see Sect. 3.2). The tropospheric ozone burden is reduced by $10 \mathrm{Tg}(3 \%)$. The changes are not uniform, however, with ozone generally decreasing in the 
upper troposphere but sometimes increasing at lower levels. For example, in the same statistical comparison with sondes discussed above, the ozone concentration at those sites is reduced by $0.6 \mathrm{ppbv}$ at $300 \mathrm{hPa}$, but increased by $1.6 \mathrm{ppbv}$ at $500 \mathrm{hPa}$. This results from enhanced downward transport of aqueous-phase $\mathrm{HNO}_{3}$ via advection and precipitation followed by evaporation. Overall the comparison with sondes generally changes by only about $1 \%$, though at the $900 \mathrm{hPa}$ level the difference between sondes and the model is reduced by $\sim 3 \%$ with the inclusion of the liquid tracer.

Surface ozone data is more widely available, and we compare modeled values with measurements from 40 sites using the climatology of Logan (1999), based on data from many sources (Cros et al., 1988; Kirchhoff and Rasmussen, 1990; Oltmans and Levy, 1994; Sanhueza et al., 1985; Sunwoo and Carmichael, 1994). The model does a reasonably good job of matching the observed annual cycle at most sites, a sample of which are shown in Fig. 8. The results for the tropospheric chemistry-only simulation are fairly similar to those of our previous model (Shindell et al., 2003), consistent with the $900 \mathrm{hPa}$ results shown in Table 4. There is some improvement at Reykjavik owing to the improved downward transport at high latitudes. At Northern middle latitudes, the simulation at Rockport is substantially improved, while that in the Northeastern U.S. is marginally better though the Hohenpeissenberg results are marginally worse. The surface ozone values in the full chemistry simulation are very similar to those in the tropospheric chemistry-only version, unsurprisingly. Interestingly, South Pole shows a substantial difference, with more wintertime ozone in the full chemistry run. While this improves the agreement with observations, it results from the overestimate of ozone in the Antarctic lower stratosphere. This does indicate that the model transports stratospheric ozone anomalies all the way to the surface at South Pole, a phenomenon also seen in observations. Interestingly, there is $22 \%$ less South Pole surface ozone in the PD run than in the 1979-stratosphere run, only marginally on the high side of the 11-19\% decrease observed over the 22 year 1975-1995 period (Oltmans et al., 1998). This suggests that the downward transport of ozone depletion is not itself drastically overestimated.

Comparing all 40 sites with the model's values shows that the mean bias has decreased from $+3.8 \mathrm{ppbv}$ in model $\mathrm{II}^{\prime}$ to $-1.4 \mathrm{ppbv}$ in the tropospheric chemistry-only run and $0.6 \mathrm{ppbv}$ in the full chemistry run. A correlation plot of the annual average surface ozone (Fig. 9), however, shows that there is still substantial scatter despite the small mean bias. It is important to remember that the observations are primarily from remote sites, and that the model's 4 by 5 degree grid boxes tend to include a mix of remote and urban locations over most continental regions, making the comparison somewhat imperfect.

It thus appears that the model generally does a reasonable job of reproducing observations throughout much of the atmosphere. The primary exception is the polar stratosphere,

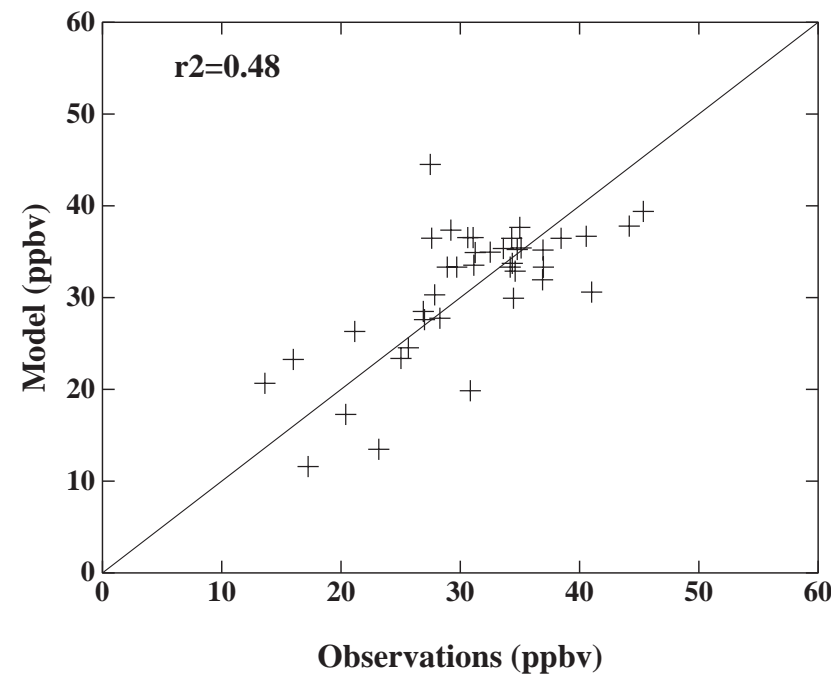

Fig. 9. Correlation diagram of observed and modeled annual average surface ozone at 40 locations using the data of Logan (1999).

as discussed above, where values show biases up to about $25 \%$. This is an important limitation, affecting the model's usefulness in performing studies of polar ozone depletion. However, the model reproduces observations in the extrapolar regions quite well, and shows especially good agreement near the surface and in the vicinity of the tropopause (Table 4). The latter is a key region for radiative forcing, and thus the results indicate that the model is useful for studies of how composition-climate interactions may affect climate and air quality.

One area that has proved difficult to study in the past has been the response of STE to climate change. Without the inclusion of stratospheric chemistry, our previous studies, and those of many other groups using tropospheric chemistryonly setups, were strongly influenced by the definition of the upper boundary for chemistry. For example, if chemistry was calculated below a fixed level, part of the upper troposphere and lowermost stratosphere, a region where data is sparse, had to be prescribed, and odd gradients could be created across this arbitrary chemical boundary. If instead chemistry followed the tropopause, changes in the location of the tropopause could dramatically affect the results as ozone amounts changed from climatology to calculated values. This latter effect could create sources and sinks as a box was categorized alternately in one region then the other. The new full chemistry model avoids these problems, and so we explore the issue of STE in some depth in Sect. 4.4. In preparation for this, we give the tropospheric ozone budget for the models discussed here, initially calculating the terms for the atmosphere below $150 \mathrm{hPa}$ and using fluxes across this level (Table 5).

The tropospheric ozone burden of $379 \mathrm{Tg}$ in the tropospheric chemistry-only model is quite similar to the $349 \mathrm{Tg}$ 
Table 5. Ozone budget (Tropospheric, Tg/yr), burdens (Tg), OH and radiative forcing (RF, W/m²).

\begin{tabular}{lcccccc}
\hline $\begin{array}{l}\text { Simulation } \rightarrow \\
\text { Quantity } \downarrow\end{array}$ & $\begin{array}{c}\text { Preindustrial (PI) } \\
\text { emiss }+ \\
\text { climate }\end{array}$ & $\begin{array}{c}1979 \text { strat } \\
\text { comp }\end{array}$ & $\begin{array}{c}\text { Present-day } \\
\text { (PD) }\end{array}$ & $\begin{array}{c}\text { A2 2100 } \\
\text { emiss }+ \\
\text { climate }\end{array}$ & $\begin{array}{c}\text { A2 2100 } \\
\text { climate }\end{array}$ & $\begin{array}{c}\text { Tropospheric } \\
\text { chemistry-only } \\
\text { (PD) }\end{array}$ \\
\hline Change by dynamics & 708 & 777 & 608 & 1360 & 810 & 502 \\
(STE) & $(100)$ & $(169)$ & & $(752)$ & $(202)$ & -956 \\
Change by dry deposition & -669 & -1031 & -976 & -1800 & -873 & 454 \\
Net change by chemistry & -39 & 254 & 368 & 349 & 64 & 4932 \\
Chemical production & 4278 & 4705 & 4957 & 9545 & 4901 & -4464 \\
Chemical loss & -4317 & -4451 & -4588 & -9194 & -4837 & 379 \\
Tropospheric burden & 379 & 503 & 420 & 845 & 413 & NA \\
Stratospheric burden & 3365 & 3134 & 2769 & 3531 & 2777 & 9.6 \\
Mean OH & 10.3 & 8.4 & 8.7 & 9.3 & 11.8 & NA \\
Shortwave RF & -0.39 & -0.21 & NA & -0.25 & -0.05 & NA \\
Longwave RF & 0.05 & 0.25 & NA & 1.01 & -0.13 & NA \\
Net RF & -0.34 & 0.04 & NA & 0.76 & -0.18 & \\
\hline
\end{tabular}

Budget values (STE, dry deposition and chemistry) and $\mathrm{OH}$ are calculated for the troposphere only. All radiative forcings are relative to present day. Values in parentheses for $\mathrm{O}_{\mathrm{x}}$ change by dynamics give the change relative to present-day. Troposphere-only chemistry model net forcing from PI to PD is $0.37 \mathrm{~W} / \mathrm{m}^{2}$ (Shindell et al., 2005b). emiss=emissions, and denotes time appropriate settings for both concentrations of long-lived gases and emissions of short-lived gases in the troposphere, comp=composition, and denotes time appropriate settings for concentrations of long-lived gases only, strat=stratospheric.

Table 6. Ozone fluxes (Tg/yr).

\begin{tabular}{lcccc}
\hline & $\begin{array}{c}\text { Southern extratropical } \\
\text { flux, downwards } \\
\text { across } 150 \mathrm{hPa}\end{array}$ & $\begin{array}{c}\text { Tropical flux, } \\
\text { upwards across } \\
50 \mathrm{hPa}\end{array}$ & $\begin{array}{c}\text { Northern extratropical } \\
\text { flux, downwards } \\
\text { across } 150 \mathrm{hPa}\end{array}$ & $\begin{array}{c}\text { Net horizontal } \\
\text { and vertical flux } \\
\text { into troposphere }\end{array}$ \\
\hline Preindustrial (PI) & $369(+104)$ & $101(-7)$ & $345(-8)$ & $693(+136)$ \\
Present-day (PD) & 265 & 108 & 353 & 557 \\
A2 emissions + climate & $710(+445)$ & $145(+37)$ & $755(+402)$ & $1333(+776)$ \\
A2 climate & $269(+4)$ & $100(-8)$ & $504(+151)$ & $742(+185)$ \\
\hline
\end{tabular}

Values in parentheses are changes relative to the present day. Tropical upward fluxes at $50 \mathrm{hPa}$ are calculated over the region where the net flux is upwards, which is typically $24^{\circ} \mathrm{S}$ to $20^{\circ} \mathrm{N}$. Extratropical fluxes are summed from 28 degrees to the pole. The final column gives fluxes across a continuous surface following $150 \mathrm{hPa}$ from 28 to 90 in each hemisphere and $50 \mathrm{hPa}$ from 28 to 28 , and including the horizontal fluxes across 28 degrees latitude from 150 to $50 \mathrm{hPa}$.

burden in the previous model $\mathrm{II}^{\prime}$ tropospheric chemistry-only version. These burdens are very close despite a large change in dry deposition between the two models that resulted from the switch between the earlier surface flux calculation to one consistent with other climate variables in the new modelE. This reinforces the point we've made previously that only the STE value is reasonably well constrained from observations. These give a best estimate of $450 \mathrm{Tg} / \mathrm{yr}$ with a range of 200 to $870 \mathrm{Tg} / \mathrm{yr}$ for the cross-tropopause flux based on $\mathrm{O}_{3}-\mathrm{NO}_{\mathrm{y}}$ correlations (Murphy and Fahey, 1994), a range of $450-590 \mathrm{Tg} / \mathrm{yr}$ at $100 \mathrm{hPa}$ from satellite observations (Gettelman et al., 1997), and a constraint from potential vorticity and ozone fluxes for the downward extrapolar flux $(\sim 80$ $100 \%$ of total downward flux) of $470 \mathrm{Tg} / \mathrm{yr}$ for the year 2000 (Olsen et al., 2003). The $502 \mathrm{Tg} / \mathrm{yr}$ STE value in the tropospheric chemistry-only model is consistent with the observa- tional constraints. The full chemistry simulation has a larger value $(608 \mathrm{Tg} / \mathrm{yr})$ that is on the high side of the range from observations, owing to the excessive downward ozone fluxes at high Southern latitudes where ozone amounts are overestimated (the full chemistry STE value at $115 \mathrm{hPa}$, our closest level to $100 \mathrm{hPa}$, is $578 \mathrm{Tg} / \mathrm{yr}$ ). Some analyses also provide estimates of the ratio of $\mathrm{NH}$ to $\mathrm{SH}$ downward flux, with the NH contributing $55 \%$ of the total in Olsen et al. (2003) and $57 \%$ in Gettelman et al. (1997). The present-day model results are in good agreement with this value, with $57 \%$ of the downward flux in the NH (Table 6). Budget terms other than STE simply respond to balance the tropospheric abundance as chemistry is typically very rapid, making the system highly buffered and the other budget of limited value for model evaluation. 


\subsection{Nitrogen species}

The model's distribution of $\mathrm{HNO}_{3}$ matches the location of maxima in the satellite observations in both extratropical regions fairly well (Fig. 5). The area within the 9 ppbv contour is too large in the $\mathrm{SH}$, however. Nitric acid can be formed by heterogeneous chemistry, and is therefore dependent upon aerosol and PSC surface areas and a parameterization of particle growth and sedimentation. Since these are quite simple in this model, it is not surprising that the abundance of $\mathrm{HNO}_{3}$ does not match perfectly with observations. In the tropics, the level with maximum $\mathrm{HNO}_{3}$ occurs too low, consistent with the tropical upward transport being too slow and mixing across the subtropics being too rapid.

In the troposphere, the nitric acid simulation is in good qualitative agreement with the limited available data, and is quantitatively much improved over previous results despite still being too large. Figure 10 shows nitric acid profiles from tropospheric chemistry-only simulations performed with and without the inclusion of heterogeneous chemistry on dust, and for a run without the use of the liquid tracer budget. These are compared with a variety of aircraft measurements (Emmons et al., 2000). In the new simulations with or without heterogeneous chemistry on dust, the overestimate of $\mathrm{HNO}_{3}$ typically seen in our earlier model $\mathrm{II}^{\prime}$ results has been reduced substantially in the new modelE, primarily as a result of the inclusion of a liquid tracer budget. The presence of a liquid tracer, allowing dissolved species to remain in the condensed phase for multiple timesteps, leads to global reductions in the abundance of soluble gases, with an overall reduction in the global $\mathrm{HNO}_{3}$ burden of $5 \%$ and a reduction in the tropospheric ozone burden of $3 \%$, as noted previously. The effect of the liquid budget is much larger for sulfur-containing species, some of whose burdens decreased by $25-30 \%$ (Koch et al., 2006). In some locations where liquid water is abundant and long-lasting, quite large reductions occur (e.g. Japan in Fig. 10). Additionally, it is clear from the figure that heterogeneous chemistry on dust further improves the results in many locations (though not all). The overall model improvement is especially striking for Japan, where the liquid tracer and the removal of nitric acid on dust particles blowing out from the Asian interior brings the modeled values down to observed levels. In contrast, profiles from model II' or modelE without the liquid tracers or dust chemistry were roughly a factor of 5 too large in this area, while those from the modelE run without dust chemistry are a factor of 2 to 3 too large.

Note that even in the new model, substantial discrepancies remain for the October comparison with SH TRACE-A observations. As emissions from biomass burning play a large role in these areas during this season, we hypothesize that differences between our emissions inventory and the actual emissions (or meteorology) during the measurement campaign may be the cause of these differences. Further work is required to confirm this.
Similar comparisons of the vertical profiles of $\mathrm{NO}_{\mathrm{x}}$ and PANs in the troposphere show good agreement between the model and observations in most locations (not shown), similar to that seen in our previous model (Shindell et al., 2003). Analysis of the modeled $\mathrm{NO}_{\mathrm{x}}$ simulation in the stratosphere is complicated by the fact that the available climatologies from HALOE record sunrise and sunset $\mathrm{NO}$ and $\mathrm{NO}_{2}$, but these species change rapidly during these times. The model's monthly mean April $\mathrm{NO}_{\mathrm{x}}$ shows a peak of $\sim 12-13$ ppbv in the tropics at $\sim 5 \mathrm{hPa}$, in reasonable agreement with the sum of $\mathrm{NO}$ and $\mathrm{NO}_{2}$ in the HALOE sunrise measurements but somewhat lower than the sunset sum which peaks at $\sim 18$ ppbv. Given that the model values are a diurnal average, it seems reasonable that they should lie below some of the sunlit observations. Since nitrogen oxide abundances change so rapidly during sunrise and sunset, even a more detailed comparison with the model results is likely to be inconclusive owing to the model's half hour chemistry timestep.

The global annual average source of $\mathrm{NO}_{\mathrm{x}}$ from lightning is 5.2 Tg N/yr in both the tropospheric chemistry-only and the full chemistry models. This source is calculated internally based on the GCM's convection using parameterizations for total and cloud-to-ground lightning modified from (Price et al., 1997). The spatial distribution of lightning agrees fairly well with observations (Boccippio et al., 1998), especially over land areas (Fig. 11). The model tends to overestimate lightning over SE Asia and Indonesia, however. This leads to overestimates of the total flash rate of $5 \%$ during boreal summer (JJA), and 17\% during boreal winter (DJF) when lightning over South America is also overestimated.

The deposition of nitrogen in the model has been extensively compared with observations from acid rain monitoring networks in the $\mathrm{NH}$ as part of a wider model intercomparison (Lamarque et al., 2005). In that study modelE was run with several different sets of sea surface temperature and sea ice boundary conditions. An example of the results is given by the comparison against the North American network of deposition measurements (Holland et al., 2005). The GISS models showed correlations of 0.82 to 0.85 (regression over all points in the network against the equivalent model grid boxes), comparable to the average of the 0.83 for the 6 different models in the intercomparison. The mean value was also in fairly good agreement at $0.20-0.25 \mathrm{gN} / \mathrm{m}^{2} /$ year compared with an observed value of 0.19. Deposition in Asia and Europe agreed less well with observations, as in other models, and may reflect limitations of the observing networks or emissions inventories in those areas. Thus overall it seems that the model does a good job in reproducing observed rates and distributions of nitrogen deposition fluxes in the NH regions where observations are considered most reliable.

\subsection{Halogens}

The $\mathrm{ClO}$ maximum in the upper stratosphere is located at approximately the correct altitude and has the right magnitude 

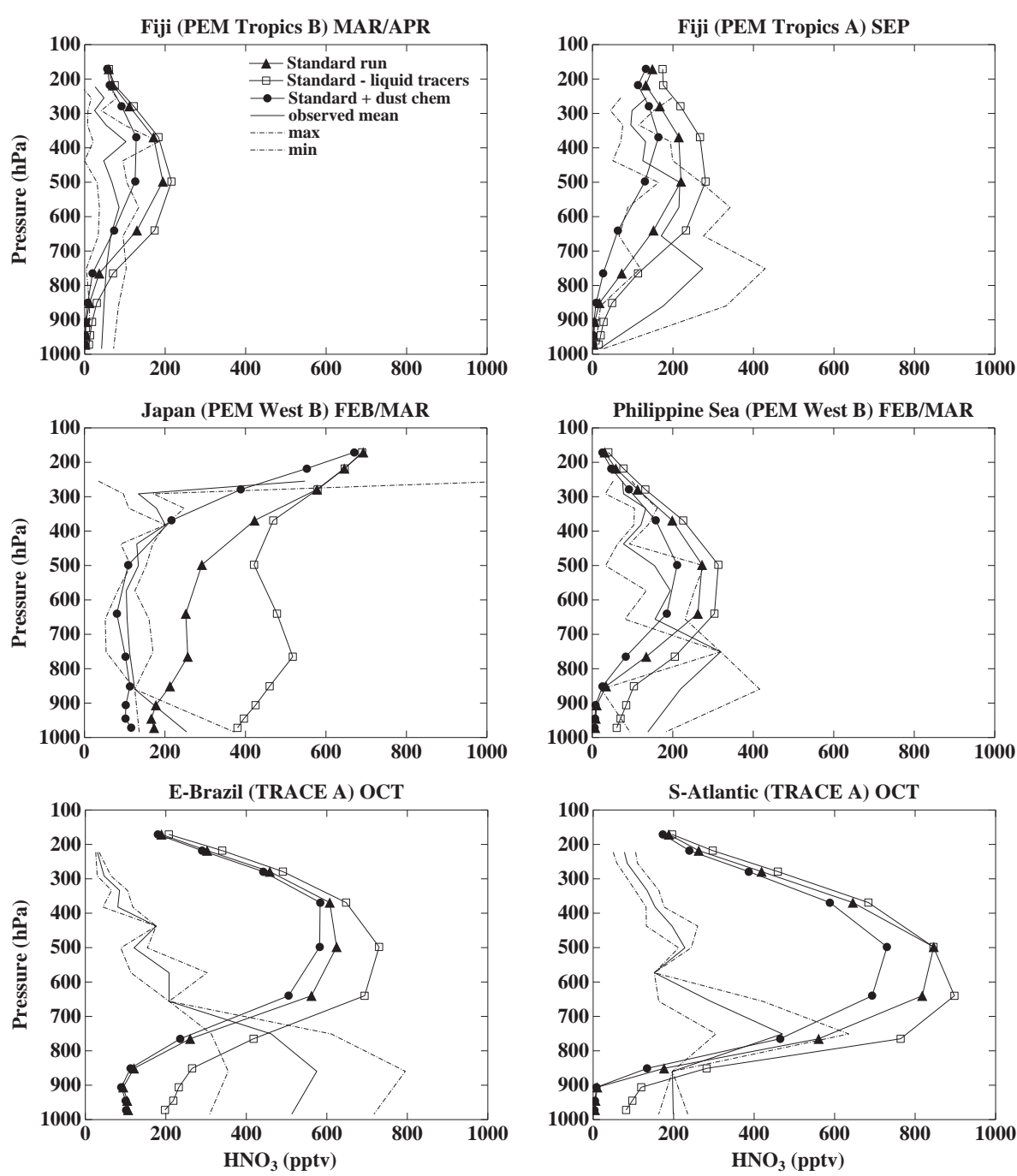

Fig. 10. Nitric acid profiles in observations and model simulations for the indicated locations and seasons. Solid and dotted lines indicate measured mean values and standard deviations, respectively. Values from the model are show as lines with symbols, with solid triangles showing the standard simulation, open squares showing the simulation with the liquid tracer budget removed, and filled circles showing the standard simulation but with heterogeneous chemistry on mineral dust included. Observations are from Emmons et al. (2000).

at high latitudes in comparison with the MLS satellite climatology (Waters et al., 1996) (Fig. 5). The model underpredicts $\mathrm{ClO}$ in the tropical upper stratosphere, however, while $\mathrm{HCl}$ (not shown) is overpredicted in this region. These features appear to result from the underprediction of water vapor in this region, which leads to a commensurate underprediction of $\mathrm{OH}$ and hence a positive bias in the $\mathrm{HCl} / \mathrm{ClO}$ ratio. $\mathrm{ClO}$ is reasonably well simulated in the polar regions, except for the underestimate of downwelling within the polar vorticies noted previously. During polar winter and spring, heterogeneous activation of reservoir chlorine to reactive species ( $\mathrm{ClO}$ in the spring) is well captured.

The model's chlorine nitrate distribution shows peaks at middle to high latitudes around $15-30 \mathrm{hPa}$. In the winter hemisphere, the peak values just exceed 1 ppbv and are lo- cated at around 60-80 degrees, while in the summer hemisphere the peak values are below $1 \mathrm{ppbv}$ and are located at mid-latitudes, in accord with CLAES observations. Distributions of most bromine species have some features in common with their chlorine analogues, with $\mathrm{BrO}_{\mathrm{x}}$ most prevalent at higher altitudes and $\mathrm{BrONO}_{2}$ showing peaks in the lower stratosphere towards the poles with a substantial seasonal cycle. $\mathrm{HBr}$, however, in contrast to $\mathrm{HCl}$, makes up only a small fraction of reactive bromine throughout the stratosphere. Satellite climatologies were not available for comparison in these cases, however. 

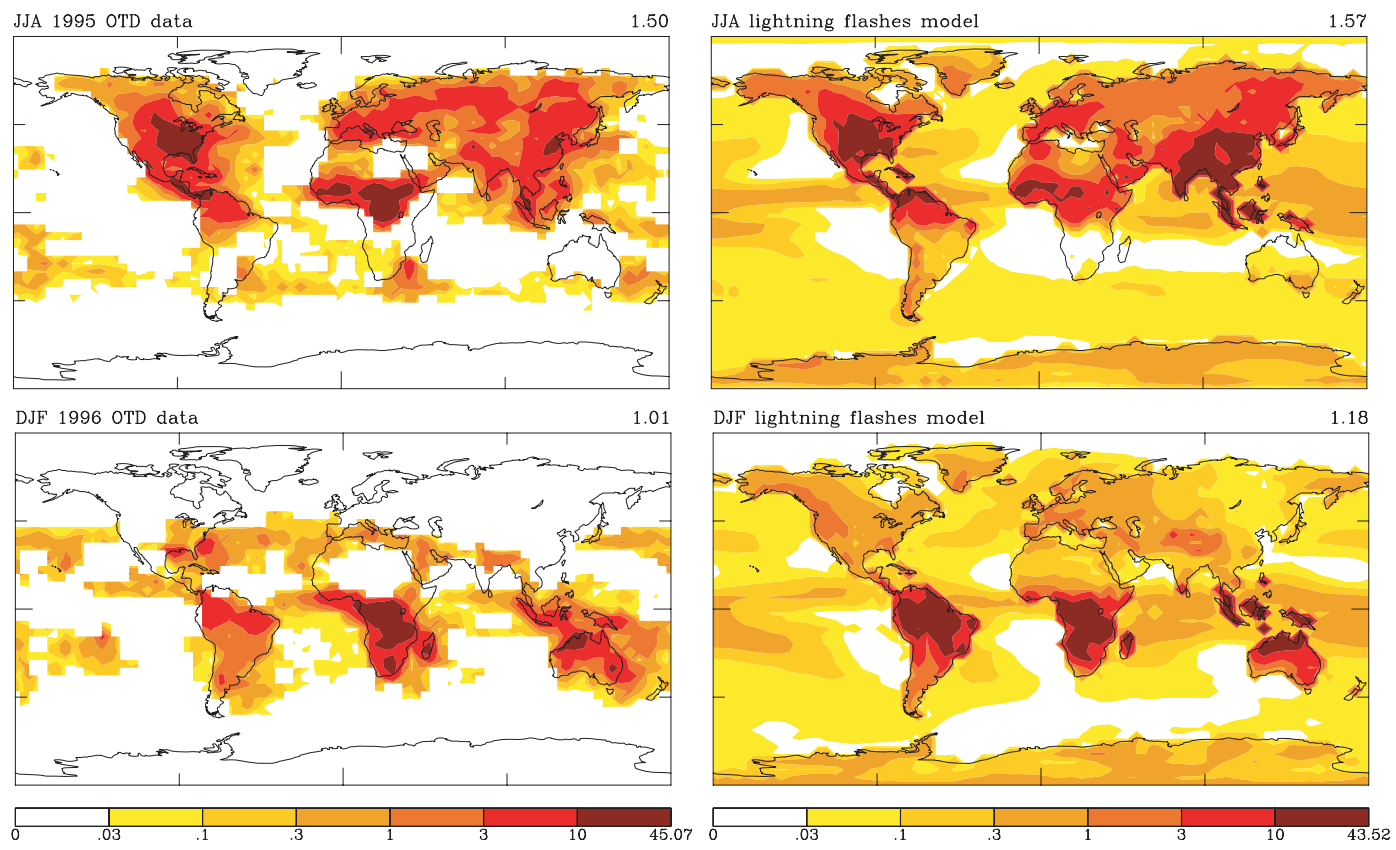

Fig. 11. Observed and modeled seasonal lightning flash rates (flashes $/ \mathrm{km}^{2} / \mathrm{season}$ ). The left column shows observations from the Optical Transient Detector during 1995-1996 (other years are similar), while the right shows model results. The top row are June-August averages, while the bottom row are December-February averages. Note that there are no measurements at high latitudes, and the scale used here is non-linear.

\subsection{Reduced carbon species in the troposphere}

Hydrocarbons and carbon monoxide play similar roles in tropospheric chemistry. The model's simulation of these species is generally similar to that of the previous version. It compares relatively well with the limited available observations. For methane, comparisons with the surface measurements of the NOAA GMD (formerly CMDL) cooperative air sampling network (Dlugokencky et al., 1994) (updated to 2000-2004) show that the model's equilibrium simulation overestimates the interhemispheric gradient slightly, and tends to put its maximum values more poleward in the $\mathrm{NH}$ than observed (Fig. 12). The very large uncertainties in methane's sources, however, easily encompass the model/measurement differences.

The model's simulation of $\mathrm{CO}$ has been compared extensively with both surface and satellite observations (Shindell et al., 2005a). It shows good agreement in both magnitude and seasonality, suggesting that the model's $\mathrm{OH}$ fields are reasonably realistic. Monthly mean correlations against mid-tropospheric satellite observations from MOPITT (Measurements of Pollution in the Troposphere) were typically in the range of $0.8-0.9$. The modelE simulation of methyl hydroperoxide is similar to that obtained in the previous model, which was in good agreement with observations (Shindell et al., 2003). Though the available dataset is quite sparse, the fidelity of the simulation of this important radical intermediate gives us confidence in the model's hydrocarbon oxidation scheme.

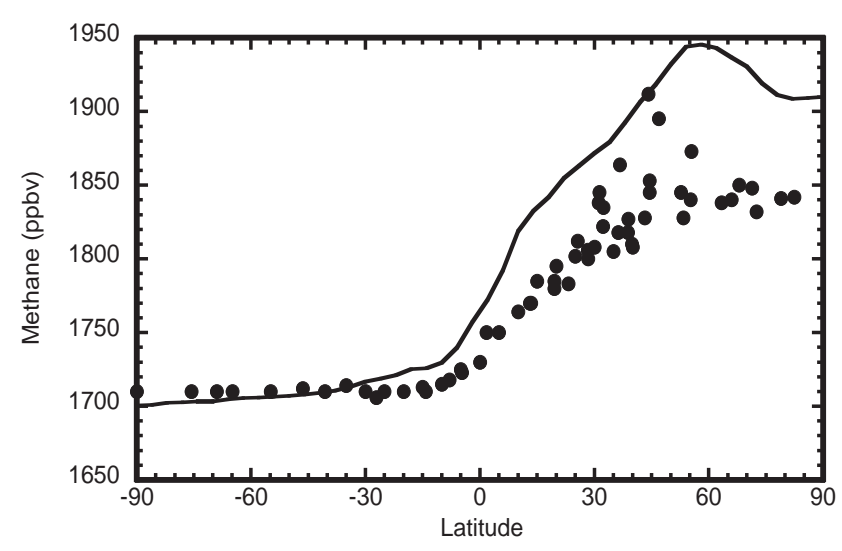

Fig. 12. Zonal mean surface methane in the NOAA GMD network (solid circles) for 2000-2004 and in the model (solid line). Note that the model is a true zonal average while the observations are averages over locations with observations.

Methane's lifetime is primarily determined by the rate of its chemical oxidation by $\mathrm{OH}$, with smaller contributions from loss to soils and the stratosphere. For comparison with other tropospheric models, we compute the methane lifetime in the GISS tropospheric chemistry model assuming a loss to soils of $30 \mathrm{Tg} / \mathrm{yr}$ and a loss to the stratosphere of $40 \mathrm{Tg} / \mathrm{yr}$. The result is a lifetime of 8.48 years, in excellent agreement with the value of $8.4 \pm 1.3$ years recommended by the IPCC Third Assessment Report (TAR) based on observations and 
modeling studies (Prather et al., 2001). Participating models in the IPCC AR4 chemistry simulations produced methane lifetimes ranging from 6.3 to 12.5 years (Stevenson et al., 2006), so it is by no means a given that a model will match observations. Thus we believe the model's simulation of $\mathrm{OH}$ is likely to be quite realistic, especially in the tropics where the bulk of methane oxidation takes place. Further supporting this conclusion, comparison of the model's simulation of hydrogen peroxide (not shown), produced by the chemical combination of two $\mathrm{HO}_{2}$ molecules, is in good agreement with observations as in our previous simulations (Shindell et al., 2003).

\section{Climate change simulations}

\subsection{Experimental setup}

As noted previously, one issue that we were not able to adequately address in our earlier studies of the interactions between composition and climate change was the response of stratosphere-troposphere exchange to altered climate states. The new full chemistry version of the model can now be used to explore this issue, as well as changes within the stratosphere, $\mathrm{NO}_{\mathrm{x}}$ from lightning that's transported into the stratosphere, etc. We have therefore run additional simulations using conditions appropriate for both the preindustrial era and estimates of possible future conditions (Table 3 ).

For the preindustrial, we removed all anthropogenic emissions into the troposphere, and set long-lived greenhouse gases to 1850 conditions. Biomass burning emissions were set to $10 \%$ of their PD values. For the future, simulations were performed for 2100 prescribing the concentrations of long-lived gases and the emissions of short-lived gases, primarily ozone precursors, following the IPCC SRES A2 "business-as-usual" style scenario. A companion future simulation was performed to separate the effects of climate and chemistry in the future. For the A2 climate-only run, the future concentration of $\mathrm{CO}_{2}$ was prescribed, thus altering temperatures throughout the atmosphere, and future SSTs from an earlier run were specified. Compositions and emissions of reactive gases were unchanged from the PD.

All these simulations for past and future time periods were run using a mixed-layer ocean to allow the climate to adjust to the imposed greenhouse gas forcing (except the A2 climate-only run). In this setup, ocean circulation is prescribed for computational efficiency and therefore does not respond to climate changes (i.e. heat convergence is prescribed while allowing SST to adjust). In order to have an appropriate comparison, a present-day simulation with a mixed-layer ocean was also performed. Initial conditions for the ocean were taken from earlier runs for the appropriate time periods, and then all simulations were run for several years to establish climate (and the faster chemical) equilibrium, at least three and up to 10 depending on how close the initial conditions were to the slightly different balanced state of these runs. Simulations were then continued for 2040 years (40 PD, 20 others), providing ample post-spinup results for analysis. All runs were performed as equilibrium time-slice (not transient) experiments. All simulations use solar minimum conditions (1986) to allow for comparison with companion solar maximum experiments to be performed later. As the influence of the solar cycle is small, about $1-2 \%$ in column ozone with a maximum impact of $\sim 3-4 \%$ in the upper stratosphere (McCormack and Hood, 1996), this introduces only a very minor bias into the model's climatology while saving a large amount of computational resources.

4.2 Response to climate and emissions changes: preindustrial conditions

We first examine the changes between the preindustrial and present day simulations including both climate and emissions changes. The annual average zonal mean temperature changes in the troposphere display a modest increase during this period, consistent with surface observations, while in the middle and upper stratosphere temperatures decrease substantially (Fig. 13). Ozone changes are clearly dominated by the chemical effects of the increased emissions. As in the tropospheric chemistry-only models, the bulk of the troposphere shows larger ozone amounts with maximum values in the NH subtropics. Unlike the tropospheric chemistryonly models, however, the SH poleward of about 45 degrees shows a reduction in ozone in the full chemistry simulations, reflective of the reduced influx from the stratosphere owing to Antarctic ozone depletion (Table 6). Though the model's downward transport at high Southern latitudes is clearly too large based on the comparison with sonde data shown previously, the influence of stratospheric ozone depletion extending down to the surface is also seen in observations (Oltmans et al., 1998). This leads to small ( $<5$ ppbv) decreases in surface ozone in the $\mathrm{SH}$ poleward of about 45 degrees, which contrast markedly with the large increases seen in the $\mathrm{NH}$, especially over mid-latitude continental areas where they exceed 20 ppbv in some areas (Fig. 14). Tropical and NH extratropical fluxes of ozone across the tropopause show relatively small changes between the preindustrial and the present-day (Table 6), indicating that the change in SH extratropical STE is indeed driven by composition changes rather than climateinduced circulation changes.

Changes in stratospheric ozone have a similar pattern to those calculated for 1979-2000, but enhanced in magnitude. The spatial pattern of the stratospheric ozone losses corresponds closely to that of increased chlorine monoxide from the PI to the PD (Fig. 15). This is not surprising as it is wellknown that increased chlorine has been the main driver of past stratospheric ozone losses (World Meteorological Organization, 1999). Stratospheric ozone has also been influenced by changes in the abundance of other radicals, with losses 


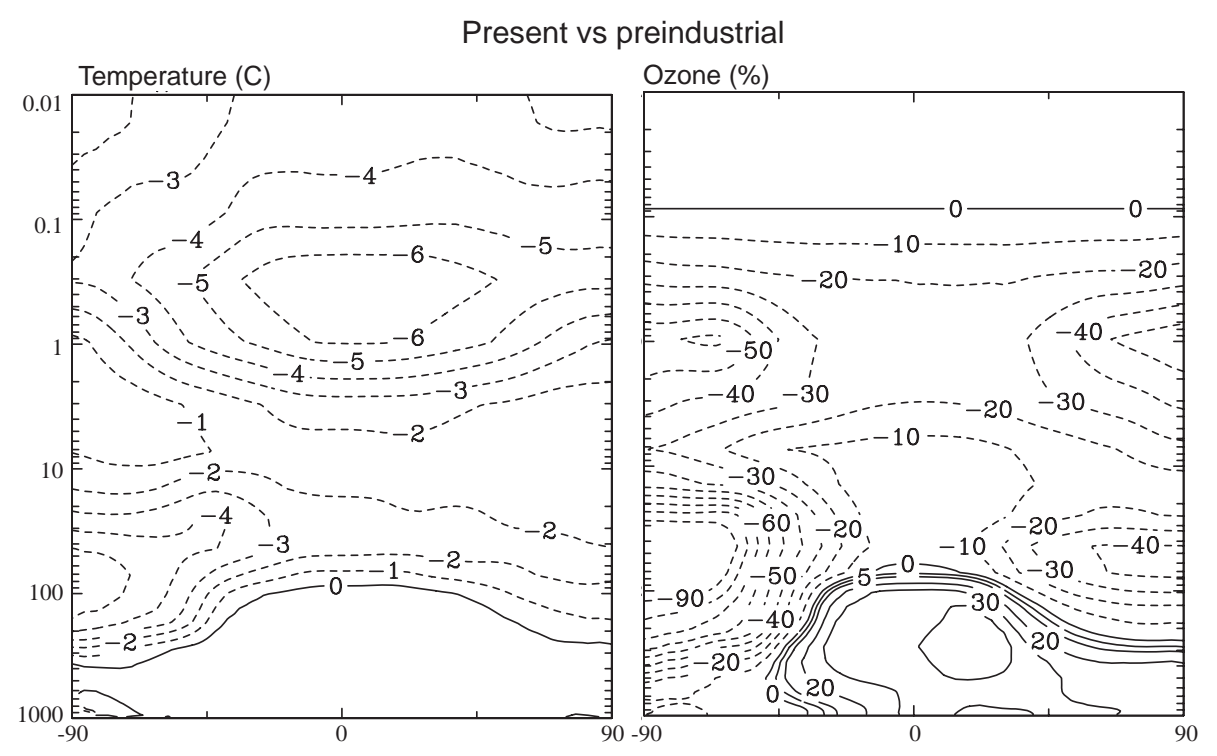

Fig. 13. Modeled differences between the present day and the preindustrial (PD minus PI) due to both emissions and climate changes in annual average zonal mean temperature (left, C) and ozone (right, \% relative to PD). Note that plotting ozone changes relative to PD makes them comparable to the results from the future simulations, but it can lead to very large values in regions where PD amounts are small.

from increased $\mathrm{NO}_{\mathrm{x}}$ and $\mathrm{HO}_{\mathrm{x}}$ in some regions. In general there is more $\mathrm{NO}_{\mathrm{x}}$ in the stratosphere, consistent with the increase in its primary source gas $\mathrm{N}_{2} \mathrm{O}$, however there is less $\mathrm{NO}_{\mathrm{x}}$ in the uppermost tropical troposphere and in the lower to middle stratosphere over Southern mid-latitudes. Both regions also show an enhancement of $\mathrm{OH}$ concentrations over this period, consistent with an overall increase in water vapor driven by increased methane and surface temperatures. The increased $\mathrm{OH}$ speeds the transformation of $\mathrm{NO}_{\mathrm{x}}$ into nitrogen reservoir species, accounting for the reduced $\mathrm{NO}_{\mathrm{x}}$ in these areas. The changes in both $\mathrm{OH}$ and $\mathrm{NO}_{\mathrm{x}}$ are quite small, however, and little clear direct effect is seen on ozone. The cooler stratospheric temperatures (Fig. 13) partially compensated for some of the enhanced catalytic losses by slowing down many temperature-sensitive chemical reactions (especially $\mathrm{O}+\mathrm{O}_{3}$ ).

The RF from ozone (tropospheric and stratospheric) is $0.34 \mathrm{~W} / \mathrm{m}^{2}$ from the PI to the PD (all RFs are instantaneous tropopause values). In the tropospheric chemistryonly model it is $0.37 \mathrm{~W} / \mathrm{m}^{2}$ (Shindell et al., 2005b). This implies a very small contribution to RF from stratospheric ozone change. This conclusion is consistent with results from the 1979 simulations as well. As noted previously, we performed the 1979 run including PD emissions of shortlived gases that primarily affect the troposphere in order to show the effects of stratospheric ozone depletion on both the stratosphere and troposphere in the absence of other changes. Thus it is not intended to show the actual time evolution of the atmosphere. The total RF due to the effects of stratospheric ozone changes from 1979 to 2000 on both the troposphere and stratosphere is quite small, only $-0.04 \mathrm{~W} / \mathrm{m}^{2}$.
This small value is consistent with other recent results with our model (Hansen et al., 2005), which found a value of $-0.06 \mathrm{~W} / \mathrm{m}^{2}$ using the observed trends which are slightly larger than those calculated by the model in the crucial region near the tropical tropopause (Fig. 6). Over the full PI to PD period, the stratospheric ozone depletion was about 1.5 times as large as during 1979-2000 (Table 5), a result in good agreement with earlier analyses based on historical data (Shindell and Faluvegi, 2002). Ozone losses prior to 1979 result from increases in methane and nitrous oxide as well as the initial input of CFCs. This then implies an overall negative forcing from stratospheric ozone depletion of about $-0.06 \mathrm{~W} / \mathrm{m}^{2}$ from the PI to the PD in our model. Given a total forcing of $0.34 \mathrm{~W} / \mathrm{m}^{2}$, the contribution from tropospheric ozone increases is about $0.40 \mathrm{~W} / \mathrm{m}^{2}$, slightly larger than that seen in the tropospheric chemistry-only model. The difference may represent the effects of tropospheric ozone increases on the stratosphere, as in the full-chemistry model the increased pollution of the troposphere can be transported into the stratosphere.

The PD run shows decreases in ozone relative to the 1979 stratosphere run in most of the troposphere as well as the stratosphere (Fig. 6). These are created by reductions in the flux of stratospheric ozone into the troposphere (Table 5), and thus maximize at middle to high latitudes. The simulations yield a decrease in the tropospheric ozone burden between 1979 and the present that is roughly $80 \mathrm{Tg}$. This is considerably larger than the total PI to PD increase in the tropospheric ozone burden of $40 \mathrm{Tg}$, suggesting that stratospheric ozone losses have indirectly offset roughly $2 / 3$ of the increase in the tropospheric ozone burden. Such a result 

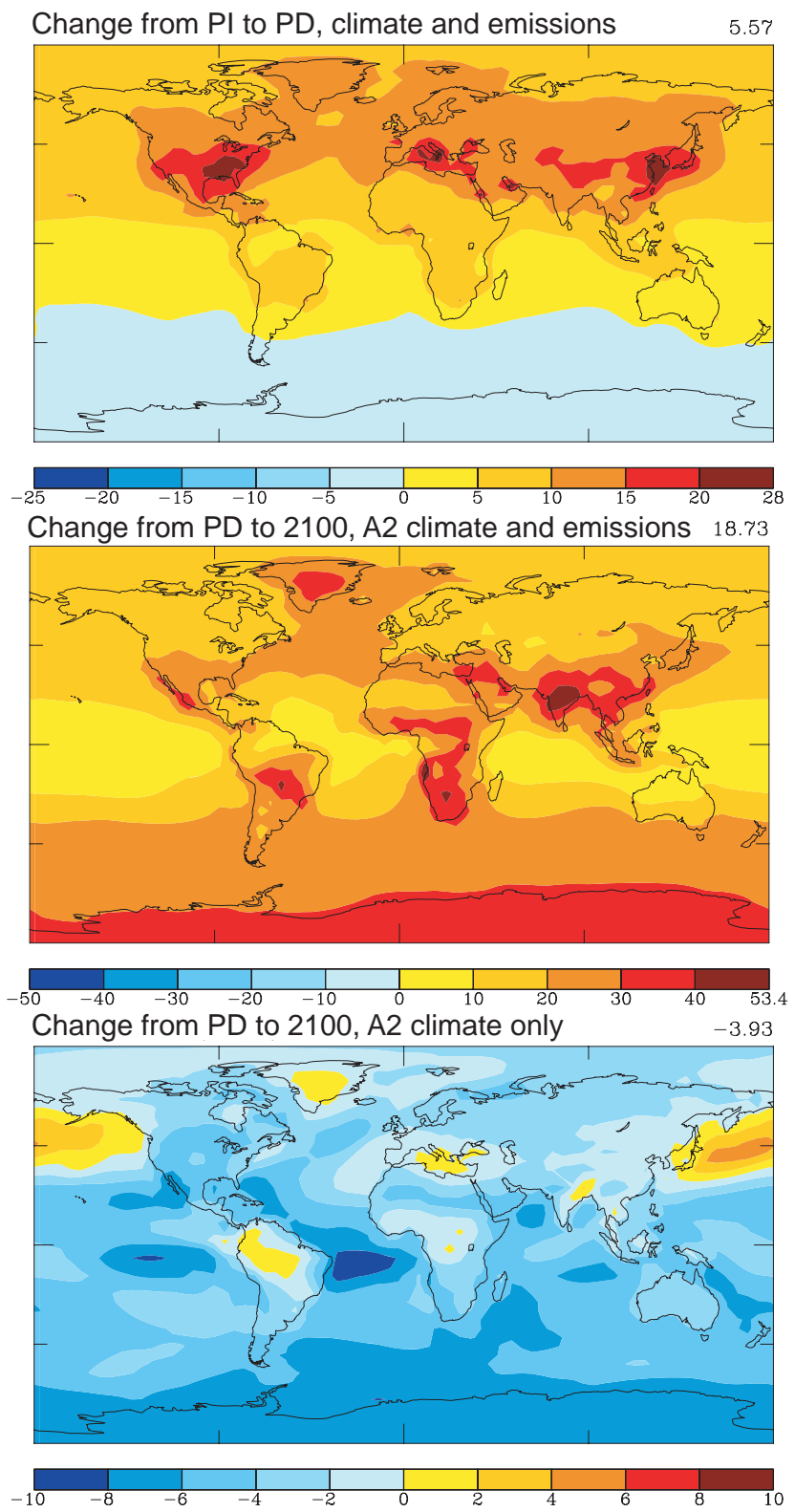

Fig. 14. Changes in annual average surface ozone (ppbv) for the indicated climate or climate and emissions perturbations. Values in the upper right corner show the global mean change. Note change in scale between panels.

implies a substantial future increase in tropospheric ozone as the stratospheric ozone layer recovers, though, as noted previously, the downward flux of ozone at high latitudes is too large in this model.
4.3 Response to climate and emissions changes: 2100 conditions

\subsubsection{A2 emissions and climate}

We first examine the response to the $2100 \mathrm{~A} 2$ emissions and climate simulation. Zonal mean temperatures show large increases in the troposphere reflective of the large surface warming in this run $\left(4.8^{\circ} \mathrm{C}\right)$, while the stratosphere shows even greater decreases in temperature (Fig. 16). Stratospheric ozone shows large increases in areas where chlorine abundances decline (Figs. 16 and 17), namely the upper stratosphere around $1 \mathrm{hPa}$ and the lower stratosphere in the polar regions. The increases are roughly double the stratospheric ozone depletion to date. This emphasizes that due to changes in climate and in greenhouse gases, even when CFCs have been fully removed from the stratosphere the ozone distribution will not look like either its earlier 1979 or preindustrial states. Instead, a super-recovery should be expected. While this holds for most of the stratosphere, in the tropics ozone decreases in both the uppermost and lower stratosphere.

Ozone in the uppermost stratosphere is dominated by catalytic cycles involving hydrogen oxides, which increase substantially in the A2 simulations. This is clear in the $\mathrm{OH}$ distribution, which is greatly enhanced in the upper stratosphere with a peak increase at $\sim 0.3 \mathrm{hPa}$ (Fig. 17), exactly where the ozone decrease is greatest (Fig. 16). The hydrogen oxides increase above $\sim 1 \mathrm{hPa}$ owing to the greater abundance of stratospheric water (Fig. 17). In the middle stratosphere, increased $\mathrm{NO}_{\mathrm{x}}$ sequesters $\mathrm{HO}_{\mathrm{x}}$, so there is little $\mathrm{OH}$ change. The ozone decreases in the tropical lower stratosphere result from the same increased water leading to more $\mathrm{HO}_{\mathrm{x}}$, and from an increase in transport of tropospheric air upward across the tropical tropopause (Table 6). This air is relatively ozone-poor, but contains pollutants such as $\mathrm{NO}_{\mathrm{x}}$ produced by lightning, which catalytically remove ozone in the stratosphere. The ozone distribution is also influenced elsewhere by the increased $\mathrm{NO}_{\mathrm{x}}$ in much of the stratosphere, which tends to deplete ozone, and by the cooler temperatures, which tend to slow ozone loss. The overall increase in the stratospheric ozone burden is $28 \%$.

Tropospheric ozone shows increases nearly everywhere. Especially large increases are seen at high latitudes, owing to increases in the downward flux of ozone from the stratosphere of 445 and $402 \mathrm{Tg} / \mathrm{yr}$ in the $\mathrm{SH}$ and $\mathrm{NH}$ extratropics, respectively (Table 6). At lower latitudes, the increased emission of pollutants such as methane (prescribed) and $\mathrm{NO}_{\mathrm{x}}$ leads to roughly a doubling of ozone chemical production. This is offset by increased destruction in the highly buffered tropospheric chemical system, so that the net change of ozone by chemistry is nearly the same as in the PD (Table 5). The tropospheric burden of ozone is more than doubled relative to the PD, with a concomitant increase in dry deposition as ozone increases substantially at the surface 

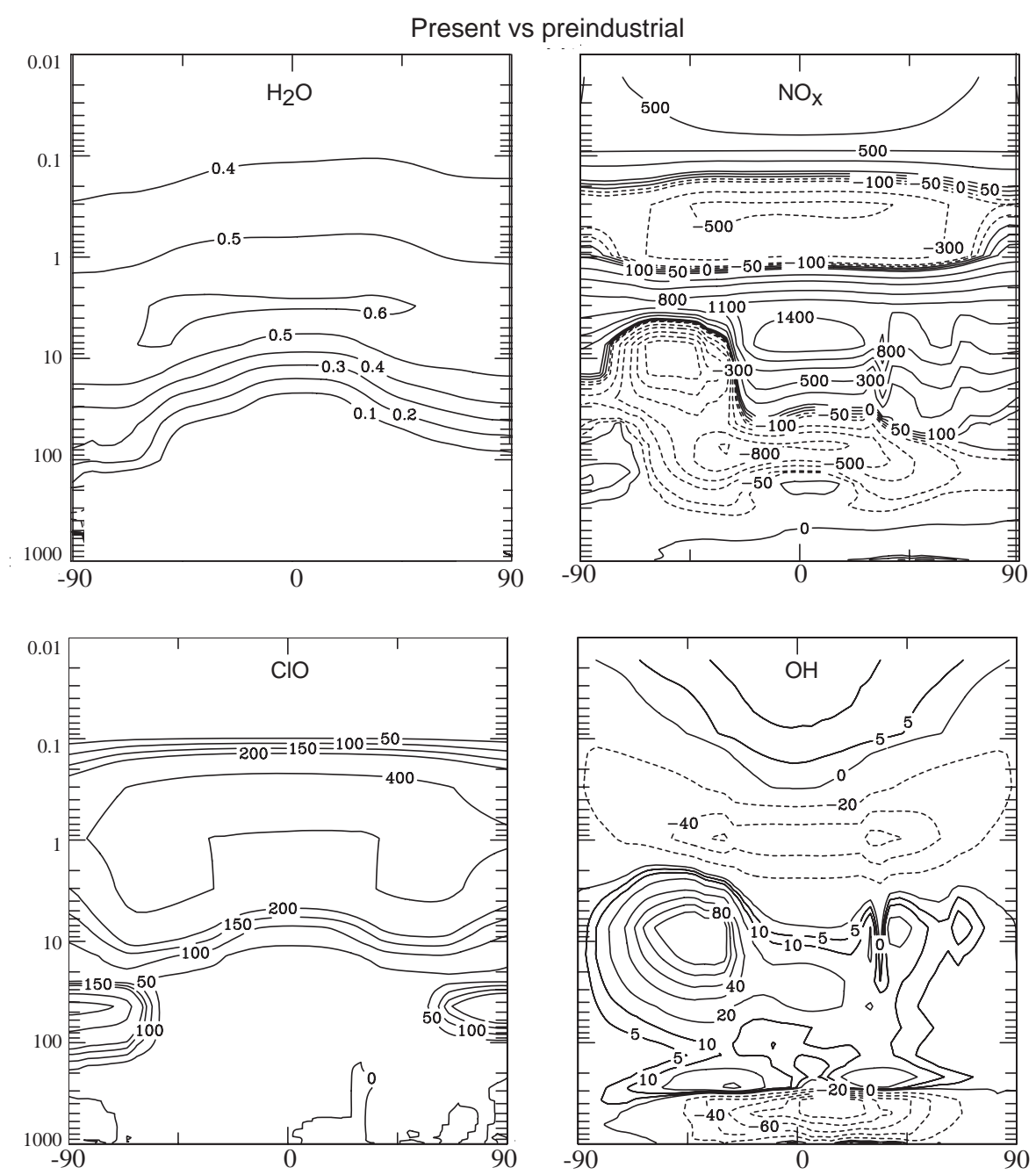

Fig. 15. Changes in water (ppmv, top left), $\mathrm{NO}_{\mathrm{x}}$ (pptv, top right), $\mathrm{ClO}$ (pptv, bottom left) and $\mathrm{OH}\left(10^{4}\right.$ molecules $/ \mathrm{cm}^{3}$ bottom right) between the present and the preindustrial in simulations forced by emissions and climate changes. Tropospheric changes in water have been blanked out for clarity.

(Fig. 14). Note that the increase in dry deposition is $84 \%$, almost exactly proportional to the increase in surface ozone of $81 \%$, indicating that the deposition velocity has changed little.

The surface ozone reflects the projected increases in emissions in the developing world, especially in Asia, and the increased flux into the SH due to stratospheric ozone recovery. Much of the tropical and subtropical land area suffers increases in surface ozone of more than 20 pbbv, with parts of India and Southern Africa showing increases in excess of $40 \mathrm{ppbv}$. Tropospheric ozone changes dominate the RF, though stratospheric ozone recovery also contributes a positive forcing, leading to a net RF of $0.76 \mathrm{~W} / \mathrm{m}^{2}$ in the $\mathrm{A} 2$ emissions and climate case.

\subsubsection{A2 climate-only}

In the climate-only run, the same SSTs as in the climate and emissions run were used, and $\mathrm{CO}_{2}$ in the atmosphere was set to future conditions (Table 3 ). The annual average zonal mean temperature changes exhibit the familiar pattern of warming in the troposphere and cooling in the stratosphere (Fig. 18). Ozone shows a much more complicated structure. In the high-latitude lower stratosphere, the ozone changes in the climate-only run are of opposite sign in the Arctic and the Antarctic. Both regions show cooling, which should lead to enhanced ozone destruction given PD composition, as seen in the SH. In the Arctic, however, changes in circulation induced by climate change dominate over the changes in local temperature for the annual average. In the climate-only simulation, the downward extratropical flux across $150 \mathrm{hPa}$ increases by only $4 \mathrm{Tg} / \mathrm{yr}$ in the $\mathrm{SH}$, but by $151 \mathrm{Tg} / \mathrm{yr}$ in the $\mathrm{NH}$ 


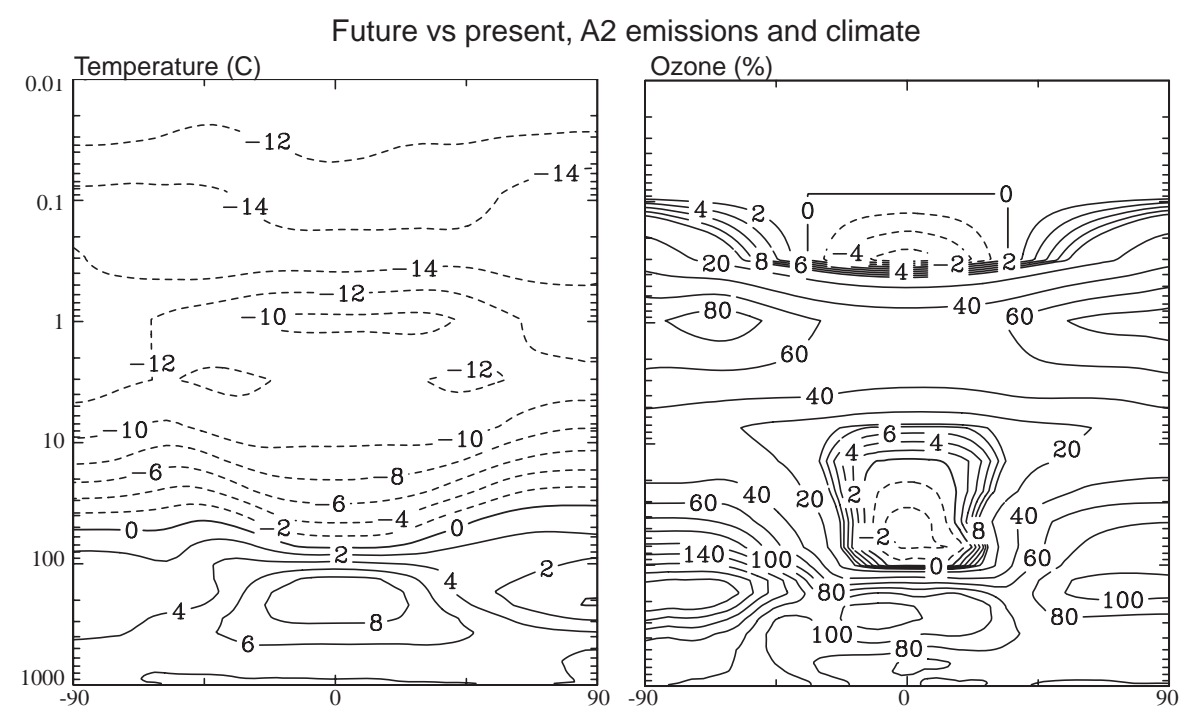

Fig. 16. Simulated changes between the 2100 A 2 emissions and climate run and the present-day for annual average zonal mean temperature (left, C) and ozone (right, \%).
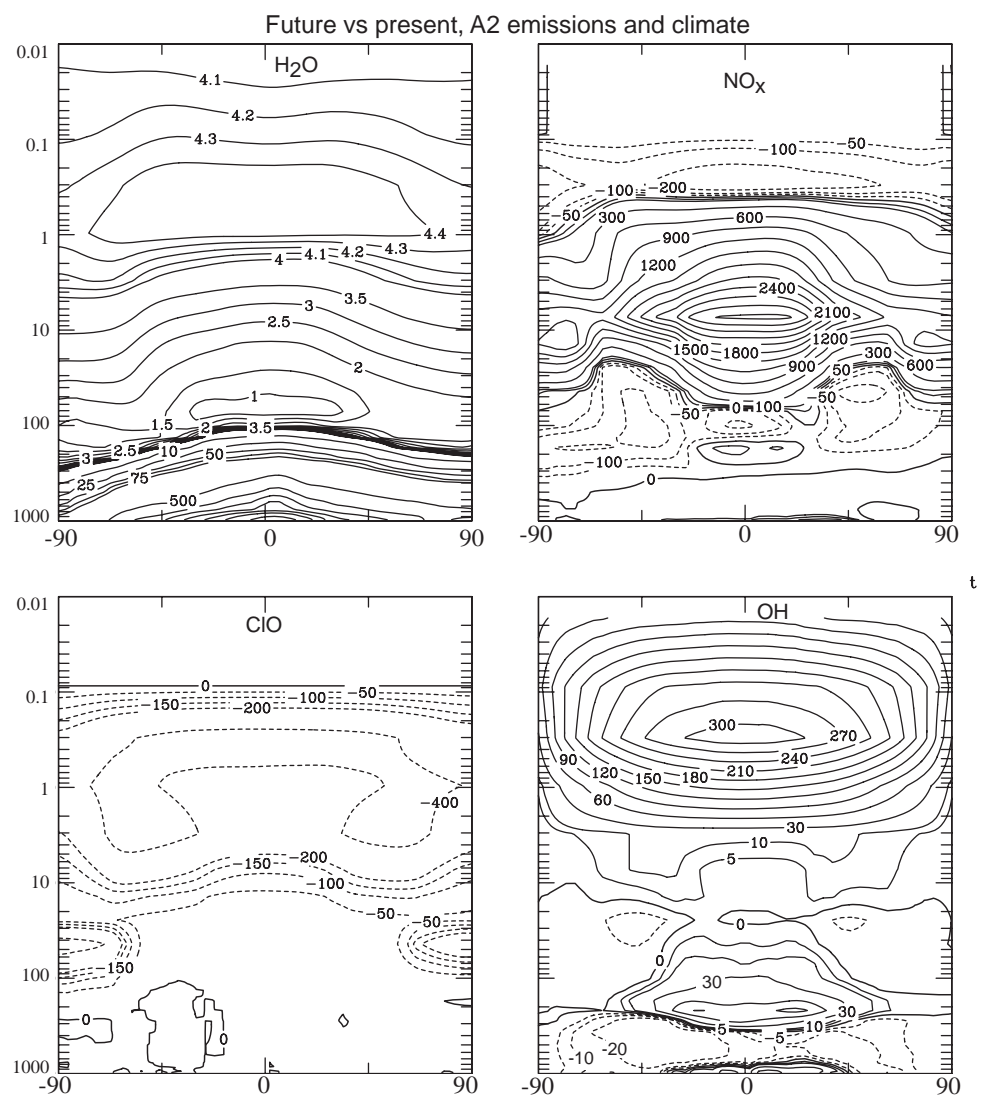

Fig. 17. Changes in water (tenths ppmv, top left), $\mathrm{NO}_{\mathrm{x}}$ (tens pptv, top right), $\mathrm{ClO}$ (tens pptv, bottom left) and $\mathrm{OH}\left(10^{4} \mathrm{molecules} / \mathrm{cm}^{3}\right.$ bottom right) between the $2100 \mathrm{~A} 2$ emissions plus climate run and the present-day simulation.

(Table 6), so that the NH circulation is indeed more sensitive to climate change in our model. This presumably results from the greater importance of wave forcing in the $\mathrm{NH}$ in coupling the troposphere and stratosphere, which makes the 


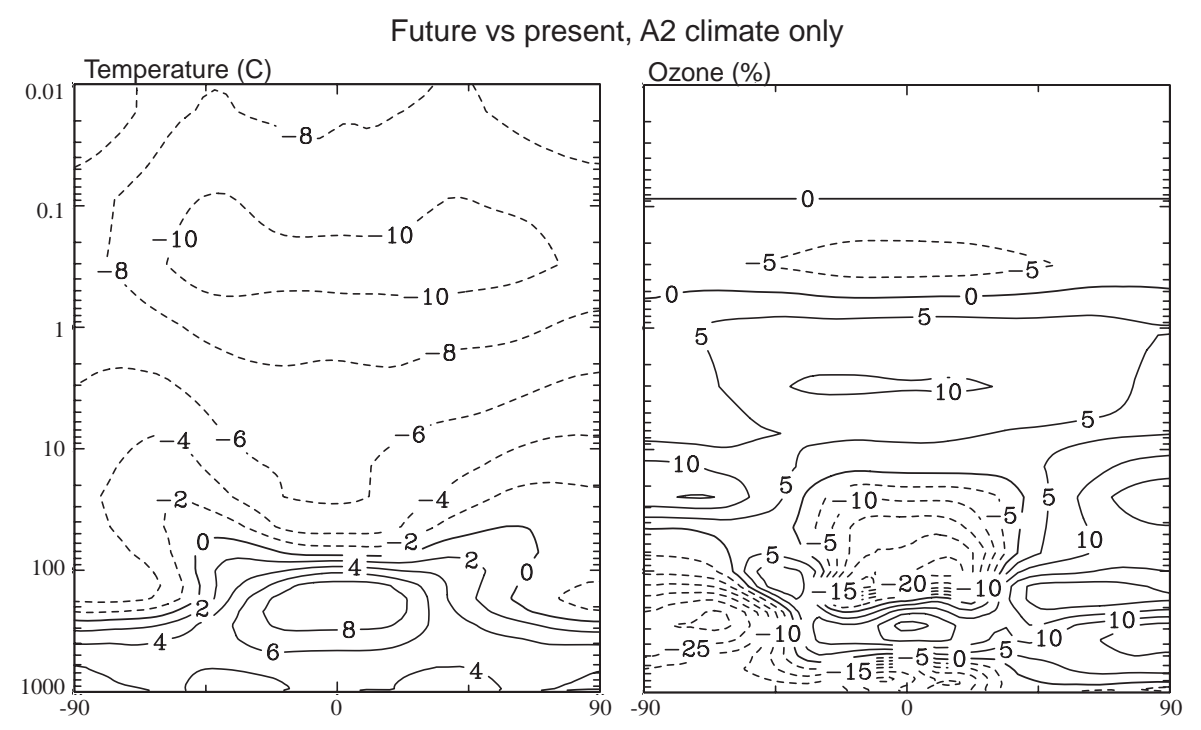

Fig. 18. Simulated changes between the 2100 A 2 climate-only run and the present-day for annual average zonal mean temperature (left, C) and ozone (right, \%).

stratospheric circulation more sensitive to changes in surface climate that affect atmospheric flow and thereby wave generation.

In the troposphere, the high latitudes reflect the changes in the stratosphere. Lower latitudes show a complex pattern, with ozone decreases near the surface, increases in a band around $300 \mathrm{hPa}$, and decreases again at higher levels extending into the tropical lower stratosphere. This pattern results from the combination of changes in both circulation and chemistry. The general circulation shows a weakening of the tropical Hadley Cell, which leads to ozone decreases near the equator and increases in the subtropics (Fig. 19, top left) as less low level comparatively polluted air is entrained into the bottom of the equatorial ascending branch while more polluted extratropical air mixes into the descending branch. Ozone increases due to the enhanced downward flux from the stratosphere at mid-latitudes (Table 6) are also visible in the change by dynamics. The general circulation moving upward across the tropical tropopause increases by $22 \%$ at $50 \mathrm{hPa}$ in the future A2 climate (Table 7), but the upward flux of ozone across this level actually decreases in the climate-only run (Table 6) as there is less ozone in the upper troposphere.

The effects of changes in convective transport and chemistry are difficult to separate from one another as they show similar but opposite spatial patterns (Fig. 19, top center and top right). Chemistry is enhanced in the upper troposphere, with a maximum at around $300 \mathrm{hPa}$ as in the net change. This is at least partially related to increased $\mathrm{NO}_{\mathrm{x}}$ generated by lightning, which goes from a PD value of $5.2 \mathrm{Tg} / \mathrm{yr}$ to $7.2 \mathrm{Tg} / \mathrm{yr}$ in the A2 simulations. In the middle troposphere the net ozone change by chemistry is less positive in the A2 climate-only simulation than in the PD. The difference rel- ative to the PD is dominated by the change in ozone loss rather than in production (Table 5), as the destruction is enhanced by the increases in the reaction of excited singlet-D oxygen atoms with water vapor in the wetter atmosphere resulting from a warmer climate. The chemical changes at low levels in the tropics are simply compensating for the reduction in ozone there due to dynamical and convective changes. Convection increases in the future simulations, contributing to ozone decreases at low levels by increasing the ventilation of the boundary layer, and increasing the transport of ozone-poor air into the tropopause region. Vertical transport by convective activity also acts to counter the altered ozone field resulting from the chemical changes, leading to a pattern that in many areas is the mirror image to the chemical changes. The net changes in ozone seem to be dominated by dynamical and convective effects at low levels, by chemical changes in the middle troposphere from about $800-200 \mathrm{hPa}$ (of opposite sign in the lower and upper portions of that region), and by convective changes in the uppermost tropical troposphere. At the surface, ozone changes show decreases nearly everywhere, with the largest changes generally over oceans where warmer temperatures enhance the ozone loss taking place in these low- $\mathrm{NO}_{\mathrm{x}}$ conditions.

\subsubsection{Relative importance of emissions and climate}

Comparison between the simulations described above allows us to examine the relative impacts of emissions and climate change. The annual average zonal mean temperature changes in the troposphere in the climate-only run (Fig. 18) are quite similar to those seen in the emissions and climate run. In the stratosphere the cooling is less partially due to the smaller GHG increases $\left(\mathrm{CO}_{2}\right.$ only), but primarily due to the greatly 
Future vs present, A2 climate only

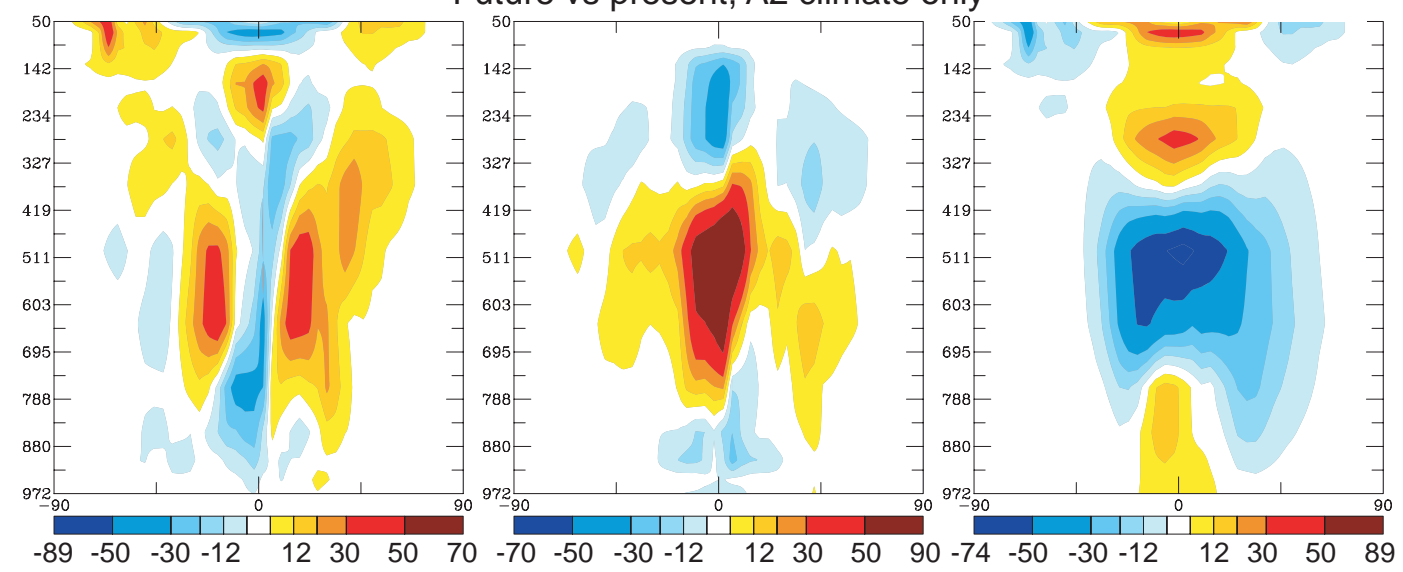

Future vs present, $\mathrm{A} 2$ emissions and climate

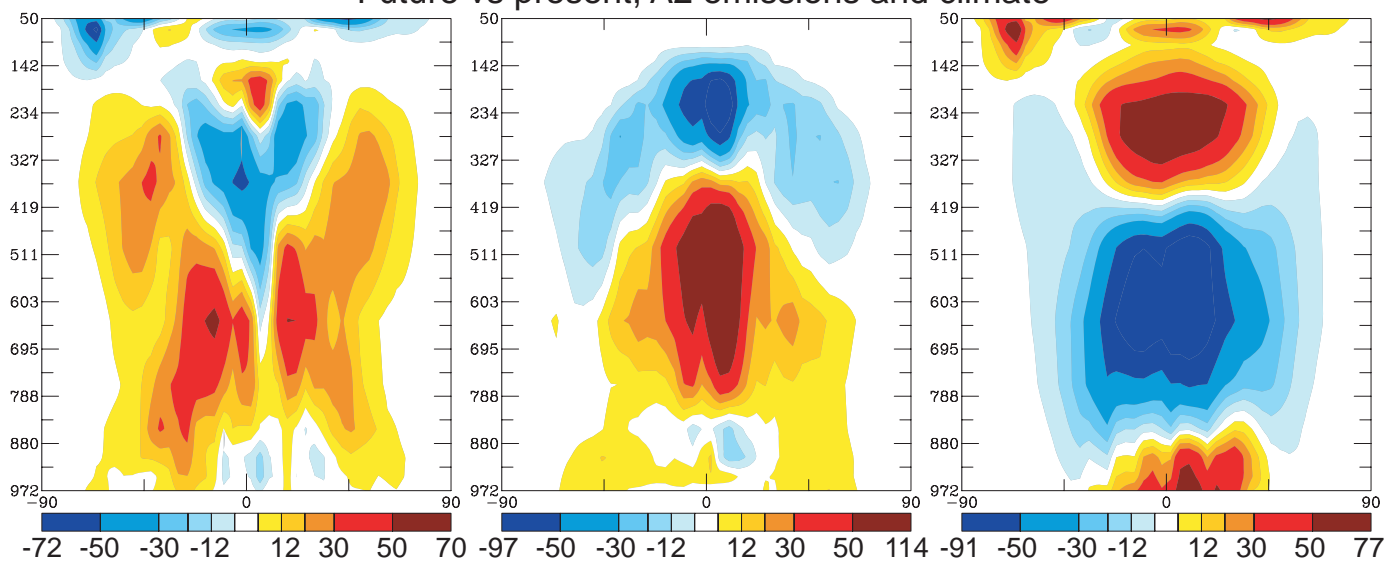

Fig. 19. Differences in zonal mean ozone change $(10 \mathrm{~kg} / \mathrm{s})$ due to dynamics (all non-convective transport, left column), moist convection (center column) and chemistry (right column) between the PD and the A2 climate-only (top row) and A2 climate and emissions (bottom row) simulations. Total change is a linear sum of these terms. Color bar divisions are $-70,-50,-30,-20,-12,-4,4,12,20,30,50$ and 70 , with the end bars encompassing all points outside this range.

Table 7. Tropical residual vertical velocities and their changes.

\begin{tabular}{lccc}
\hline & $150 \mathrm{hPa}$ & $86 \mathrm{hPa}$ & $50 \mathrm{hPa}$ \\
\hline PD amounts (mm/s) & .32 & .17 & .15 \\
PD to A2 future & $15 \%$ & $18 \%$ & $22 \%$ \\
PI to PD & $6 \%$ & $13 \%$ & $14 \%$ \\
\hline
\end{tabular}

Changes are relative to the present-day velocities, and all velocities are calculated using area-weighted averages over the region with positive (upward) values. The future simulation included changes in both emissions and climate.

reduced increase in water vapor. As each methane molecule yields two waters, the increase of $\sim 2$ ppmv methane in the emissions and climate run led to increases in upper stratospheric methane over those seen near the tropical tropopause of 3-4 ppmv (Fig. 17), which are not present in the climate- only run. Thus this run has a substantially smaller cooling despite a much reduced stratospheric ozone increase than in the emissions and climate run, though the spatial patterns of the temperature changes are quite similar. Ozone shows only small changes in most of the stratosphere in the climate-only run (Fig. 18), with small increases associated with cooler temperatures. Thus it is clear that the ozone increases seen in the upper stratosphere around $1 \mathrm{hPa}$ in the emissions and climate simulation (Fig. 16) are driven primarily by emissions changes. The ozone reduction seen in the uppermost tropical stratosphere in the emissions and climate run (Fig. 16) is present in the climate-only run as well, indicating that a substantial portion of this decrease results from $\mathrm{HO}_{\mathrm{x}}$ enhancements due to the increased influx of water across the tropopause. Direct examination of stratospheric $\mathrm{OH}$ changes in the climate-only run (not shown) reveals that the increase in the uppermost stratosphere is about one-third that in the emissions and climate run (Fig. 17). 
Table 8. Tropospheric nitric acid.

\begin{tabular}{lccc}
\hline Simulation & $\begin{array}{c}\text { Removal by } \\
\text { moist convection } \\
(\mathrm{Tg} / \mathrm{yr})\end{array}$ & $\begin{array}{c}\text { Burden } \\
(\mathrm{Tg})\end{array}$ & $\begin{array}{c}\text { Wet removal } \\
\text { lifetime } \\
\text { (days) }\end{array}$ \\
\hline PD & -31.3 & 3.4 & 40 \\
A2 emissions and climate & -98.1 & 6.9 & 26 \\
A2 climate-only & -35.3 & 4.0 & 41 \\
\hline
\end{tabular}

The pattern of ozone changes by transport and chemistry for the emissions and climate run is similar to that seen in the climate-only run, but with larger positive values in all the terms (Fig. 19, bottom). This reflects the increased emissions of pollutants and the greater influx of stratospheric ozone in that simulation. Changes in the chemical production and loss are much larger in the emissions and climate run than in the response to climate change alone (Table 5). In both simulations, more subtle effects also take place within the troposphere owing to the thermal and hydrologic changes in future climates. While a complete description of these changes is beyond the scope of this paper, several examples stand out. The tropospheric burden of PANs decreases by $21 \%$ in the climate-only run as the warmer temperatures cause this thermally unstable molecule to more readily dissociate. Nitric acid abundances increase in the tropical upper troposphere in this run due to the availability of nitrogen oxides from lightning. At the same time, however, the removal of nitric acid by wet processes follows changes in the hydrologic cycle, with increased precipitation enhancing removal near the equator and decreased precipitation reducing removal in the subtropics. Similar behavior is seen in the removal of other soluble gases such as hydrogen peroxide. The net effect on nitric acid is an increase in overall wet removal (primarily by moist convection) that is outweighed by the increase in production, leading to a greater burden and longer lifetime in the climate-only run (Table 8). Clearly the emissions perturbations in the emissions and climate case overwhelm the climate signal for nitric acid, as they did for tropospheric ozone, so that the burden roughly doubles while the lifetime decreases markedly (Table 8).

We can also examine change in the oxidation capacity of the troposphere. In general, a warmer climate leads to increased $\mathrm{OH}$ via enhancement of $\mathrm{OH}$ production by the chemical reaction of oxygen atoms and water vapor (Table 5). In contrast, increased emissions of pollutants typically leads to reduced $\mathrm{OH}$, as the effect of the greater abundance of hydrocarbons and $\mathrm{CO}$ outweighs increased production of oxygen atoms from increased ozone. From the PI to the PD, the increased emissions of pollutants have a larger effect than the modest climate warming, so that $\mathrm{OH}$ decreases by $16 \%$. In the future, the reverse is true, so that the combined effects of pollutant emissions and climate change in the A2 simula- tion is to increase $\mathrm{OH}$ by $7 \%$. The response is larger in the climate-only run, in which $\mathrm{OH}$ increases by $36 \%$. The effects of changing stratospheric ozone can be clearly seen in the comparison of the OH values in the PD and 1979 simulations, which had identical emissions of short-lived tropospheric gases (though methane was increased in the PD). The depletion of ozone in the present relative to 1979 allows more short wavelength photons to penetrate the troposphere, where they can produce excited oxygen atoms that can form $\mathrm{OH}$. Hence the global mean mass-weighted $\mathrm{OH}$ value increases by $0.3 \times 10^{5}$ molecules $/ \mathrm{cm}^{3}(\sim 4 \%)$. As the increase in tropospheric methane of $\sim 12 \%$ will have reduced $\mathrm{OH}$ by $\sim 1 \%$, the influence of stratospheric ozone depletion on $\mathrm{OH}$ may in fact be slightly larger. Thus stratospheric ozone recovery in the future will lead to reduced $\mathrm{OH}$.

Changes in $\mathrm{OH}$ affect the oxidation rates of most reduced species. Changes to the lifetime of methane, which are roughly proportional to the percentage change of $\mathrm{OH}$, are especially important due to the large RF from methane. However, it is difficult to estimate the net effect of climate change on methane. The climate-only simulation led to an increase in the methane oxidation rate of $15 \%$ (with equilibrated methane) owing to greater $\mathrm{OH}$ and warmer temperatures. However, ecosystems would also respond to the warmer temperatures, with increased emissions of VOCs and of methane from wetlands both leading to increased methane, which could more than offset the enhanced sink.

\subsection{Stratosphere-troposphere exchange}

As discussed previously, we calculated STE of ozone across the $150 \mathrm{hPa}$ surface for comparison with observations. Continuing with this definition, we find an increase in STE from the present day to 2100 of $752 \mathrm{Tg} / \mathrm{yr}$ (124\%) including A2 emissions and climate (Table 5). In the companion climateonly simulation, STE increased $202 \mathrm{Tg} / \mathrm{yr}(+33 \%)$. The difference between emissions and climate and climate-only indicates that the emissions contribute the bulk of the increase. With the long simulations we performed, the standard deviation in global STE is only $\sim 16 \mathrm{Tg} / \mathrm{yr}$.

As noted earlier, the model's polar ozone fields and polar downward transport have substantial errors. Since most of the stratosphere-to-troposphere flux occurs in the subtropics 
and middle latitudes, however, we believe the model's STE values are only marginally influenced by the high latitude deficiencies. In the PD simulations, $97 \%$ of the $\mathrm{NH}$ downward flux across $150 \mathrm{hPa}$ takes place equatorward of $68^{\circ} \mathrm{N}$, and $86 \%$ of the $\mathrm{SH}$ downward flux is equatorward of $68^{\circ} \mathrm{S}$, for example.

Other GCMs have also typically looked at A2 or similar scenarios. Our change in STE of $202 \mathrm{Tg} / \mathrm{yr}$ for the A2 climate alone, with a warming of $4.8^{\circ} \mathrm{C}$, is smaller than the increase of $390 \mathrm{Tg} / \mathrm{yr}$ (across $200 \mathrm{hPa}$ ) found in a study using a similar magnitude warming $\left(5^{\circ} \mathrm{C}\right)$ in the Hadley Center Unified Model (UM) (Collins et al., 2003). Their base flux was also much larger, however, at $1068 \mathrm{Tg} / \mathrm{yr}$. In percentage terms, the UM change due to climate alone was $37 \%$, while ours is a quite similar $33 \%$. We note that their model has no stratospheric chemistry, and hence does not include changes in extratropical downward fluxes due to changing stratospheric composition. Since these were negative in the $\mathrm{SH}$ and positive in the $\mathrm{NH}$ in our model in response to climate change alone (Fig. 18), and the stratospheric burden change was minimal, these may have contributed little to the overall change, however.

Again using the UM model, but including a different tropospheric chemistry scheme than Collins et al. (2003) and also allowing this scheme to operate in the stratosphere, Zeng and Pyle (2003) find STE increased by $373 \mathrm{Tg} / \mathrm{yr}$ due to A2 emissions plus climate change, an increase of $80 \%$ over their base present-day value. STE was calculated across the surface where ozone values exceeded $150 \mathrm{ppbv}$, the so-called 'chemical tropopause', making comparisons with other models somewhat difficult. Their increase is somewhat less than the $124 \%$ enhancement seen in our results. As their simulations did not include halogen chemistry, they did not include the effects of decreases in future CFC emissions on stratospheric chemistry, so that there was no ozone recovery from halogen-induced depletion. Climate change played the dominant role in the STE changes seen in their model. This is quite clear in that the increase in STE between their present-day simulation and a run with $2100 \mathrm{~A} 2$ emissions but present-day climate was only $5 \mathrm{Tg} / \mathrm{yr}$. In contrast, emissions had a larger effect than climate in our simulations which did include recovery of stratospheric ozone (Table 5).

Similar experiments run within the CCSR/NIES GCM show decreases in STE of $20 \%$ with 2100 A2 emissions when compared with present day simulations, and increases of $83 \%$ including both emissions and climate change (Sudo et al., 2003). In this case, STE values were computed across a surface at $100 \mathrm{hPa}$ from $35^{\circ} \mathrm{S}$ to $35^{\circ} \mathrm{N}$, and at $250 \mathrm{hPa}$ poleward of that region. The total change in the CCSR/NIES model in response to A2 emissions and climate is similar to, though again somewhat smaller than, that seen in our study. These simulations included the effects of future HFCs on radiation, but not on chemistry, so that again they did not include the recovery of stratospheric ozone. Thus as with the Zeng and Pyle, 2003 runs, they find that future climate dom- inated STE changes and even that the impact of emissions may be to reduce STE, while our simulations indicate a larger role for emissions than for climate. The lack of stratospheric ozone recovery in the other models is probably the dominant factor accounting for this difference.

Examining our STE changes in more detail, we find that the downward $\mathrm{NH}$ extratropical ozone flux across the $150 \mathrm{hPa}$ surface tends to increase as climate warms, while changes in the $\mathrm{SH}$ extratropics and the tropics (across $50 \mathrm{hPa}$ ) are generally small (Table 6). The area poleward of $68^{\circ} \mathrm{N}$ contributes minimally $(<5 \mathrm{Tg} / \mathrm{yr})$ to the changes, so the $\mathrm{NH}$ values should be reasonably well-simulated. Standard deviations of the area-averaged STE values are $\sim 16 \mathrm{Tg} / \mathrm{yr}$ in the extratropics, and only $2 \mathrm{Tg} / \mathrm{yr}$ in the tropics. We choose these levels to roughly follow the tropopause, with a primary concern that the tropical level is high enough so that the calculation is not influenced by changes in the Hadley Cell circulation. The NH flux changes are consistent with an overall strengthening of the Brewer-Dobson circulation, which is clearly visible in the tropical residual vertical velocity (Table 7). The results are presented at several levels, showing that the response is consistent above about $100 \mathrm{hPa}$, but that the response is quite different at $150 \mathrm{hPa}$, reflecting the strong influence of the Hadley Cell at lower levels. This may account for a small portion of the differences between our results and those of Collins et al. (2003).

Note that the definition of the tropical tropopause does not have a great effect on the PD global STE value, as seen by comparing the STE values across $150 \mathrm{hPa}$ (Table 5) with the sum of fluxes following the surface of $150 \mathrm{hPa}$ in the extratropics and $50 \mathrm{hPa}$ in the tropics (Table 6 , last column). The differences are mostly in the range of $15-50 \mathrm{Tg} / \mathrm{yr}$. That the differences are typically small is not surprising given the relatively small contribution of tropical upwelling to the total. The differences can be important in the tropics, however, and the variable pressure surface consistently yields lower values. The results imply that in some simulations, such as the $\mathrm{PD}$, there is substantial chemical production of ozone in the tropical tropopause layer as the STE is reduced by $51 \mathrm{Tg} / \mathrm{yr}$ changing from the $150 \mathrm{hPa}$ surface in the tropics to the $50 \mathrm{hPa}$ surface plus horizontal fluxes from $150-50 \mathrm{hPa}$ (i.e. there is greater upward transport of ozone at 50 than at $150 \mathrm{hPa}$ ).

In the $\mathrm{NH}$ extratropics, there is also some evidence for chemical processing of ozone between 115 and $150 \mathrm{hPa}$ with little chemical change from 150 to $250 \mathrm{hPa}$ (Table 9). In the SH extratropics, changes are most apparent between 150 and $190 \mathrm{hPa}$. The comparison of STE values at different pressure levels indicates that the global value is relatively robust in the vicinity of the tropopause. Extratropical fluxes can show variations of 10-20\% between constant pressure surfaces, however, and the results appear to be sensitive to the atmospheric composition. Additionally, the sensitivity of STE to climate and composition change is strongly affected by the choice of tropopause boundary. The change in global STE relative to the PD (values in parentheses in Table 9) 
is nearly a factor of three larger at $115 \mathrm{hPa}$ than at $250 \mathrm{hPa}$ for the PI. For the A2 2100 case, the increase in extratropical STE becomes generally larger at higher pressures in both hemispheres, while in the PI case it becomes weaker with increasing pressure. Sensitivity differences are apparent in the SH extratropics despite the similarity between PD values at the various pressure levels. Thus is seems likely that the differences in tropopause definitions used in the various models contribute to sensitivity differences.

A general increase in tropical upwelling (mass flux rather than ozone flux) as climate warms is seen in many GCMs (Butchart et al., 2006). It is surprising, however, that the increase in tropical upwelling from the preindustrial to the present is more than half that seen going from the present to the A2 2100 future (Table 7, above $100 \mathrm{hPa}$ where the values are robust), despite the much larger climate change in the latter. We hypothesize that this results from the influence of ozone changes on the tropical temperature structure. The ozone changes from the preindustrial to the present, with increases below the tropopause and decreases above, tend to reduce the positive vertical gradient of temperature in the tropical lower stratosphere (Fig. 13), while the projected future recovery of stratospheric ozone, and the slight ozone decreases in the tropical uppermost troposphere, tend to increase this gradient (Fig. 16), slowing vertical transport.

Changes in ozone transport reflect changes in atmospheric composition as well as transport. From the preindustrial to the present-day, the downward extratropical fluxes decreased substantially in the SH and increased marginally in the $\mathrm{NH}$ when both climate and composition changes were included (Table 6). Given that warming induces an acceleration of the Brewer-Dobson circulation, the stratospheric ozone depletion induced by the composition changes leads to a reduction in ozone transport which outweighs the effects of climate in the $\mathrm{SH}$ where ozone losses are greatest. Changes in the $\mathrm{SH}$ are influenced by the high latitudes, however. Roughly half the PI-to-PD flux change across $150 \mathrm{hPa}$ occurs poleward of $68^{\circ} \mathrm{S}$, so that the SH extratropical STE change may be affected by the model's large polar biases.

In the case of present-day to future changes, the climate warming is much larger. Additionally, the projected ozone changes are also large, with a greater stratospheric ozone burden in the A2 2100 emissions and climate scenario than in the PI (Table 5). The distribution of changes is rather similar to those between the PI and PD, however, except in the vicinity of the tropical tropopause (Figs. 14 and 17). The result is that in the extratropical SH, the combined effects of ozone recovery and an enhanced stratospheric overturning lead to an STE increase of $\sim 170 \%$ in the A2 emissions and climate simulation. In the $\mathrm{NH}$ extratropics, the increase is similar in absolute terms to the $\mathrm{SH}$, but smaller in percentage though still quite substantial at $114 \%$ (Table 6). Interestingly, the increased downward flux in the SH results almost entirely from composition changes, while in the $\mathrm{NH}$ both climate and emissions play a substantial role. Thus a comparison across
Table 9. STE across various surfaces (Tg/yr).

\begin{tabular}{lccc}
\hline $\begin{array}{l}\text { Simulation } \rightarrow \\
\text { STE } \downarrow\end{array}$ & $\begin{array}{c}\text { Preindustrial } \\
(\mathrm{PI})\end{array}$ & $\begin{array}{c}\text { Present-day } \\
(\mathrm{PD})\end{array}$ & $\begin{array}{c}\text { A2 emiss }+ \\
\text { climate }\end{array}$ \\
\hline Global $115 \mathrm{hPa}$ & 735 & 578 & 1324 \\
& $(157)$ & & $(746)$ \\
Global $150 \mathrm{hPa}$ & 708 & 608 & 1360 \\
& $(100)$ & & $(752)$ \\
Global $190 \mathrm{hPa}$ & 676 & 587 & 1342 \\
& $(89)$ & & $(755)$ \\
Global $250 \mathrm{hPa}$ & 647 & 590 & 1325 \\
& $(57)$ & & $(735)$ \\
NH ext $115 \mathrm{hPa}$ & 337 & 315 & 690 \\
& $(22)$ & & $(375)$ \\
NH ext $150 \mathrm{hPa}$ & 345 & 353 & 755 \\
& $(-8)$ & & $(402)$ \\
NH ext $190 \mathrm{hPa}$ & 353 & 352 & 744 \\
& $(1)$ & & $(392)$ \\
NH ext $250 \mathrm{hPa}$ & 353 & 371 & 771 \\
& $(-18)$ & & $(400)$ \\
SH ext $115 \mathrm{hPa}$ & 380 & 247 & 608 \\
SH ext $150 \mathrm{hPa}$ & $(133)$ & & $(361)$ \\
SH ext $190 \mathrm{hPa}$ & 369 & 265 & 710 \\
& $(104)$ & & $(445)$ \\
SH ext $250 \mathrm{hPa}$ & 319 & 230 & 641 \\
& $(89)$ & & $(411)$ \\
& $(73)$ & & 663 \\
& & & $(417)$ \\
\hline
\end{tabular}

Values in parentheses are changes relative to the present day. $\mathrm{NH}$ and SH ext indicates extratopics (28-90 degrees). Positive values indicate flux into the troposphere.

models would be much more meaningful if the response of STE to climate in each region could be compared. The other models discussed here do not report separate values for each hemisphere in the extratropics however, but we strongly encourage future studies to do so.

\section{Discussion and conclusions}

The new GISS composition-climate model is able to represent interactions between atmospheric composition and the rest of the GCM in response to changes in trace species emissions, volcanic aerosol, solar radiation and greenhouse gas abundances. These interactions are incorporated using atmospheric species whose surface fluxes and transport via the general circulation and the hydrologic cycle are physically consistent with the treatment of other physical quantities such as heat and moisture in the climate model. Thus this model will be useful for a wide variety of compositionclimate interaction studies. Biases in the transport of stratospheric constituents are a primary weakness of the current setup, leading to distributions of long-lived gases with gradients that are too weak in the meridional direction and to 
an underestimate of the age of air at high latitudes. These circulation deficiencies also cause substantial biases in high latitude ozone. However, the simulation of ozone is quite realistic in the troposphere and in the remainder of the stratosphere. Thus the observed total ozone columns are well reproduced throughout the tropics and are fairly well simulated in most of the mid-latitudes. As discussed in Sect. 4.5, modeled STE is also realistic except for the generally minor contribution from high latitudes. Ozone also is well simulated in the vicinity of the tropopause (outside high latitudes), where it has the greatest effect on climate. Thus the radiative forcing produced by the composition-climate model is likely reliable. We have also shown that the sensitivity of stratospheric ozone to perturbations over the past two decades is reasonably well modeled.

The model has been used to investigate changes in STE without the difficulties associated with arbitrary boundaries between chemically active and non-chemically active regions found in tropospheric chemistry-only or stratospheric chemistry-only models. We find substantial changes in STE in the $\mathrm{SH}$ extratropics going from the PI to the PD, which are due to Antarctic ozone depletion and its dilution to lower latitudes. In the future, large changes in STE are simulated for both hemispheres. The $\mathrm{SH}$ is primarily sensitive to the projected recovery of lower stratospheric ozone, while the $\mathrm{NH}$ is most strongly influenced by the projected circulation response to climate change. The strong asymmetry in the circulation response to climate change is consistent with wavemean flow interactions linking surface climate to the stratosphere more closely in the NH (Shindell et al., 2001b). Planetary waves produced by flow over land-ocean contrasts and orography, and by storm systems, are more important in the NH. As climate warms and the flow increases, wave generation also increases (as seen in vertical Eliassen-Palm fluxes (not shown)). They drive the stratospheric overturning, so a greater wave response in the $\mathrm{NH}$ would be expected to lead to a greater change in the Brewer-Dobson circulation there, especially during winter. Other models do not report hemispheric values for STE, precluding evaluation of the robustness of this asymmetric circulation response to climate change. Our results do agree with analysis of satellite tracer observations during the 1990s and early 2000s, a period of climate warming but one that does not yet show clear ozone recovery. Measured trends in these gases in the stratosphere provide evidence of a more rapid increase in residual circulation in the $\mathrm{NH}$ than in the SH (Youn et al., 2006).

Our results also indicate that substantial chemical processing of ozone can take place in the vicinity of the tropopause under some conditions, making regional STE calculations sensitive to the tropopuase definition (though the global value is fairly robust). Additionally, we show that both the global and regional STE response to climate is sensitive to the definition of the surface across which STE is calculated. We suggest that multiple surfaces, perhaps 50,100 and $150 \mathrm{hPa}$ from $28^{\circ} \mathrm{S}$ to $28^{\circ} \mathrm{N}$ and 100,150 and $250 \mathrm{hPa}$ poleward of 28 degrees, be used for models and most importantly that each hemisphere's extratropical downward fluxes be reported in addition to global fluxes.

Composition changes in the stratosphere were also projected. These show an increase of ozone in the future that substantially exceeds "recovery" to 1979 levels. In the A2 scenario, the stratospheric ozone burden increase between the PD and 2100 (28\%) is roughly twice the loss between 1979 and the PD. The 2100 stratospheric burden exceeds even the levels simulated for the PI. The projection of future stratospheric values in excess of the 1979 or PI values results from the influence of greenhouse gases other than CFCs on the temperature and composition of the stratosphere. These gases also had an influence in the past, so we find that $\sim 38 \%$ of the total depletion between the PI and the PD took place prior to 1979 (though a small portion of this resulted from the small quantity of CFCs released prior to 1979). A substantial role for non-CFC greenhouse gases in affecting past and future stratospheric ozone is consistent with studies of historical observations (Shindell and Faluvegi, 2002) and other modeling results (Randeniya et al., 2002).

Projections of future composition in the polar regions are less reliable in this model. Examination of springtime temperatures shows that the lower stratosphere is projected to cool in response to climate change, as in our earlier studies (Shindell et al., 1998). This occurs despite an increase in ozone transported to the lower stratosphere in future climates, which is especially large in the NH (Fig. 18), and suggests a dynamic feedback that strengthens the Arctic vortex along with the radiative cooling induced by greenhouse gas increases. As halogen loading has dropped dramatically by 2100 , heterogeneous ozone chemistry no longer takes place at levels sufficient to cause substantial ozone depletion in the 2100 emissions and climate simulations, however. Future model versions with higher vertical resolution and an enhanced parameterization of polar heterogeneous chemistry will be used to address the issue of transient ozone changes as climate warms while halogens decline.

The effect of future climate on the tropospheric ozone burden appears to be relatively robust across models. Applying projected future A2 2100 climate, the tropospheric ozone burden in our model decreases from 420 to $413 \mathrm{Tg}$. The experiments of Collins et al. (2003) show a similarly small decrease from 284 to $271 \mathrm{Tg}$. Using the different setup of taking the difference between A2 emissions plus climate and A2 emissions alone, the burden increases from 489 to $505 \mathrm{Tg}$ in the model of Zeng and Pyle (2003). Thus it appears that the overall influence of climate change on the tropospheric burden is consistently small, as several competing factors offset one another, while the absolute sign of the change depends on the relative importance of individual processes (e.g. increases in humidity, lightning, rainout of soluble gases, etc.) in the particular models. The response to changes in emissions appears to be more sensitive to intermodel variations, though this is difficult to gauge due to the varying assumptions used 
in future simulations. In the runs of Zeng and Pyle (2003) that did not include present or future influence of halogens on ozone, the tropospheric burden increased from 317 to $505 \mathrm{Tg}$ with 2100 A2 emissions and climate. In our model, which did include both the depletion to the present-day and future stratospheric ozone recovery, the burden increased from 420 to $845 \mathrm{Tg}$.

Comparison of simulations with 1979 and PD stratospheric conditions but identical tropospheric emissions indicates that a reduction in the influx of ozone from the stratosphere to the troposphere coincident with stratospheric ozone depletion may have played a large role in compensating for tropospheric ozone burden increase driven by enhanced pollutant emissions. The model results suggest that as much as $2 / 3$ of the burden increase may have been offset, with the changes nearly all arising from the SH. Projected future ozone recovery leads to an enhanced influx of ozone from the stratosphere, again with potentially large impacts on the tropospheric ozone burden. The overall effect of projected climate and emissions changes is an increased RF of about $0.8 \mathrm{~W} / \mathrm{m}^{2}$ from ozone. Climate change alone alters ozone via chemistry and transport, reducing the RF by about $0.2 \mathrm{~W} / \mathrm{m}^{2}$.

Acknowledgements. The authors thank NASA's Atmospheric Chemistry Modeling and Analysis Program for support, the NSF Climate Dynamics Program for grant ATM-06-20066 in support of dust modeling, and the SPARC data center for satellite trace-gas climatologies. We also thank B. Collins and the other reviewers for their helpful criticisms and comments.

Edited by: M. Dameris

\section{References}

Andrews, A. E., Boering, K. A., Daube, B. C., Wofsy, S. C., Hintsa, E. J., Weinstock, E. M., and Bui, T. P.: Empirical age spectra for the lower tropical stratosphere from in situ observations of $\mathrm{CO}_{2}$ : Implications for stratospheric transport, J. Geophys. Res., 104, 26 581-26596, 1999.

Austin, J., Shindell, D., Beagley, S. R., et al.: Uncertainties and assessments of chemistry-climate models of the stratosphere, Atmos. Chem. Phys., 3, 1-27, 2003,

http://www.atmos-chem-phys.net/3/1/2003/.

Bauer, S. E. and Koch, D.: Impact of heterogeneous sulfate formation at mineral dust surfaces on aerosol loads and radiative forcing in the Goddard Institute for Space Studies general circulation model, J. Geophys. Res., 110, D17202, doi:10.1029/2005JD005870, 2005.

Bell, N., Koch, D., and Shindell, D.: Impacts of chemistryaerosol coupling on tropospheric ozone and sulfate simulations in a general circulation model, J. Geophys. Res., 110, D14305, doi:10.1029/2004JD005538, 2005.

Benkovitz, C. M., Scholtz, M. T., Pacyna, J., Tarrason, L., Dignon, J., Voldner, E. C., Spiro, P. A., Logan, J. A., and Graedel, T. E.: Global gridded inventories of anthropogenic emissions of sulfur and nitrogen, J. Geophys. Res., 101, 29 239-29 253, 1996.
Bian, H. and Prather, M.: Fast-J2: Accurate simulations of photolysis in global climate models, J. Atmos. Chem., 41, 281-296, 2002.

Boccippio, D. J., Driscoll, K., Koshak, W., Blakeslee, R., Boeck, W., Mach, D., Christian, H. J., and Goodman, S. J.: Cross-sensor validation of the Optical Transient Detector (OTD), J. Atmos. Sol. Terr. Phys., 60, 701-712, 1998.

Boering, K. A., Wofsy, S. C., Daube, B. C., Schneider, H. R., Loewenstein, M., Podolske, J. R., and Conway, T. J.: Stratospheric Mean Ages and Transport Rates from Observations of Carbon Dioxide and Nitrous Oxide, Science, 274, 1340-1343, 1996.

Butchart, N., Scaife, A. A., Bourqui, M., et al.: A multi-model study of climate change in the Brewer-Dobson circulation, Clim. Dyn., doi:10.1007/s00382-006-0162-4, 2006.

Cakmur, R. V., Miller, R. L., Perlwitz, J., Koch, D., Geogdzhayev, I. V., Ginoux, P., Tegen, I., and Zender, C. S.: Constraining the global dust emission and load by minimizing the difference between the model and observations, J. Geophys. Res., 111, D06207, doi:10.1029/2005JD005791, 2006.

Collins, W. J., Derwent, R. G., Garnier, B., Johnson, C. E., Sanderson, M. G., and Stevenson, D. S.: Effect of stratospheretroposphere exchange on the future tropopsheric ozone trend, J. Geophys. Res., 108, doi:10.1029/2002JD002617, 2003.

Cros, B., Delmas, R., Nganga, D., Clairac, B., and Fontan, J.: Seasonal trends of ozone in equatorial Africa: experimental evidence of photochemical formation, J. Geophys. Res., 93, 8355-8366, 1988.

Dameris, M., Grewe, V., Ponater, M., Deckert, R., Eyring, V., Mager, F., Matthes, S., Schnadt, C., Stenke, A., Steil, B., Brühl, C., and Giorgetta, M. A.: Long-term changes and variability in a transient simulation with a chemistry-climate model employing realistic forcing, Atmos. Chem. Phys., 5, 2121-2145,2005.

Dlugokencky, E. J., Steele, L. P., Lang, P. M., and Masarie, K. A.: The growth rate and distribution of atmospheric methane, J. Geophys. Res., 99, 17 021-17 043, 1994.

Elkins, J. W., Fahey, D. W., Gilligan, J. M., et al.: Airborne gas chromatograph for in situ measurements of long-lived species in the upper troposphere and lower stratosphere, Geophys. Res. Lett., 23, 347-350, 1996.

Emmons, L. K., Hauglustaine, D. A., Muller, J. F., Carroll, M. A., Brasseur, G. P., Brunner, D., Staehelin, J., Thouret, V., and Marenco, A.: Data composites of airborne observations of tropospheric ozone and its precursors, J. Geophys. Res., 105, $20497-$ 20538, 2000.

Gettelman, A., Holton, J. R., and Rosenlof, K. H.: Mass fluxes of $\mathrm{O}_{3}, \mathrm{CH}_{4}, \mathrm{~N}_{2} \mathrm{O}$, and $\mathrm{CF}_{2} \mathrm{Cl}_{2}$ in the lower stratosphere calculated from observational data, J. Geophys. Res., 102, 19 149-19159, 1997.

Ginoux, P., Chin, M., Tegen, I., Prospero, J., Holben, B., Dubovik, O., and Lin, S. J.: Sources and distributions of aerosols simulated with the \{GOCART\} model, J. Geophys. Res., 106, $20255-$ $20273,2001$.

Hall, T. M., Waugh, D. W., Boering, K. A., and Plumb, R. A.: Evaluation of transport in stratospheric models, J. Geophys. Res., 104, 18 815-18 839, 1999.

Hanisch, F. and Crowley, J. N.: The heterogeneous reactivity of gaseous nitric acid on authentic mineral dust samples, and on individual mineral and clay mineral components, Phys. Chem. 
Chem. Phys., 3, 2474-2482, 2001

Hansen, J., Sato, M., Ruedy, R., et al.: Efficacy of Climate Forcings, J. Geophys. Res., 110, D18104, doi:10.1029/2005JD005776, 2005.

Hanson, D. and Mauersberger, K.: Laboratory studies of the nitric acid tridydrate: Implications for the south polar stratosphere, Geophys. Res. Lett., 15, 855-858, 1988.

Harnisch, J., Borchers, R., Fabian, P., and Maiss, M.: Tropospheric trends for $\mathrm{CF}_{4}$ and $\mathrm{C}_{2} \mathrm{~F}_{6}$ since 1982 derived from $\mathrm{SF}_{6}$ dated stratospheric air, Geophys. Res. Lett., 23, 1099-1102, 1996.

Holland, E. A., Braswell, B. H., Sulzman, J., and Lamarque, J.-F.: Nitrogen deposition onto the United States and Western Europe: Synthesis of observations and models, Ecological Applications, $15,38-57,2005$.

Kirchhoff, V. W. J. H. and Rasmussen, R. A.: Time variations of CO and ozone concentrations in a region subject to biomass burning, J. Geophys. Res., 95, 7521-7532, 1990.

Koch, D. and Hansen, J.: Distant origins of Arctic Black Carbon: A GISS ModelE experiment, J. Geophys. Res., 110, D04204, doi:10.1029/2004JD005296, 2005.

Koch, D., Schmidt, G., and Field, C.: Sulfur, sea salt and radionuclide aerosols in GISS ModelE, J. Geophys. Res., 111, D06206, doi:10.1029/2004JD005550, 2006.

Lamarque, J.-F., Kiehl, J. T., Brasseur, G. P., et al.: Assessing future nitrogen deposition and carbon cycle feedback using a multimodel approach. Part 1: Analysis of nitrogen deposition, J. Geophys. Res., 110, D19303, doi:10.1029/2005JD005825, 2005.

Logan, J. A.: An analysis of ozonesonde data for the troposphere: Recommendations for testing 3-D models and development of a gridded climatology for tropospheric ozone, J. Geophys. Res., 104, 16 115-16 149, 1999.

McCormack, J. P. and Hood, L. L.: Apparent solar cycle variations of upper stratospheric ozone and temperature: Latitude and seasonal dependances, J. Geophys. Res., 101, 20 933-20 944, 1996.

Miller, R. L., Cakmur, R. V., Perlwitx, J., et al.: Mineral Dust Aerosols in the NASA Goddard Institute for Space Studies ModelE AGCM, J. Geophys. Res., 111, D06208, doi:10.1029/2005JD005796, 2006.

Murphy, D. M. and Fahey, D. W.: An estimate of the flux of stratospheric reactive nitrogen and ozone into the troposphere, J. Geophys. Res., 99, 5325-5332, 1994.

Nicolet, M.: On the photodissociation of water vapour in the mesosphere, Planet. Space Sci., 32, 871-880, 1984.

Nicolet, M. and Cieslik, S.: The photodissociation of nitric oxide in the mesosphere and stratosphere, Planet. Space Sci., 28, 105$115,1980$.

Olsen, M. A., Douglass, A. R., and Schoeberl, M. R.: A comparison of Northern and Southern Hemisphere crosstropopause ozone flux, Geophys. Res. Lett., 30(7), 1412, doi:10.1029/2002GL016538, 2003.

Oltmans, S. J. and Levy, H.: Surface ozone measurements from a global network, Atmos. Environ., 28, 9-24, 1994.

Oltmans, S. J., Lefohn, A. S., Scheel, H. E., et al.: Trends of ozone in the troposphere, Geophys. Res. Lett., 25, 139-142, 1998.

Plumb, R. A. and Eluszkiewicz, J.: The Brewer-Dobson circulation: dynamics of the tropical upwelling, J. Atmos. Sci., 56, 868-890, 1999.

Prather, M., Numerical advection by conservation of second-order moments, J. Geophys. Res., 91, 6671-6681, 1986.
Prather, M. J., Ehhalt, D., Dentener, F., et al.: Atmospheric Chemistry and Greenhouse Gases, in: Climate Change 2001, edited by: Houghton, J. T., Cambridge Univ. Press, Cambridge, 239287, 2001.

Price, C., Penner, J., and Prather, M.: NOx from lightning, 1, Global distribution based on lightning physics, J. Geophys. Res., 102, 5929-5941, 1997.

Randel, W. J. and Wu, F.: A stratospheric ozone trends data set for global modeling studies, Geophys. Res. Lett., 26, 3089-3092, 1999.

Randel, W. J., Wu, F., Russell, J., Roche, A., and Waters, J.: Seasonal cycles and QBO variations in stratospheric $\mathrm{CH}_{4}$ and $\mathrm{H}_{2} \mathrm{O}$ observed in UARS HALOE data, J. Atmos. Sci., 55, 163-185, 1998.

Randeniya, L. K., Vohralik, P. F., and Plumb, I. C.: Stratospheric ozone depletion at northern mid latitudes in the 21st century: The importance of future concentrations of greenhouse gases nitrous oxide and methane, Geophys. Res. Lett., 29(4), 1051, doi:10.1029/2001GL014295, 2002.

Rosenlof, K. H.: Seasonal cycle of the residual mean meridional circulation in the stratosphere, J. Geophys. Res., 100, 5173-5191, 1995.

Sander, S. P., Friedl, R. R., Golden, D. M., et al.: Chemical kinetics and photochemical data for use in stratospheric modeling, Eval. 13, JPL Publ. 00-003, 2000.

Sanhueza, E., Octavio, K. H., and Arrocha, A.: Surface ozone measurements in the Venezuelan tropical savannah, J. Atmos. Chem., 2, 377-385, 1985 .

Sato, M., Hansen, J. E., McCormick, M. P., and Pollack, J. B.: Stratospheric aerosol optical depths, 1850-1990, J. Geophys. Res., 98, 22 987-22 994, 1993.

Scheele, M. P., Siegmund, P. C., and van Velthoven, P. F. J.: Stratospheric age of air computed with trajectories based on various 3D-Var and 4D-Var data sets, Atmos. Chem. Phys., 5, 1-7, 2005, http://www.atmos-chem-phys.net/5/1/2005/.

Schmidt, G. A., Hoffmann, G., Shindell, D. T., and Hu, Y.: Modeling atmospheric stable water isotopes and the potential for constraining cloud processes and stratospheretroposphere water exchange, J. Geophys. Res., 110, D21314, doi:10.1029/2005JD005790, 2005.

Schmidt, G. A., Ruedy, R., Hansen, J. E., et al.: Present day atmospheric simulations using GISS ModelE: Comparison to in-situ, satellite and reanalysis data, J. Climate, 19, 153-192, 2006.

Schoeberl, M. R., Douglass, A. R., Zhu, Z., and Pawson, S.: A comparison of lower stratospheric age spectra derived from a general circulation model and two data assimilation systems, J. Geophys. Res., 108, 4113, doi:10.1029/2002JD002652, 2003.

Shindell, D. T. and Faluvegi, G.: An exploration of ozone changes and their radiative forcing prior to the chlorofluorocarbon era, Atmos. Chem. Phys., 2, 363-374, 2002, http://www.atmos-chem-phys.net/2/363/2002/.

Shindell, D. T., Faluvegi, G., and Bell, N.: Preindustrial-to-presentday radiative forcing by tropospheric ozone from improved simulations with the GISS chemistry-climate GCM, Atmos. Chem. Phys., 3, 1675-1702, 2003, http://www.atmos-chem-phys.net/3/1675/2003/.

Shindell, D. T., Faluvegi, G., Bell, N., and Schmidt, G. A.: An emissions-based view of climate forcing by methane and tropospheric ozone, Geophys. Res. Lett., 32, L04803, 
doi:10.1029/2004GL021900, 2005b.

Shindell, D. T., Faluvegi, G., and Emmons, L.: Inferring carbon monoxide pollution changes from space-based observations, J. Geophys. Res., 110, D23303, doi:10.1029/2005JD006132, 2005a.

Shindell, D. T., Grenfell, J. L., Rind, D., Price, C., and Grewe, V.: Chemistry-climate interactions in the Goddard Institute for Space Studies general circulation model 1. Tropospheric chemistry model description and evaluation, J. Geophys. Res., 106, 8047-8076, 2001a.

Shindell, D. T., Rind, D., and Lonergan, P.: Increased polar stratospheric ozone losses and delayed eventual recovery due to increasing greenhouse gas concentrations, Nature, 392, 589-592, 1998.

Shindell, D. T., Schmidt, G. A., Miller, R. L., and Rind, D.: Northern Hemisphere winter climate response to greenhouse gas, volcanic, ozone and solar forcing, J. Geophys. Res., 106, 71937210, 2001b.

Stevenson, D. S., Dentener, F. J., Schulz, M. G., et al.: Multi-model ensemble simulations of present-day and nearfuture tropospheric ozone, J. Geophys. Res., 111, D08301, doi:10.1029/2005JD006338, 2006.

Sudo, K., Takahashi, M., and Akimoto, H.: Future changes in stratosphere-troposphere exchange and their impacts on future tropospheric ozone simulations, Geophys. Res. Lett., 30(24), 2256, doi:10.1029/2003GL018526, 2003.
Sunwoo, Y. and Carmichael, G.: Characteristics of background surface ozone in Japan, Atmos. Environ., 28, 25-38, 1994.

Swinbank, R. and O'Neill, A.: A stratosphere-troposphere data assimilation system, Mon. Weather Rev., 122, 686-702, 1994.

Unger, N., Shindell, D. T., Koch, D. K., Amann, M., Cofala, J., and Streets, D. G.: Influences of man-made emissions and climate changes on tropospheric ozone, methane and sulfate at 2030 from a broad range of possible futures, J. Geophys. Res., 111, D12313, doi:10.1029/2005JD006518, 2006.

Waters, J. W., Read, W. G., Froidevaux, L., et al.: Validation of UARS MLS ClO measurements, J. Geophys. Res., 101, $10091-$ $10127,1996$.

World Meteorological Organization: Scientific Assessment of Ozone Depletion, 1998, Rep. 44, Geneva, 1999.

World Meteorological Organization: Scientific Assessment of Ozone Depletion, 2002, Rep. 47, Geneva, 2003.

Youn, D., Choi, W., Lee, H., and Wuebbles, D. J.: Interhemispheric differences in changes of long-lived tracers in the middle stratosphere over the last decade, Geophys. Res. Lett., 33, L03807, doi:10.1029/2005GL024274, 2006.

Zeng, G. and Pyle, J. A.: Changes in tropospheric ozone between 2000 and 2100 modeled in a chemistry-climate model, Geophys. Res. Lett., 30(7), 1392, doi:10.1029/2002GL016708, 2003. 